\title{
MODELAGEM FARMACOCINÉTICA E ANÁLISE DE SISTEMAS LINEARES PARA A PREDIÇÃO DA CONCENTRAÇÃO DE MEDICAMENTOS NO CORPO HUMANO
}

Dissertação apresentada à Escola Politécnica da Universidade de São Paulo para obtenção do Título de Mestre em Engenharia Mecânica. 


\section{MODELAGEM FARMACOCINÉTICA E ANÁLISE DE SISTEMAS LINEARES PARA A PREDIÇÃO DA CONCENTRAÇÃO DE MEDICAMENTOS NO CORPO HUMANO}

Dissertação apresentada à Escola Politécnica da Universidade de São Paulo para obtenção do Título de Mestre em Engenharia Mecânica.

Área de Concentração:

Engenharia Mecânica de Energia e Fluidos

Orientador:

Jurandir Itizo Yanagihara 


\section{FICHA CATALOGRÁFICA}

Gallo-Neto, Milton

Modelagem Farmacocinética e análise de sistemas lineares para a predição da concentração de medicamentos no corpo humano/ M. Gallo-Neto. São Paulo, 2012.

$108 \mathrm{p}$.

Dissertação (Mestrado) - Escola Politécnica da Universidade de São Paulo. Departamento de Engenharia Mecânica.

1. Modelagem de Sistemas Biológicos 2. Transferência de Massa em Sistemas Biológicos 3. Farmacocinética I. Universidade de São Paulo. Escola Politécnica Departamento de Engenharia Mecânica. II. t. 
Never give up. Trust your instincts.

(James McCloud) 


\section{AGRADECIMENTOS}

Agradeço ao Professor Jurandir Itizo Yanagihara pela orientação, apoio e ensinamentos. Aos Professores Maurício Silva Ferreira e Cyro Albuquerque Neto pelas sugestões para melhoria do modelo. À toda minha família por ser a minha base de sustentação, em especial aos meus pais Milton Gallo Junior e Sandra Tanuri Gallo, aos meus irmãos Daniel Gallo e Giovanni Gallo e às minhas avós Helena Sameck Gallo e Dionéia Baltazar Tanuri. À minha companheira Letícia Langsdorff de Oliveira por todo o incentivo dado desde o ingresso no Mestrado até o término da dissertação, pelas conversas sobre biologia e química e por caminhar ao meu lado sempre, me motivando quando as dificuldades surgem. 


\section{RESUMO}

A modelagem farmacocinética permite prever a concentração de medicamentos em diferentes tecidos do organismo humano. O desenvolvimento de modelos matemáticos é importante para verificar a adequação de certos procedimentos realizados na administração de medicamentos. O objetivo deste trabalho é o desenvolvimento de um modelo farmacocinético capaz de prever a concentração plasmática de drogas no organismo para diversas formas de infusão. Foram utilizados dois tipos de abordagem. Inicialmente, na abordagem monocompartimental, considerou-se que a droga adentra ao organismo diretamente no compartimento sanguíneo, que representa todo o corpo humano. Já na abordagem bicompartimental foram considerados os seguintes compartimentos: um representando o meio pelo qual a droga é infundida no organismo (podendo ser via gastrointestinal, transdermal ou pulmonar) e outro representando o plasma sanguíneo. Em ambos os casos, foi considerada a hipótese de concentração homogênea da droga nos compartimentos em questão. O modelo foi estruturado na forma de diagramas de blocos e a solução foi feita com a utilização da Transformada de Laplace. Foi feita a validação dos modelos e verificou-se que os resultado gerados foram muito próximos dos resultados presentes na literatura. A utilização do modelo monocompartimental permitiu comparar os resultados da administração da mesma quantidade de droga por infusão constante e por infusão periódica. A análise dos resultados gerados pelo modelo mostrou que as concentrações atingidas pelos dois métodos não são as mesmas. O modelo bicompartimental permitiu simular administrações orais e transdermais, e inalação. Foi possível prever a concentração sanguínea após a interrupção da terapia com anti-concepcionais e anti-depressivos e foi verificado o tempo necessário para que esta concentração seja atingida novamente. Foram propostos métodos para que esta concentração fosse atingida em um menor período de tempo. Outra aplicação foi na comparação entre o tratamento com comprimidos inteiros e tomados pela metade em um intervalo menor de tempo. Verificou-se que a concentração atingida é diferente mesmo que a massa ingerida seja a mesma. O modelo também foi utilizado para calcular a concentração de nicotina após o consumo de cigarros e verificou-se que, o indivíduo que fuma a cada três horas não consegue eliminar totalmente a nicotina de seu organismo. Além disso, foi possível simular a sobredosagem de um anti-inflamatório e verificar o tempo em que a concentração fica acima do nível terapêutico. Foi proposto um método para obtenção do parâmetro farmacocinético relacionado à absorção, que pode ser obtido facilmente a partir de dados presentes nas bulas dos medicamentos. Este método é muito mais simples e preciso do que e proposto na literatura, que utiliza análise gráfica e dados clínicos que não são obtidos com tanta facilidade.

Palavras chave: Farmacocinética, Modelagem de Sistemas Biológicos, Transferência de massa em sistemas biológicos. 


\begin{abstract}
The pharmacokinetic modeling can predict the concentration of drug in different tissues of the human body. The development of mathematical models is an important tool to verify the appropriateness of certain procedures performed in medication administration. The objective of this work is to develop a pharmacokinetic model able to predict the plasma concentration of drug in the body after various forms of infusion. Two approaches were used. Initially, in the one-compartment approach it was considered that the drug enters the body directly into the blood compartment, which represents the entire human body. In the two-compartment approach it was considered the following compartments: one representing the means by which the drug is infused into the body (either via the gastrointestinal tract, lung, or transdermal) and one representing the blood plasma. In both cases, it was considered homogeneous concentration of the drug in the compartments. The model was built by using block diagrams and the solution was obtained using the Laplace Transform. The model was validated by comparing its results to literature data, with very good agreement. The model allowed comparing the one-compartment constant infusion of drug in the body with the periodic infusion. The analysis of the results generated by the model showed that the concentrations achieved by these methods are not the same. The two-compartment model allowed simulating oral and transdermal administration, and inhalation. It was possible to predict blood concentration after interruption of therapy with anti-depressants and anti-conceptional drugs. The model was able to verify the time it takes to reach the former level. Methods have been proposed to achieve the same concentration in a shorter period of time. Another application was the comparison of the treatment with whole tablets and taken by half in a smaller interval of time. It was found that the concentration achieved is different even though the same mass is ingested in both cases. The model was also used to calculate the concentration of nicotine after cigarette smoking and it was found that the individual who smokes every three hours, nicotine is not entirely eliminated from body. Furthermore, it was possible to simulate overdose of an anti-inflammatory and the period of time when the concentration is above the therapeutic level. It has been proposed a method to obtain pharmacokinetic parameter related to absorption, which can be easily obtained based on data present in the drug bull. This method is much simpler and more accurate than the method proposed in the, which uses graphical analysis and clinical data that are not so easy to be obtained.
\end{abstract}

Keywords: Pharmacokinetics, Biological System Modeling, Mass Transfer in Biological Systems. 


\section{SUMÁRIO}

\section{Lista de Abreviaturas e Siglas}

\section{Lista de Símbolos}

1 Introdução

1.1 Modelagem Matemática de Sistemas Biológicos . . . . . . . . . . . . 16

1.2 Modelagem Farmacocinética . . . . . . . . . . . . . . . . . 17

1.3 Modelagem Farmacodinâmica . . . . . . . . . . . . . . . . 18

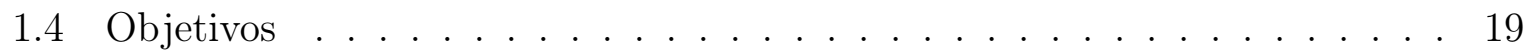

2 Conceitos Fisiológicos e Farmacocinéticos 20

2.1 Conceitos Farmacocinéticos Básicos . . . . . . . . . . . . . 20

2.1.1 Droga e dosagem ..................... 20

2.1.2 Farmacodinâmica . . . . . . . . . . . . . . . . . 21

2.1.3 Concentração plasmática . . . . . . . . . . . . . . . . . . . . . 21

2.1.4 Absorção, Distribuição, Metabolismo e Eliminação . . . . . . . . . . 22

2.1.5 Faixa terapêutica . . . . . . . . . . . . . . . . 24

2.1.6 Passagem da droga atravéz das membranas . . . . . . . . . . . . . 24

2.1 .7 Tipos de Infusão . . . . . . . . . . . . . . . . . . . . . . . . 25

2.1.8 Rotas na administração sistêmica . . . . . . . . . . . . . . . 26

2.1.8.1 Infusão intravascular . . . . . . . . . . . . . . . . 26

2.1.8.2 Infusão extravascular . . . . . . . . . . . . . . . 26 
2.1.9 Biodisponibilidade . . . . . . . . . . . . . . . 28

2.1 .10 Taxa de remoção . . . . . . . . . . . . . . . . . . . . . 29

2.1.11 Volume de Distribuição . . . . . . . . . . . . . . . . . . . . . . . 30

2.1.12 Tempo de meia vida plasmática . . . . . . . . . . . . . . 31

2.2 Conceitos Fisiológicos . . . . . . . . . . . . . . . . . . . . . . . 31

2.2.1 Sistema Circulatório . . . . . . . . . . . . . . . . 32

2.2 .2 Os Rins . . . . . . . . . . . . . . . . . 32

2.2 .3 Absorção Gastro Intestinal . . . . . . . . . . . . . . . . . . 33

3 Revisão da Literatura 35

3.1 Modelos experimentais . . . . . . . . . . . . . 36

3.1 .1 Modelo de Tasso (2008) . . . . . . . . . . . . 36

3.1.2 Modelo de Santos (2008) . . . . . . . . . . . . 37

3.1.3 Modelo de Araujo (2008) . . . . . . . . . . . . . . 38

3.1.4 Modelo de Dershwitz et al. (2000) . . . . . . . . . . . . 38

3.1.5 Modelo de Hunault et al. (2010) . . . . . . . . . . . . . . . . . 41

3.2 Modelos Farmacocinéticos Baseados em Fisiologia . . . . . . . . . . . . . . 42

3.2.1 Modelo de Granero et al. (1993) . . . . . . . . . . . . . . . . 43

3.2.2 Modelo de Kwon e Bourne (1987) . . . . . . . . . . . . . . . . . 46

3.2.3 Modelo de Chen e Andrade (1976) . . . . . . . . . . . . . 51

3.2.4 Outros Modelos Farmacocinéticos Baseados em Fisiologia . . . . . . 53

4 Modelagem Monocompartimental $\quad 57$

4.1 Balanço de massa do compartimento plasma . . . . . . . . . . . . 57 
4.2 Parâmetros farmacocinéticos utilizados . . . . . . . . . . . . . . . . . . 59

4.2 .1 Volume aparente . . . . . . . . . . . . . . . . . 59

4.2.2 Constante de eliminação total . . . . . . . . . . . . . . . . . . . . . 59

4.2 .3 Dosagem em função do tempo . . . . . . . . . . . . . . . . . . . . . 59

5 Modelagem Bicompartimental $\quad 60$

5.1 Balanço de massa nos compartimentos . . . . . . . . . . . . . . . . 60

5.2 Parâmetros utilizados . . . . . . . . . . . . . . . . . 62

5.2 .1 Massa no compartimento central . . . . . . . . . . . . . . 62

5.2.2 Constante de absorção de primeira ordem . . . . . . . . . . . . . 63

6 Solução do modelo $\quad 64$

6.1 Modelagem Farmacocinética Utilizando a Transformada de Laplace . . . . 64

6.1.1 Utilização da Transformada de Laplace na Solução de Sistemas regidos Equações Diferenciais Ordinárias . . . . . . . . . . . . . . 66

6.1.2 Obtenção das Funções de Transferência no Modelo Farmacocinético Monocompartimetal ................. 67

6.1.3 Obtenção das Funções de Transferência no Modelo Farmacocinético Bicompartimental . . . . . . . . . . . . . . . 68

6.1.4 Tipos de Infusões Utilizadas . . . . . . . . . . . . . . . . . . . . . 70

6.2 Obtenção do Parâmetro Farmacocinético Constante de Absorção $k_{a}$. . . . 71

6.3 Implementação Computacional . . . . . . . . . . . . . . . . . . . . . 74

7 Resultados

7.1 Validação do Modelo Monocompartimental . . . . . . . . . . . . . . . . 75

7.1.1 Comparação com o modelo de Hoskin et al. (1989) . . . . . . . . . 75 
7.1.2 Comparação com o modelo de Granero et al. (1993). ....... 78

7.2 Validação do Modelo Bicompartimental . . . . . . . . . . . . . . . 78

7.2.1 Comparação com o modelo de Hunault et al. (2010). . . . . . . . . 79

7.2.2 Comparação com o modelo de Foulds et al. (2003). . . . . . . . . . 80

7.2.3 Comparação com dados presentes em bulas de medicamentos . . . . 81

7.3 Variação de Infusão de Morfina no Modelo Monocompartimental . . . . . . 83

7.3.1 Comparação entre Infusão Constante e Injeções Intravenosas Periódicas. . . . . . . . . . . . . . . . . 83

7.3.2 Tentativa de Aproximação da Concentração de Regime Permanente 83

7.4 Simulação de Condições Adversas no Modelo Bicompartimental . . . . . . 85

7.4.1 Alterações na Posologia de Paroxetina . . . . . . . . . . . . . . 85

7.4.1.1 Interrupção no Tratamento . . . . . . . . . . . . 86

7.4.1.2 Aumento da Frequência de Dosagem com Dose Menor . . 87

7.4.1.3 Infusão Dobrada no Início do Tratamento . . . . . . . . . 87

7.4.1.4 Eliminação Completa do Organismo . . . . . . . . . . . 88

7.4.2 Simulação para verificação da concentração de nicotina no plasma após o fumo de cigarros. . . . . . . . . . . . . . . . . 88

7.4.3 Utilização de medicamentos anti-concepcionais . . . . . . . . . . . . 92

7.4.3.1 Comparação entre anti-concepcional transdermal e em comprimidos ..................... 92

7.4.3.2 Interrupção no tratamento . . . . . . . . . . . . . 95

7.4.3.3 Aumento da dosagem inicial . . . . . . . . . . . . . 95

7.4.4 Sobre dosagem de analgésicos . . . . . . . . . . . . . . 97 
8.1 Modelo Monocompartimental _. . . . . . . . . . . . . . . . . . . . . 99

8.2 Modelo Bicompartimental . . . . . . . . . . . . . . 100

8.3 Trabalhos futuros . . . . . . . . . . . . . . . . . 103

Referências 


\title{
LISTA DE ABREVIATURAS E SIGLAS
}

PK/PD Pharmacokinetics/pharmacodynamics

\author{
ADME Absorção, Distribuição, Metabolismo e Excreção \\ CTM Concentração Tóxica Máxima \\ CEF Concentração Efetiva Mínima \\ CIM Concentração Inibitória Mínima \\ CBM Concentração Bactericida Máxima \\ ACP Administração com Bomba de Infusão Controlada pelo Paciente \\ CEC Circulação Extra Corpórea \\ ASC Área sob Curva \\ VCR Antifúngico Voricozanol \\ THC Tetrahidrocanabinol \\ LTI Linear Time Invariant
}




\section{LISTA DE SÍMBOLOS}

\section{Variáveis}

C concentração $(\mathrm{ng} / \mathrm{ml})$ ou $(\mathrm{mg} / \mathrm{ml})$

$\mathrm{Cl}$ clearance $(\mathrm{ml} / \mathrm{h})$

di diâmetro (mm)

$E \quad$ efeito (adimensional)

EC concentração que produz metade do efeito $(\mathrm{ng} / \mathrm{ml})$

$G(s)$ função de transferência no domínio s

$H \quad$ coeficiente de transferência de massa $(\mathrm{ml} / \mathrm{h})$

$i(t) \quad$ impulso em função do tempo

$k \quad$ constante de transferência de massa $\left(\mathrm{h}^{-1}\right)$

$K \quad$ constante de primeira ordem relativa ao lúmen $(\mathrm{ml} / \mathrm{h})$

$m \quad$ massa (ng) ou (mg)

$M(s)$ massa no domínio s

$n \quad$ índice

$P \quad$ permeabilidade $(\mathrm{cm} / \mathrm{h})$

$P(s) \quad$ pulso no domínio s

$p(t) \quad$ pulso em função do tempo

$Q \quad$ vazão de plasma $(\mathrm{ml} / \mathrm{min})$

$R$ coeficiente de partição tecido-plasma (adimensional)

$S \quad$ área $\left(\mathrm{cm}^{2}\right)$ ou fator de Hill (adimensional) 
$t \quad$ tempo (h) ou (min)

$u$ função degrau (adimensional)

$V \quad$ volume $(\mathrm{ml})$

$W(s)$ série de pulsos no domínio $\mathrm{s}$

$X(s)$ entrada $x(t)$ no domínio $\mathrm{s}$

$x(t)$ entrada em função do tempo

$Y(s)$ saída $y(t)$ no domínio s

$y(t) \quad$ saída em função do tempo

$\beta \quad$ biodisponibilidade (adimensional)

$\chi \quad$ fração de droga (adimensional)

$\delta \quad \operatorname{atraso}(\mathrm{h})$ ou (min)

$\mathcal{L} \quad$ transformada de Laplace

\section{Subscritos}

abs absorvido

ap aparente

ar arterial

bi bile

ca carcaça

ce cerebral

co coração

cte constante

ef efetiva

es estômago 
et eliminação total

fe fezes

fi fígado

gi gastro-intestinal

gr gorduras

he hepático

ig intestino-gástrico

in intestino

li lúmen intestinal

max máxima

me metabolismo

mu músculos

os ossos

$p \quad$ plasmático

pa pâncreas

pe pele

$p k \quad$ farmacocinético

pu pulmão

re renal

ri rins

rp regime permanente

te testículos

$u 1$ maior quantidade de droga livre 
u2 menor quantidade de droga livre

ur urina

$\xi \quad$ assíntota tangente da relação sigmoidal

$0 \quad$ inicial

a absorção 


\section{INTRODUÇÃO}

O desenvolvimento de modelos matemáticos que simulem o comportamento do organismo humano é uma ferramenta que possibilita a obtenção de resultados sem que sejam realizados experimentos com seres vivos. Este tipo de abordagem possui a vantagem de possibilitar a realização de simulações em condições críticas, que possam colocar em risco a saúde dos indivíduos, o que seria inviável experimentalmente. Além disso, uma vez validado por meio de comparação com dados experimentais, o modelo gera uma maior gama de dados, uma vez que as análises não necessitam de novos experimentos e apenas a alteração de parâmetros já cria uma situação nova.

A modelagem farmacocinética permite prever a concentração da distribuição de drogas no organismo. Um modelo matemático farmacocinético possibilita diversos tipos de infusão de drogas no organismo podendo esta ser em quantidade terapêutica (em caso de otimização no tratamento utilizando medicamentos) ou em doses que possam gerar concentrações nocivas ao organismo. Estes modelos, além de serem usados para predição da concentração de medicamentos, são úteis na análise de entorpecentes ou substâncias tóxicas ao organismo.

Existem diversos tipos de modelos farmacocinéticos e a concepção destes depende do tipo de resultado que se deseja obter. No caso de uma infusão intravascular, utiliza-se o modelo monocompartimental, em que apenas o plasma é o foco de análise. Em administração extra-vascular utilizam-se modelos bicompartimentais, em que um compartimento representa o local de administração e o outro o plasma sanguíneo. Uma extensão deste é o modelo tricompartimental, em que além do local de administração existe um compartimento relativo aos tecidos por onde a substância ira se difundir. 
O principal foco da análise farmacocinética é a obtenção da concentração da substância no sangue, devido à facilidade da extração de plasma sanguíneo em análises clínicas. Basicamente é feita a análise de como varia a concentração de droga no organismo após a infusão, não existindo preocupação da reação que esta concentração irá ocasionar no organismo. A relação entre concentração e efeito é obtida por meio da análise farmacodinâmica.

Neste trabalho, serão desenvolvidos modelos capazes de prever as concentrações de diversos tipos de drogas a partir de infusões tanto extra vasculares como intra vasculares.

\subsection{Modelagem Matemática de Sistemas Biológicos}

Modelos matemáticos de sistemas biológicos são desenvolvidos para simular o comportamento de um organismo vivo exposto a determinadas condições. Entre estes modelos, podem-se citar:

- Modelos do sistema térmico: Modelos de Ferreira e Yanagihara (2009),Gordon, Roemer e Horvath (1976) e Pennes (1948).

- Modelos do sistema respiratório: Modelos de Albuquerque-Neto, Yanagihara e Turri (2008) e Grodins et al. (1954).

- Modelos do sistema circulatório: Modelos de Mirzae, Ghasemalizadeh e Firoozabadi (2008) e Hassani, Navidbakhsh e Rostami (2006).

O desenvolvimento destes modelos visa à obtenção de resultados sem que sejam realizados experimentos com seres vivos. Esta abordagem tem a vantagem de possibilitar simulações em condições adversas, que possam colocar em risco a saúde dos indivíduos ou provocar situações extremas desnecessariamente. Por exemplo, no modelo de Pennes (1948) foram realizadas medições com perfurações do antebraço dos indivíduos, possibilitando que obtenha-se o conhecimento de dados que somente poderiam ser obtidos desta forma invasiva. Com a utilização dos modelos, podem-se obter este tipo de dados sem que indivíduos sejam expostos a estas condições. 
Desta forma, o desenvolvimento de modelos matemáticos gera uma gama de resultados a serem explorados, sem que sejam realizados procedimentos experimentais, uma vez que delimitar condições e valores numericamente é relativamente simples do que criar novas condições em laboratório. Tendo o modelo sido validado a partir de dados experimentais, é possível que sejam obtidos novos resultados sem realizar mais experimentos, o que torna o modelo uma ferramenta útil para reduzir o número de ensaios.

\subsection{Modelagem Farmacocinética}

A modelagem farmacocinética visa prever a variação da concentração de substâncias no organismo de um indivíduo no decorrer do tempo. O modelo matemático possibilita infusão do medicamento de diversas maneiras e em quantidades que poderiam danificar o organismo. Como a abordagem é apenas numérica, podem-se criar situações extremas das mais variadas com grande facilidade. No modelo numérico, por exemplo, basta inserir o valor desejado na entrada do sistema e o tipo de infusão que deverá ser feita. Se o mesmo procedimento fosse realizado em laboratório, além do risco gerado ao organismo em teste, seria necessária a utilização da certa quantidade de medicamento, gerando custo.

Os parâmetros farmacocinéticos levam em consideração alguns fatores. Após a droga ser inserida no organismo, ela vai para o plasma sanguíneo e é distribuída ao longo do corpo. A velocidade com que o fármaco se propaga e é eliminado depende de como ele foi administrado no organismo (de forma intravenosa, intramuscular, subcutânea, por inalação, via oral, entre outros), de como os tecidos o absorvem e de como é feita a eliminação deste pelo organismo.

Existem modelos farmacocinéticos monocompartimentais (considerando apenas o plasma sanguíneo), bicompartimentais (incluindo além do plasma um compartimento periférico) e multicompartimentais (com a divisão dos órgãos e tecidos). Cada tipo de modelo tem seu tipo de abordagem, sendo que a mais simples é a primeira em que se considera apenas a concentração da substância no sangue. A partir desta podem-se de- 
senvolver modelos em que se obtenham os perfis de concentração no plasma, nos tecidos e em órgãos específicos. Um modelo farmacocinético pode ser utilizado para:

- determinar o tempo decorrido entre entrada de um medicamento no organismo e a situação de concentração ótima desejada;

- verificar o comportamento da eliminação de entorpecentes no plasma sanguíneo;

- obter o tempo de estado estacionário de medicamentos de concentração final constante no sangue;

- comparar as repostas dos diferentes tipos de infusões;

- simular situações de superdosagem;

- validar riscos que correm pacientes que se esqueceram de se medicar, quando o seu tratamento deve ser feito de maneira contínua.

\subsection{Modelagem Farmacodinâmica}

A modelagem farmacodinâmica visa estabelecer uma relação entre a concentração do fármaco e sua ação no organismo. Para este tipo de abordagem, é necessária a realização de procedimento experimental, uma vez que a simulação numérica é limitada a calcular os valores das concentrações. A união destes dois modelos é chamada de modelagem PK/PD (Pharmacokinetics/pharmacodynamics), ou farmacocinética farmacodinâmica, em que a coexistência de um perfil da concentração e de uma análise da resposta do organismo para a referida curva estabelece, além da relação concentração e tempo, uma relação entre o tempo e a reação provocada nos organismos.

Assim pode-se definir que os parâmetros farmacocinéticos de um fármaco definem a velocidade e a extensão da penetração do mesmo na corrente sanguínea, bem como a velocidade de sua eliminação. Já os parâmetros farmacodinâmicos definem a relação entre a concentração do fármaco e os efeitos provocados por esta concentração que podem ser terapêuticos ou podem provocar uma intoxicação, quando excedem os valores que trazem benefícios. 


\subsection{Objetivos}

O objetivo do presente trabalho é a elaboração de um modelo farmacocinético que simule a reposta do organismo para diferentes tipos de infusões. Para isto serão desenvolvidos dois tipos de modelo. Primeiramente será desenvolvido um modelo monocompartimental para simular a infusão intravenosa, tanto constante quanto periódica. Posteriormente será desenvolvido um modelo bicompartimental em que será possível outros tipos de administração que não a intravenosa.

Os modelos serão validados a partir de resultados empíricos presentes na literatura e a partir desta validação serão criadas novas condições de simulação. Assim, será obtida uma relação entre tempo, dosagem e efeito. Outra aplicação será a utilização destes para verificar a eliminação de substâncias tóxicas ao organismo, bem como suas concentrações no sangue. Esta abordagem permitirá que se tenha uma noção do período de risco que o indivíduo corre ao possuir determinada toxina em corpo, sendo útil para otimizar o tratamento. 


\section{CONCEITOS FISIOLÓGICOS E FARMACOCINÉTICOS}

Neste capítulo serão abordados inicialmente, na seção 2.1, os conceitos básicos envolvidos na abordagem farmacocinética e farmacodinâmica como os conceitos de droga, dosagem, bioequivalência, absorção e distribuição. Os dados apresentados tiveram como

referência os livros de Bauer (2008), Rosenbaum (2011), Jambhekar e Brenn (2009) e Makoid, Vuchetich e Banakar (1999).

Posteriormente, na secção 2.2, serão discutidos alguns parâmetros fisiológicos relativos a estes conceitos.

\subsection{Conceitos Farmacocinéticos Básicos}

Nesta seção serão abordados e discutidos conceitos importantes para a compreensão dos modelos existentes na literatura.

\subsubsection{Droga e dosagem}

Droga é uma substância química que altera processos fisiológicos ou bioquímicos no corpo humano. A droga pode ser usada como medicamento.

Quando isso ocorre, a frequência de administração e a rota do fármaco são fatores importantes para a eficácia do tratamento, bem como são úteis para minimizar a ocorrência de efeitos colaterais. Para a criação do modelo, é necessário o domínio completo das informações referentes a todos os processos e etapas desde a entrada até a eliminação da substância. Estes parâmetros variam de acordo com o paciente, sendo levados em consideração a idade, o sexo e a massa do indivíduo. A Tabela 1 mostra alguns tipos 
de medicamentos, sua dosagem diária, frequência de administração e a rota pela qual a droga entra no organismo.

Tabela 1: Exemplos de dosagens e intervalos (ROSENBAUM, 2011).

\begin{tabular}{cccc}
\hline Droga & Dose Diária $(\mathrm{mg})$ & Frequência da Dose $(\mathrm{h})$ & Rota \\
\hline Carbonato de Cálcio & 3000 & 2 & oral \\
Ibuprofeno & 1600 & 6 & oral \\
Vancomicina* & 2000 & 12 & intravenosa \\
Amoxilina & 750 & 8 & oral \\
Vancomicina** & 1000 & 6 & oral \\
Atenolol & 100 & 24 & oral \\
Fluoxetina & 20 & 24 & oral \\
Ramipril & 10 & 12 & oral \\
Digoxina & 0,25 & 24 & oral \\
Cloroquina & 300 & semanalmente & oral \\
\hline${ }^{*}$ para Staphylococcus aureus resistentes a meticilina & \\
${ }^{* *}$ para pseudomembranuscolitis & & \\
\hline
\end{tabular}

\subsubsection{Farmacodinâmica}

Pharmacos significa droga e dynamics variação de intensidade, portanto a farmacodinâmica visa analisar a resposta do organismo de acordo com a variação do fármaco.

A resposta da droga se inicia pela interação química entre esta e o receptor. Esta interação gera um estímulo que leva a uma resposta biológica ou bioquímica, sendo que esta interação pode ser reversível ou irreversível.

O fármaco provoca alterações no meio intracelular, mas a membrana lipofílica da célula representa uma barreira física para muitas drogas e ligantes endógenos. Desta maneira, muitos receptores se localizam na própria membrana plasmática. A ação final da droga é dependente do estímulo inicial resultante da interação da droga com o receptor presente na membrana. Este estímulo inicial gera um sinal, que envolve uma cascata de diferentes passos durante os quais este respectivo sinal pode ser amplificado ou atenuado.

\subsubsection{Concentração plasmática}

Após a infusão, a droga é distribuída aos órgãos e tecidos. Não existe a possibilidade de medir-se clinicamente a concentração da droga nos diferentes órgãos e tecidos. Sendo assim a concentração plasmática é o foco principal da análise. A concentração plasmática 
da droga deve ser suficientemente grande para produzir uma resposta do organismo, mas não deve ultrapassar o nível que gera toxidade.

Considera-se a hipótese de que a concentração plasmática reflete a concentração da droga no local de sua ação. Esta relação é linear e sendo assim a consideração dessa hipótese normalmente é válida, devido às mudanças na concentração plasmática serem reflexos de alterações proporcionais no local de ação. De uma maneira geral, sempre que ocorrer alteração na concentração plasmática, significa que houve uma mudança no local de ação da droga, mas o inverso não ocorre. Se acontecer uma alteração em um tecido isso não implicará necessariamente na mudança da concentração plasmática (ROSENBAUM, 2011).

Outra vantagem da análise plasmática é a possibilidade de extração de sangue e amostragem do mesmo para variados intervalos de tempo. Quando é feita a extração de sangue, é necessária a utilização de um anticoagulante que pode interferir no resultado final. Algumas drogas podem associar-se a proteínas, assim no sangue podem existir drogas livres ou associadas a proteínas. Quando é feita a análise da concentração plasmática, é contabilizada tanto a quantidade de droga livre no plasma, como as que estão associadas. Somente a parcela referente às drogas livres que é importante para a análise, pois é este tipo que poderá ultrapassar membranas e interagir com os receptores, gerando uma resposta farmacológica.

\subsubsection{Absorção, Distribuição, Metabolismo e Eliminação}

A compreensão dos processos de absorção, distribuição, metabolismo e eliminação é de suma importância para a análise farmacocinética. O conjunto de todos estes processos recebe o nome de ADME. A Figura 1 mostra o processo de absorção de uma medicamento tomado por via oral.

- Absorção: transferência da droga do local de administração para o plasma sanguíneo. 


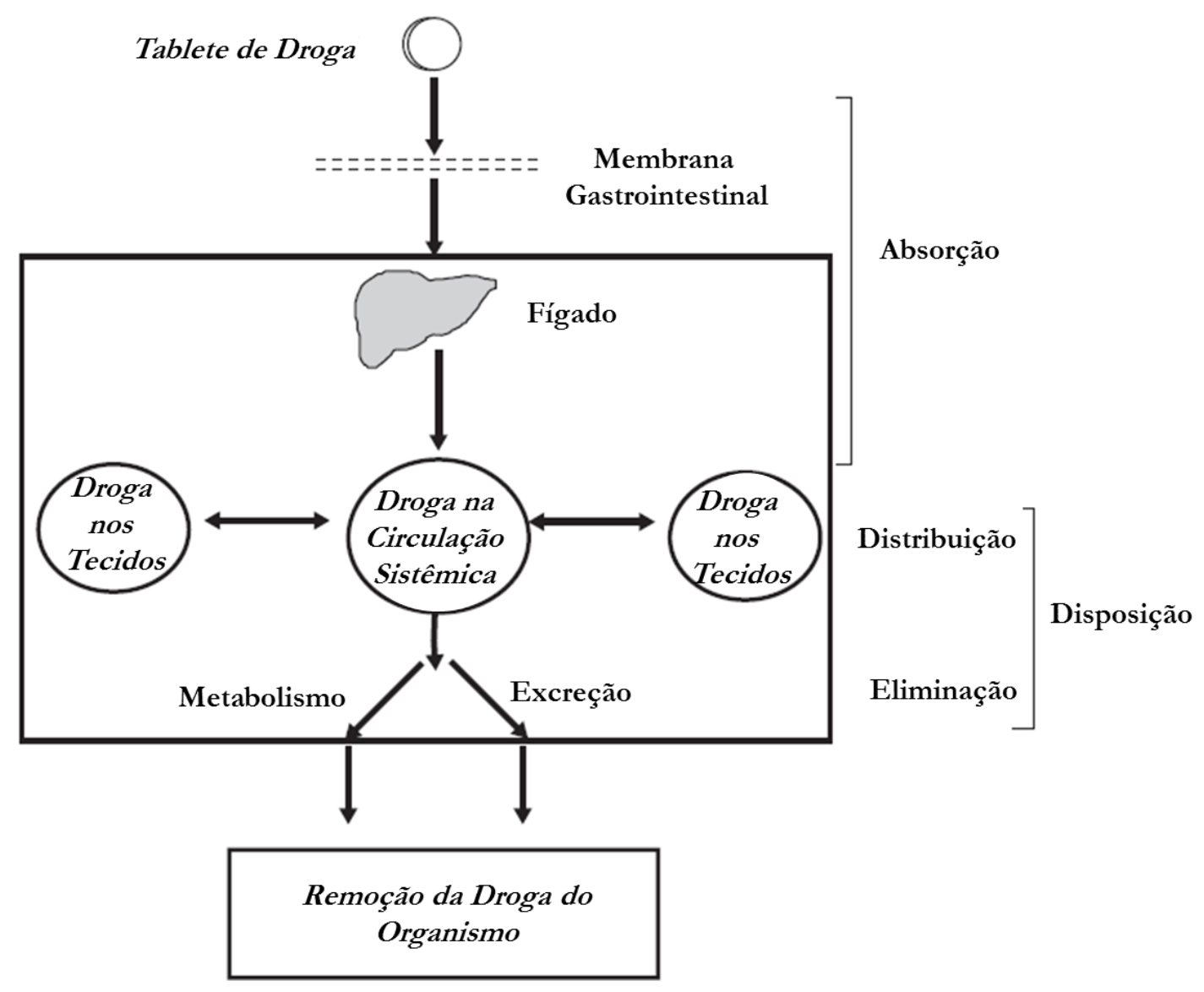

Figura 1: Processo de absorção de um tablete de droga. O medicamento atravessa a membrana gastrointestinal e passa para o fígado e posteriormente para a circulação sistêmica e para os tecidos, sendo finalmente metabolizado e excretado. Adaptado de Rosenbaum (2011).

- Distribuição: transferência da droga do sangue para o local de ação. Depende da perfusão sanguínea, da associação da droga às proteínas plasmáticas e componentes de tecidos e da permeabilidade da droga na membrana plasmática.

- Metabolismo: processo em que a droga se transforma em outras espécies químicas, denominadas metabólitos.

- Eliminação: remoção da droga pelos rins.

Sabe-se que a concentração farmacocinética é função da dose e do tempo, sendo:

$$
C_{p}=f_{p k}(\text { dose,tempo })
$$


sendo que $C_{p}$ refere-se a concentração plasmática e $f_{p k}$ indica que se trata de uma função farmacocinética. A resposta do organismo é uma função farmacodinâmica da concentração.

\subsubsection{Faixa terapêutica}

Uma maneira de se expressar uma margem segura oferecida pela droga é sua faixa terapêutica, sendo representada pela relação entre a dose que produz efeitos tóxicos em metade dos pacientes em relação à dosagem terapêutica mínima. Quanto maior esta faixa terapêutica, mais segura a utilização da droga. Por exemplo, uma faixa terapêutica de valor 100 significa que a dosagem tóxica é 100 vezes maior do que a dosagem efetiva mínima. A faixa terapêutica é mostrada na Figura 2.

\subsubsection{Passagem da droga atravéz das membranas}

Neste item serão discutidos os meios pelos quais a droga atravessa a membrana plasmática e adentra o meio celular.

Na difusão passiva ocorre passagem da droga do meio de maior concentração para o meio de menor concentração. O processo de difusão é governado pela Lei de Fick, segundo a 2.2 :

$$
\frac{\mathrm{d} m_{d i}}{\mathrm{~d} t}=P_{m e m} S_{m e m}\left(C_{u 1}-C_{u 2}\right)
$$

em que:

$\frac{\mathrm{d} m_{d i}}{\mathrm{~d} t}=$ massa de droga sendo difundida por unidade de tempo $(\mathrm{mg} / \mathrm{h})$;

$P_{m e m}=$ permeabilidade da membrana $(\mathrm{cm} / \mathrm{h}) ;$

$S_{m e m}=$ área superficial da membrana $\left(\mathrm{cm}^{2}\right)$;

$C_{u 1}=$ maior concentração de droga $(\mathrm{mg} / \mathrm{ml})$;

$C_{u 2}=$ menor concentração de droga $(\mathrm{mg} / \mathrm{ml})$. 


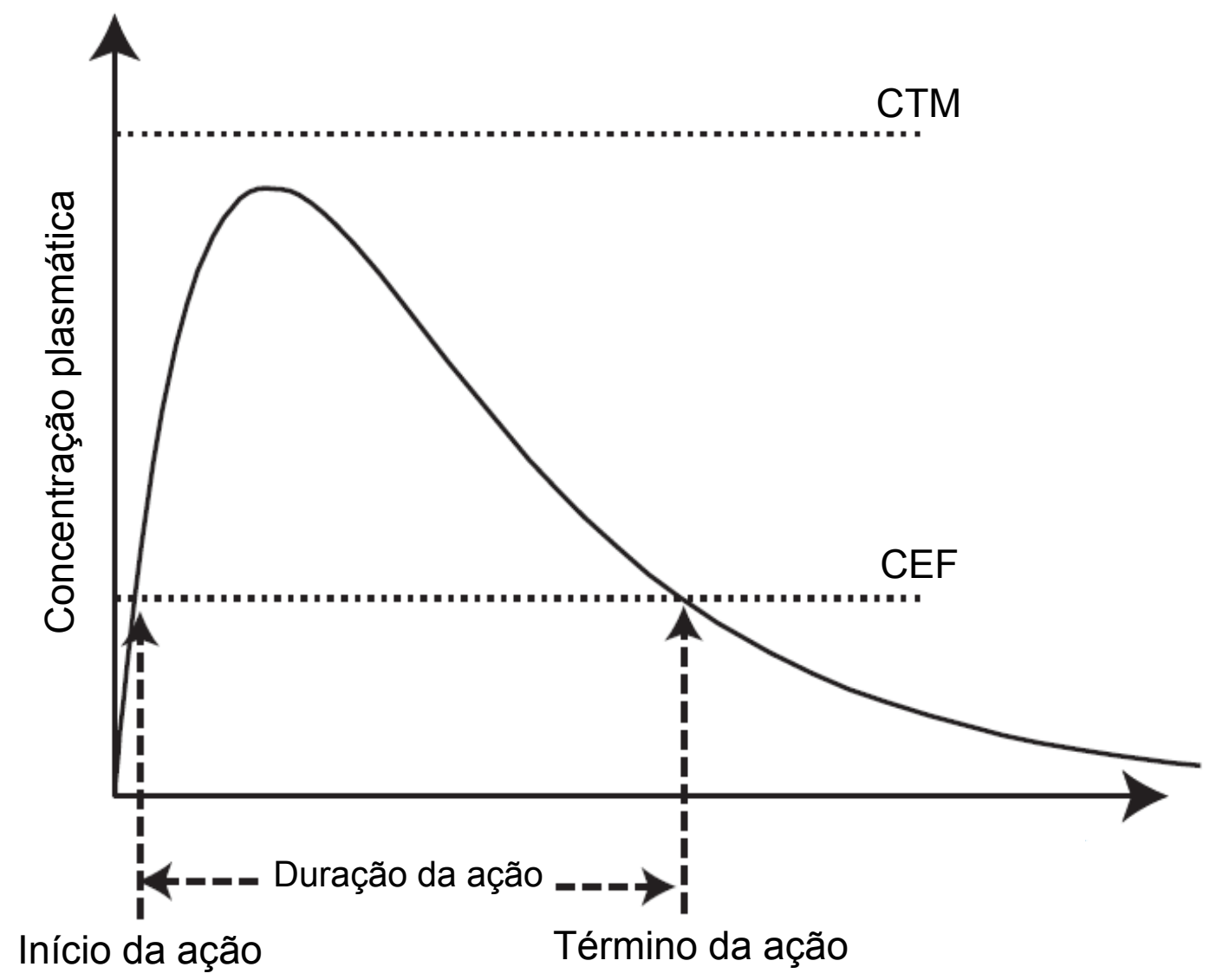

Figura 2: Concentração de uma droga no plasma sanguíneo. A CTM refere-se a concentração tóxica máxima a CEF a concentração efetiva mínima. Para que ocorra um efeito terapêutico, a concentração deve ser maior do que a CEF e menor do que a CTM, a fim de que haja efeito sem que o organismo seja prejudicado. Adaptado de Jambhekar e Brenn (2009).

Pode-se fazer a hipótese de que $C_{u 1}>>C_{u 2}$ e, sendo assim é obtida a Equação 2.3 que representa a difusão da droga de um local de maior concentração para um de menor concentração, desprezando-se a concentração menor $C_{u 2}$. Dependendo da situação,a maior ou menor concentração pode ocorrer tanto no meio plasmático como no meio celular.

$$
\frac{\mathrm{d} m_{d i}}{\mathrm{~d} t}=P_{m e m} S_{m e m} C_{u 1}
$$

\subsubsection{Tipos de Infusão}

A escolha do tipo de administração depende do período de tempo apropriado para que o medicamento chegue ao local de ação. A aplicação pode ser local ou sistêmica. 
- Administração local: consiste na aplicação direta da droga no seu local de ação. Como exemplo pode-se citar cremes, pomadas, géis ou inalação de corticosteróides.

- Administração sistêmica: ocorre a absorção para que posteriormente ocorra a distribuição. Exemplos são as injeções e os comprimidos.

\subsubsection{Rotas na administração sistêmica}

A administração sistêmica pode ser de maneira intravascular ou extravascular. Nesta seção serão discutidos estes dois tipos de infusões.

\subsubsection{Infusão intravascular}

Pode ser feita na forma intravenosa ou intra-arterial.

No caso da infusão intravenosa, o objetivo é que a droga se espalhe pelo organismo rapidamente, almejando-se um efeito rápido, uma precisão na quantidade de droga inserida ou ainda quando outras formas de infusão são ineficientes. A infusão é invasiva e exige a presença de um profissional qualificado para que o paciente não sofra danos. Este tipo de infusão apresenta um alto valor de biodisponibilidade.

Já a infusão intra-arterial é utilizada quando objetiva-se o foco em algum órgão específico. Um exemplo deste tipo de aplicação é o tratamento anticancerígeno de células hepáticas.

Tanto a infusão intravenosa como a intra-arterial garantem que toda a dose administrada adentre a circulação sistêmica, já que a droga é inserida no próprio sangue.

\subsubsection{Infusão extravascular}

A infusão extravascular pode ser por rota parenteral (por via não digestória) ou por rota não parenteral (por via digestória). A seguir serão descritos os tipos de administração extravasculares existentes. 
- Intramuscular e subcutânea: São utilizadas para que a droga não passe pelo fluido gastrointestinal que pode destruí-la ou devido ao tamanho de sua molécula, que impediria a penetração pela membrana. Nestes tipos de infusão, a droga chega ao sangue mais rapidamente do que por via oral.

- Bucal e sublingual: Devido à boca ser uma região extremamente porosa e bem vascularizada, este tipo de administração possui a vantagem de propiciar uma grande absorção. Além disso, os capilares desta região não levam à artéria hepática, oferecendo uma alternativa a drogas que são metabolizadas pelo fígado, já que estas seriam removidas pelo organismo antes de atingirem a circulação sistêmica.

- Retal: Este tipo de administração também possui a característica de fazer com que a droga não passe pelo fígado, sendo utilizada em pacientes que não podem tomar o medicamento por via oral devido a possibilidade de ocorrência de enjôos, náuseas, vômitos, ou ainda ser utilizada em pacientes que estejam inconscientes.

- Transdermal: Outra maneira desenvolvida para que a droga não passasse pelo fígado. Sua vantagem é possibilitar uma administração contínua por um período extenso.

- Intranasal: Possui a vantagem da região interna nas narinas possuir uma extensa área de absorção, com grande permeabilidade e perfusão sanguínea, propiciando rápida absorção. A infusão intranasal permite um acesso direto ao sistema nervoso central, sendo muito útil no tratamento de Parkinson e Alzheimer.

- Pulmonar: Utilizada no tratamento de asma e outras doenças respiratórias. O pulmão possui uma grande área vascularizada com alta perfusão sanguínea da membrana alveolar.

- Oral: Infusão mais comum e amplamente utilizada. Pode ser feita por meio de comprimidos, cápsulas, suspenções, entre outros. Na infusão oral a droga passa por várias etapas: desintegração do comprimido ou cápsula, dissolução da droga, difusão da droga através da membrana gastrointestinal, absorção ativa da droga através da membrana gastrointestinal, efluxo da droga(devolução), metabolismo da droga na 
membrana gastrointestinal e metabolismo hepático. A Figura 3 mostra como uma quantidade de droga é perdida no metabolismo tanto do fígado como da parede do estômago.

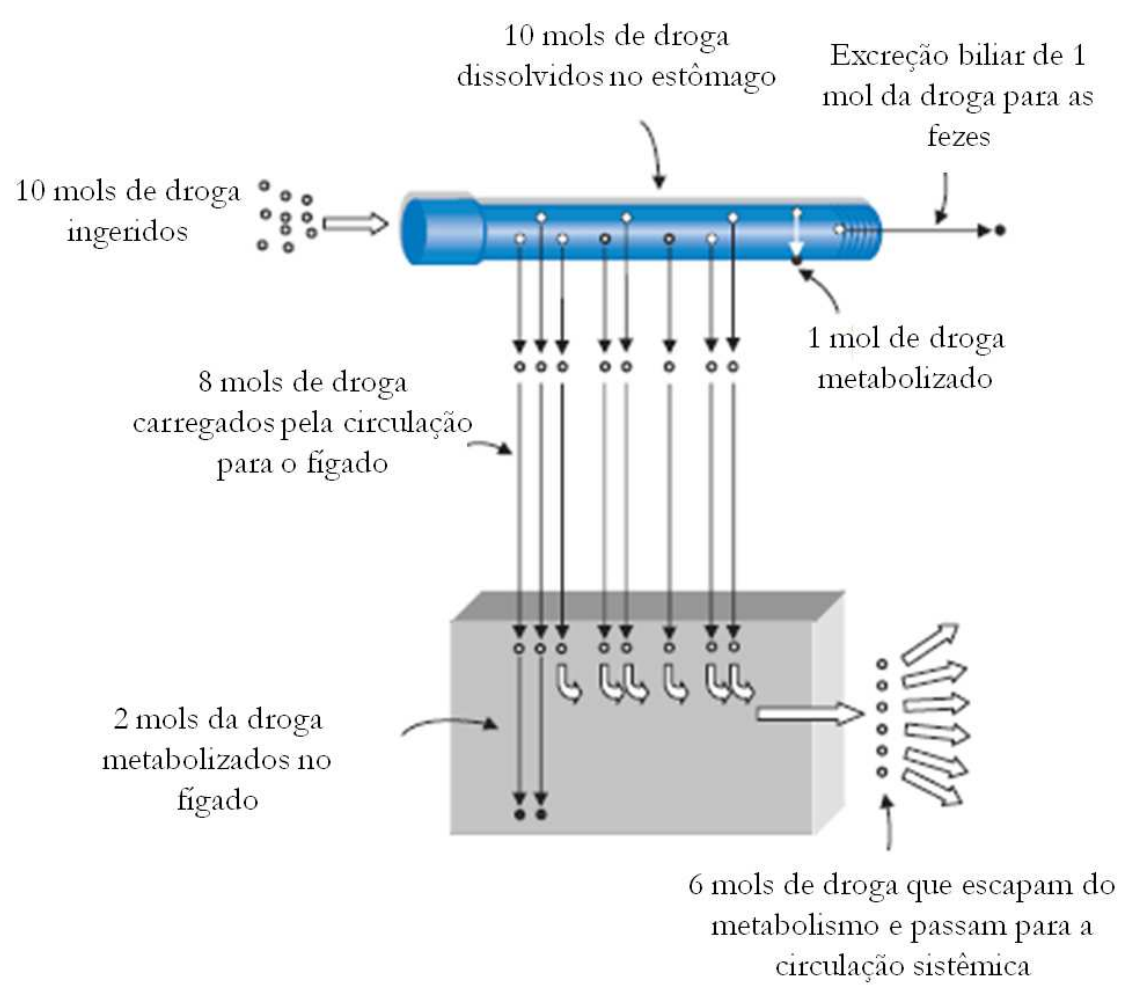

Figura 3: Droga sendo perdida durante o metabolismo. Adaptado de Jambhekar e Brenn (2009).

\subsubsection{Biodisponibilidade}

Uma boa porção da droga pode ser perdida durante seu processo de absorção. Podese definir biodisponibilidade como a fração de droga que realmente atinge a circulação sistêmica.

Os fatores que determinam a biodisponibilidade são: desintegração, dissolução e excipientes (substâncias passivas que dão a forma ao medicamento). Já os fatores que influenciam na taxa da absorção são presença de alimentos no estomago, a área de absor- 
ção e a perfusão sanguínea nos tecidos onde a droga será absorvida. A biodisponibilidade é definida pela Equação 2.4 :

$$
\beta=\chi_{a b s} \chi_{g i} \chi_{h e}
$$

em que:

$\chi_{a b s}=$ fração absorvida da droga;

$\chi_{g i}=$ fração da droga que escapa do metabolismo gastro intestinal;

$\chi_{h e}=$ fração da droga que escapa do metabolismo hepático.

Existe ainda um parâmetro denominado fator salino que representa a fração de medicamento existente na massa total de um comprimido. Isto se deve ao fato do remédio estar misturado com outra substância, normalmente um sal, para que possa dar forma a um tablete. Assim, a dose efetiva pode ser definida pela Equação 2.5:

$$
D_{e f}=\phi \beta D
$$

em que:

$\phi=$ fator salino;

$\beta=$ biodisponibilidade;

$D=$ dose do medicamento no comprimido (ng);

$D_{e f}=$ dose efetiva $(\mathrm{ng})$;

\subsubsection{Taxa de remoção}

A taxa de remoção é um parâmetro farmacocinético importante pois é com base neste que se determina qual será a infusão constante de um medicamento para que este atinja uma concentração em regime permanente. Atingir esta concentração dentro da faixa 
terapêutica, possibilita a otimização da ação do medicamento. Pode-se definir a dose constante que será inserida no organismo, segundo a Equação 2.6 :

$$
D(t)_{c t e}=C_{r p} C l
$$

sendo $D(t)_{c t e}$ a dose constante $(\mathrm{ng} / \mathrm{h}), C_{r p}$ a concentração em regime permanente $(\mathrm{ng} / \mathrm{ml})$ e $C l$ a taxa de remoção (clearance) $(\mathrm{ml} / \mathrm{h})$.

Assim, a taxa de remoção é definida como o volume de sangue por unidade de tempo em que a droga já foi completamente removida. Esta remoção deve-se principalmente ao metabolismo que ocorre no fígado e a eliminação por parte dos rins. Ocorre metabolismo do medicamento também na parede gastrointestinal, no pulmão e nos rins, mas a parcela mais significativa ocorre no fígado. Assim a taxa de remoção total é dada pela Equação 2.7:

$$
C l=C l_{h e}+C l_{r e}
$$

sendo:

$C l_{h e}=$ remoção hepática $(\mathrm{L} / \mathrm{h})$

$C l_{r e}=\operatorname{remoção~} \operatorname{renal}(\mathrm{L} / \mathrm{h})$

\subsubsection{Volume de Distribuição}

O volume de distribuição, ou volume aparente, é a relação entre a quantidade de droga presente no organismo em um determinado momento e a sua concentração plasmática neste mesmo momento. Esta relação pode ser expressa pela Equação 2.8:

$$
V_{a p}=\frac{D_{e f}}{C_{p}}
$$

O volume aparente se deve a maneira como a droga é distribuida no organismo. Quanto menor o volume de distribuição, maior será a concentração plasmática. Isto se 
deve ao fato de os orgãos e tecidos absorverem droga. Se uma dose $D=5 \mathrm{mg}$ for inserida no sangue por meio intravenoso, sua concentração deveria ser dada pela Equação 2.9:

$$
C_{p}=\frac{D_{e f}}{V_{p}}
$$

em que $V_{p}$ se refere ao volume de plasma. O volume de plasma em seres humanos é de aproximadamente $3000 \mathrm{ml}$ (GIBALDI; PERRIER, 1982). Sendo assim, a concentração plasmática assumiria um valor de $C_{p}=1666,7 \mathrm{ng} / \mathrm{ml}$. Entretanto não se verifica esta concentração devido a droga ser difundida por todo organismo. Assim, a Equação 2.9 não representa o real valor da concentração plasmática.

Com base nisto, pode-se dizer que a concentração plasmática não reflete a quantidade real de droga existente no corpo, mas as análises farmacocinéticas podem ser feitas utilizando-se este parâmetro.

\subsubsection{Tempo de meia vida plasmática}

Define-se tempo de meia-vida como o tempo que a droga leva para atingir metade da sua concentração inicial, no caso de uma injeção intravenosa. Este valor pode ser obtido experimentalmente, analisando-se amostras de plasma sanguíneo em diferentes períodos de tempo.

\subsection{Conceitos Fisiológicos}

Nesta seção serão discutidos parâmetros fisiológicos importantes para compreensão dos processos farmacocinéticos. O conteúdo presente no capítulo teve como base conceitos presentes nos livros de Jambhekar e Brenn (2009) e Guyton (1981). 


\subsubsection{Sistema Circulatório}

Para compreender a maneira como os medicamentos se distribuem por todo o organismo é necessário o entendimento do funcionamento do sistema circulatório uma vez que é por meio do sangue que as drogas são distribuídas.

O sistema circulatório é composto pelo sangue, veias, artérias e coração. O sangue arterial, bombeado a partir do coração, parte para os órgãos e tecidos por meio da artéria aorta, realizando trocas com os órgãos e tecidos por meio dos capilares. Após estas trocas, o sangue retorna para o coração pela veias cavas carregado de dióxido de carbono partindo para os pulmões por meio da artéria pulmonar, sendo oxigenado novamente, retornando ao coração por meio da veia pulmonar. O procedimento ocorre novamente, com o sangue oxigenado partindo da aorta.

No caso de injeções intravenosas, a droga que adentra ao sangue arterial tem como rota o coração. Após adentrar no ventrículo direito, o sangue parte para os pulmões onde é oxigenado, volta ao coração e é distribuído a todo o organismo.

Já no caso de inalação, a absorção da droga pelo organismo se dá em nível alveolar. Após ser inalada pelo paciente, a droga passa para o sangue por meio da troca com os alvéolos pulmonares para ser posteriormente distribuída.

$\mathrm{Na}$ infusão gastro intestinal, ocorrem trocas entre as paredes do estômago e do intestino com o sangue por meio dos capilares.

\subsubsection{Os Rins}

Os rins desempenham importante papel na análise farmacocinética já que é por meio destes que a droga é filtrada do plasma sanguíneo para ser eliminada na urina. A Figura 4 mostra a estrutura deste órgão.

O rim apresenta duas regiões: a zona cortical e a zona medular. As unidades excretoras dos rins são denominadas néfrons. Em um rim existem cerca de 1 milhão de néfrons. Em cada néfron existe um microscópico capilar sanguíneo enrolado denominado glomérulo. 
Os glomérulos são envoltos por uma cápsula denominada Cápsula de Bowman dotada de um fino epitélio. Desta cápsula saem um túbulo enrolado (Túbulo proximal), um túbulo em forma de alça (alça de Henle) e outro túbulo enrolado (Túbulo distal). A filtração do sangue ocorre da seguinte maneira: o sangue entra no glomérulo sob alta pressão arterial. O líquido filtrado recebe o nome de filtrado glomerular, sendo equivalente ao plasma sanguíneo sem proteínas. Ao longo dos túbulos do néfron ocorre a reabsorção de certas substâncias por transporte ativo ou osmose. Assim, a formação de urina é um processo que envolve filtração e reabsorção seletiva.

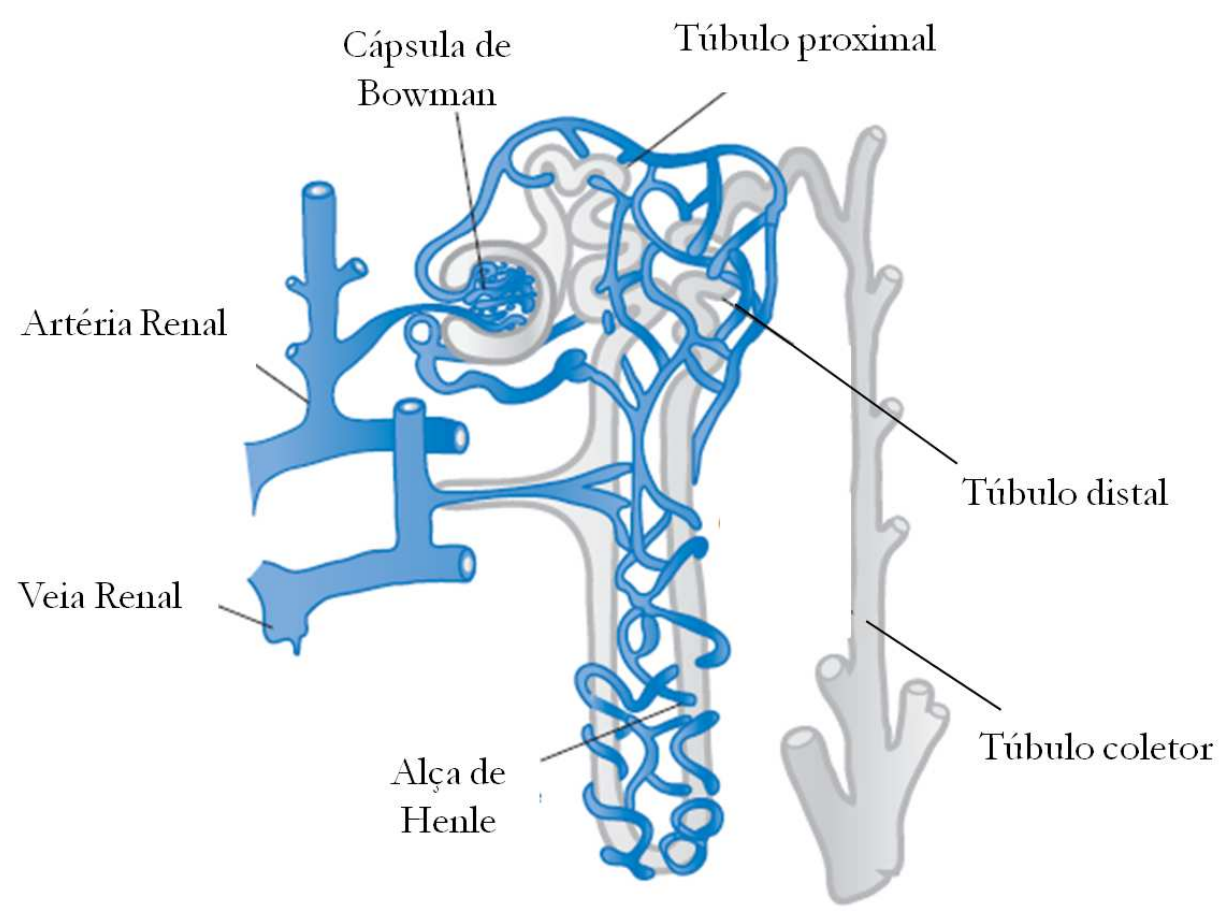

Figura 4: Anatomia renal. Adaptado de Jambhekar e Brenn (2009).

\subsubsection{Absorção Gastro Intestinal}

O estômago é um órgão que não possui membrana absortiva típica, não possibilitando uma alta taxa de absorção. Apenas substâncias lipossolúveis como o álcool e certos medicamentos podem ser absorvidos.

A maior absorção ocorre no intestino, onde existem pregas denominadas válvulas coniventes que aumentam a área de superfície da mucosa absortiva em cerca de 10 vezes. A absorção pode ocorrer por transporte ativo (contra o gradiente de concentração), ou por difusão. A Figura 5 mostra como os medicamentos atravessam a membrana gastro 


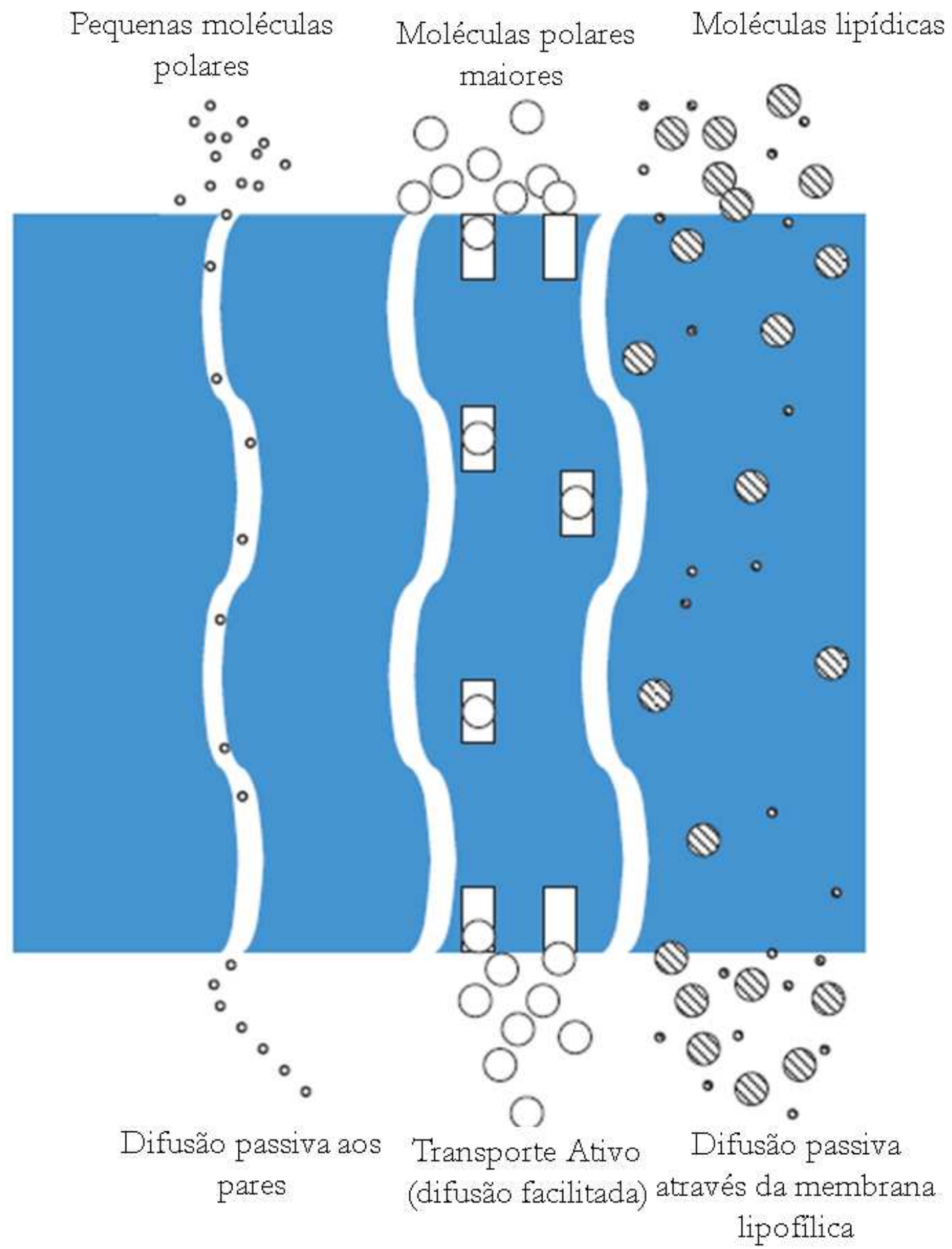

Figura 5: Medicamento atravessando a membrana gastrointestinal. Adaptado de Jambhekar e Brenn (2009).

intestinal. Moléculas polares menores atravessam a parede por meio da difusão passiva. Já as moléculas polares maiores atravessam por meio do transporte ativo. As substâncias lipídicas atravessam por meio da difusão, devido a membrana apresentar característica lipofílica. 


\section{REVISÃO DA LITERATURA}

Neste item serão citados alguns exemplos de modelos farmacocinéticos encontrados na literatura com o objetivo de que sejam compreendidos os métodos utilizados e qual melhor maneira para escolher o modelo e validá-lo, dependendo do objetivo almejado.

Ramsey e Andersen (1984) consideram que o primeiro trabalho visando prever o que ocorria com substâncias que adentravam o organismo foi o de Teorell (1937a;1937b). Neste trabalho, Teorell apresentou uma descrição matemática dos fenômenos ocorridos com o medicamento após sua infusão no organismo, a partir de fatores como o fluxo sanguíneo e a permeabilidade das membranas, e desenvolveu um conjunto de equações para prever a concentração da droga no organismo. Embora Teorell seja considerado o pai da farmacocinética, Ramsey e Andersen (1984) observaram um trabalho ainda mais antigo em que Haggard (1924a;1924b) descreve relações fisiológicas importantes no processo ADME.

Outro modelo precursor foi de Mapleson (1963) em que foi feita uma descrição genérica da farmacocinética dos gases inertes utilizando analogia elétrica. Bischoff et al. (1971) e Himmelstein e Lutz (1979) desenvolveram algoritmos computacionais e hardwares para solucionar o conjunto de equações diferenciais lineares e não lineares presente na modelagem matemática do balanço de massa da droga no organismo.

Adolph (1949), Dedrick (1973) e Lutz, Dedrick e Zaharko (1980) propõem que a partir de parâmetros e respostas farmacocinéticas obtidas a partir da análise de modelos utilizando animais, possa ser feita a extrapolação para seres humanos, utilizando-se o aumento de escala, desde que se estabeleça uma relação correta entre estes parâmetros (RAMSEY; ANDERSEN, 1984). 
Segundo Weiss (1998), a validação de um modelo é definida em termos dos objetivos da modelagem. Sendo assim, se o objetivo do modelo é conhecer a concentração plasmática, o modelo monocompartimental (caixa preta) é o mais adequado. No entanto, modelos estruturais, que são empíricos, são necessários para que parâmetros farmacocinéticos e bioquímicos sejam mais bem compreendidos, sendo que para estes é necessário o aprofundamento de parâmetros anatômicos e fisiológicos. Weiss propõe a seguinte divisão: os modelos compartimentais são baseados na resposta de um sistema linear, cuja entrada seria a dose e a saída a concentração; os modelos multi-órgão são baseados na análise de dados ajustados a uma curva de uma função poli exponencial.

\subsection{Modelos experimentais}

Nesta seção serão abordados os modelos farmacocinéticos experimentais. Estes modelos se baseiam em administrar medicamentos em um grupo de indivíduos e fazer o levantamento das concentrações plasmáticas em certos intervalos de tempo.

\subsubsection{Modelo de Tasso (2008)}

O modelo Tasso (2008) consistiu em estabelecer um modelo farmacocinéticofarmacodinâmico para descrever o comportamento temporal da ação do bactericida levofloxacino e do gatifloxacino no combate ao Streptococcus pneumoniae. Segundo o autor, um dos principais objetivos desta análise é estabelecer uma relação entre a concentração do fármaco e o efeito farmacológico alcançado por estas concentrações. Avaliou-se a CIM (combinação inibitória mínima) e a CBM (concentração bactericida mínima), obtidas com análise em modelo in vitro. A combinação da análise farmacocinética e farmacodinâmica permitiu uma aproximação do que ocorre na atividade in vivo. No caso de fármacos antimicrobianos, alguns índices PK/PD são utilizados para avaliar a eficácia do mesmo. São estes índices: Tempo acima da concentração inibitória mínima ( $>$ CIM), razão entre o pico de concentração e a concentração inibitória mínima $\left(C_{m a x} / \mathrm{CIM}\right)$, razão entre a área da curva do perfil de concentração em função do tempo e a concentração inibitória mínima (ASC/CIM). Cada índice PK/PD é mais apropriado para determinada classe de fármacos. 
A análise farmacodinâmica foi feita de suas maneiras: pelo modelo $E_{\max }$ (Equação 3.1) e pelo modelo $E_{\text {max-sigmoidal }}$ (Equação 3.2). O modelo $E_{\max }$ descreve uma relação hiperbólica de concentração-efeito, onde se observa ausência de efeito quando não existe fármaco e efeito máximo quando a concentração tende a infinito. O modelo $E_{\text {max-sigmoidal, }}$ que é uma extensão do primeiro, quando a curva não pode ser descrita de forma hiperbólica.

$$
\begin{gathered}
E=\frac{E_{\max } C}{E C_{50}+C} \\
E=\frac{E_{\max } C^{S}}{E C_{50}^{S}+C^{S}}
\end{gathered}
$$

em que em que $E$ é o efeito do fármaco; $E_{\text {max }}$ é o efeito máximo obtido pelo fármaco; $C$ é a concentração do fármaco; $E C_{50}$ é a concentração do fármaco que produz metade do efeito máximo; $S$ é o fator de Hill, que influencia a curvatura da curva efeito-concentração.

\subsubsection{Modelo de Santos (2008)}

O modelo proposto por Santos (2008) busca correlacionar a influência da morfina intratecal (administrada por meio de injeção no canal raquideano) e da circulação extracorpórea (CEC) sobre o consumo de morfina ACP (administrada com bomba de infusão controlada pelo paciente), área sob curva e escores de dor no período pós-operatório. A utilização de bomba ACP permite que o paciente, através da bomba de infusão controlada, possa administrar morfina em seu próprio organismo. Tal método no entanto pode provocar efeitos adversos. A CEC é um procedimento relevante na cinética de fármacos. No período intra operatório ocorre perda de sangue e a CEC mantém o fluxo de sangue e a irrigação dos tecidos contínuos, devido ao coração ter suas funções interrompidas. Na tese em questão, 36 pacientes participaram do estudo da farmacocinética e da modelagem PK/PD, em análise clínica. Estes 36 pacientes, submetidos a revascularização do miocárdio, foram divididos em 4 grupos distintos: Anestesia Geral com CEC (Grupo 1) e sem CEC (Grupo 3), ambos sem a administração de morfina intratecal e anestesia geral + Raqui com CEC(Grupo 2) e sem CEC (Grupo 4), sendo estes com a administração 
de morfina intratecal. O modelo $E_{\max }$ foi escolhido para explicar a correlação não linear obtida entre os parâmetros AUC (área sob curva) em função do consumo de morfina. Estabeleceu-se a correlação linear direta entre AUC e $C_{\max }$.

\subsubsection{Modelo de Araujo (2008)}

O modelo desenvolvido por Araujo (2008) objetivou desenvolver um modelo PK/PD para descrever a ação do antifúngico voricozanol (VCR) contra a Candida. Os índices são os mesmos empregados na análise de antibacterianos, sendo o fator mais importante o CIM. Os modelos usados foram o $E_{\max }$ e o $E_{\max -\text { sigmoidal }}$ que previnem o efeito mínimo e máximo da ação do fármaco, também utilizados por Tasso (2008).

O desenvolvimento do modelo foi realizado a partir de simulações, utilizando modelo de infecção experimental in vitro, do perfil de concentração tecidual livre esperado em tecido muscular de humanos após administração intravenosa de piperacilina.

Não há descrito na literatura a aplicação de modelos $\mathrm{PK} / \mathrm{PD}$ para antifúngicos, e considerando-se que a cinética de crescimento de leveduras não é muito distinta das estudadas para bactérias, no que se refere às limitações de crescimento, o trabalho objetivou testar a aplicabilidade dos modelos descritos na literatura e modificá-los casos seja necessário para descrever a relação entre o efeito e o tempo do VRC.

\subsubsection{Modelo de Dershwitz et al. (2000)}

O modelo desenvolvido por Dershwitz et al. (2000) visou comparar os efeitos da morfina administrada por meio intravenosa com a inalada, sendo feitas análises farmacocinéticas e farmacodinâmicas simultaneamente. O modelo matemático utilizado para descrever o comportamento da injeção intravenosa consistiu em uma soma de três decaimentos exponenciais enquanto o modelo utilizado na inalação utilizou também três decaimentos exponenciais precedidos por duas exponenciais, referentes a absorção. Na administração por inalação foi obtida uma biodisponibilidade de $59 \%$, sendo que $43 \%$ foram absorvidos quase que instantaneamente e os restantes $57 \%$ foram absorvidos com uma meia vida de 
18 minutos. O aerossol utilizou dosagens de $45 \mu \mathrm{l}$ de uma solução de $50 \mathrm{mg} / \mathrm{ml}$ de sulfato de morfina.

A amostragem de sangue arterial foi feita a cada minuto durante a administração e $2,5,7,10,15,20,45,60,90,120,150,180$ e 240 minutos após a administração da droga. A análise da concentração de morfina foi feita por meio de cromatografia, uma técnica de separação de misturas, seguido de análise com espectrômetro de massa. Para análise farmacodinâmica, foi medido o diâmetro da pupila dos voluntários.

A Figura 6 mostra o modelo compartimental utilizado. O compartimento central 1 corresponde ao plasma, e os compartimentos periféricos 2 e 3 a tecidos e outros órgãos, dos quais não ocorreu uma especificação, visando apenas analisar a concentração do compartimento central. A Figura 7 mostra os dados obtidos juntamente com a curva calculada pelo modelo. A Figura 8 mostra a variação do diâmetro da pupila em função do tempo. A Equação 3.3 descreve a concentração da morfina no compartimento central a partir da administração intravenosa :

$$
C_{p}=\left(A e^{-a(t-\delta)}+B e^{-b(t-\delta)}+C e^{-c(t-\delta)}\right) U(t-\delta)
$$

sendo que as constantes $A, B, C, a, b, c$ e $\delta$ foram obtidas por meio de uma estimação a partir dos dados coletados e a função $U(t-\delta)$ representa a função degrau e $\delta$ seria um atraso, correspondente ao tempo levado entre a aplicação da injeção intravenosa e o aparecimento da droga no compartimento.

A Equação 3.4 que utiliza o modelo $E_{\text {max-sigmoidal }}$ (TASSO, 2008), é dada por:

$$
d i=d i_{0}\left(1-\chi_{\text {pupila }}\left(\frac{C^{\zeta}}{C^{\zeta}+E C_{50}^{C^{\zeta}}}\right)\right)
$$

sendo:

$d i=$ diâmetro da pulila $(\mathrm{mm})$;

$d i_{0}=$ diâmetro da pulila em repouso $(\mathrm{mm}) ;$

$\chi_{\text {pupila }}=$ fração máxima de diminuição do tamanho da pupila; 
$C=$ concentração que produz efeito no local de ação $(\mathrm{ng} / \mathrm{ml})$;

$E C_{50}=$ concentração que produz metade do efeito máximo $(\mathrm{ng} / \mathrm{ml})$;

$\zeta=$ assíntota tangente da relação sigmoidal;

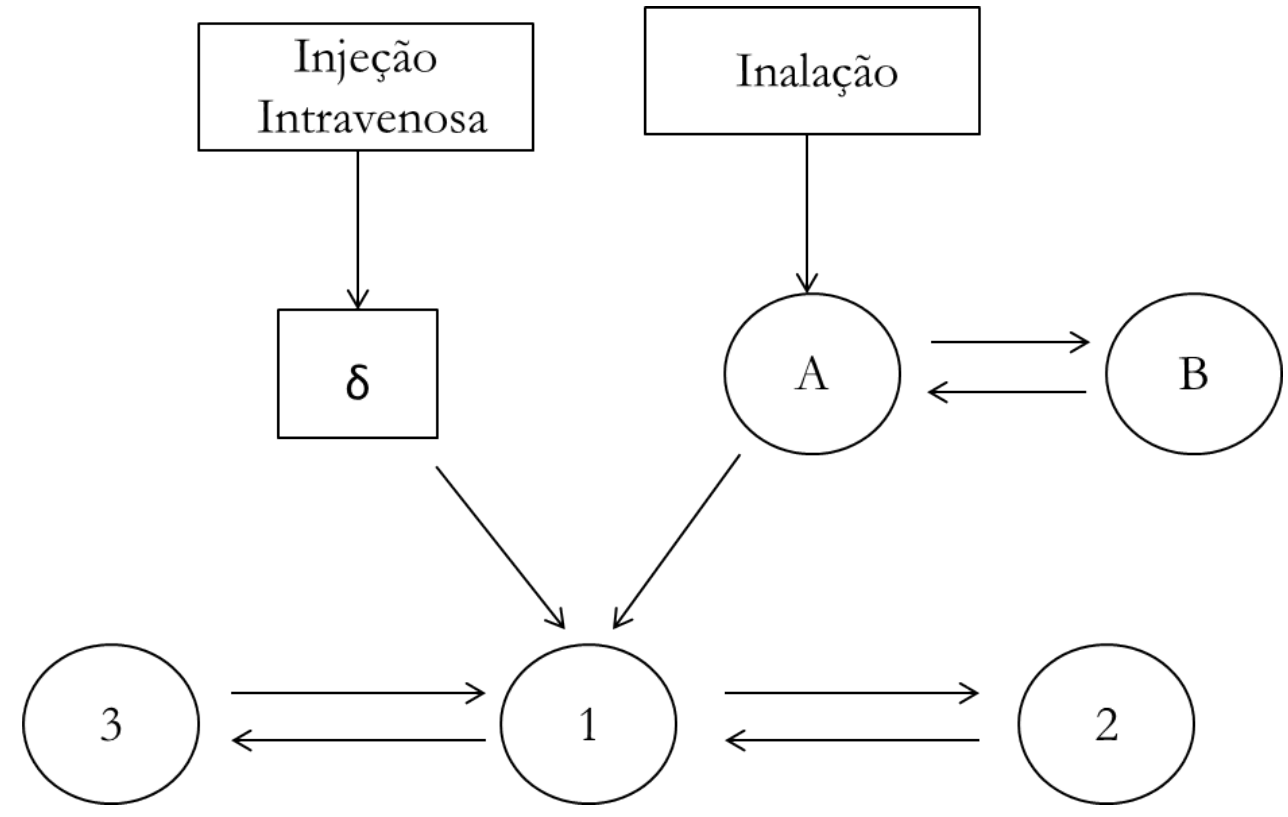

Figura 6: Modelo multicompartimental para injeção intravenosa inalação de morfina. Na injeção intravenosa o parâmetro $\delta$ representa o tempo de atraso entre a administração e a aparição da droga no sangue. Na inalação existem dois compartimentos referentes a absorção da droga via aerossol. Em ambas infusões, a droga passa a um compartimento central representado pelo número 1. Redesenhado de Dershwitz et al. (2000).


Figura 7: Concentrações plasmáticas da morfina intravenosa e inalada. As linhas representam os valores calculados pelo modelo e os pontos os medidos. O gráfico A apresenta uma descontinuidade entre 60 e 100 minutos e o gráfico B mostra o período inicial de tempo com maior detalhe. Adaptado de Dershwitz et al. (2000). 

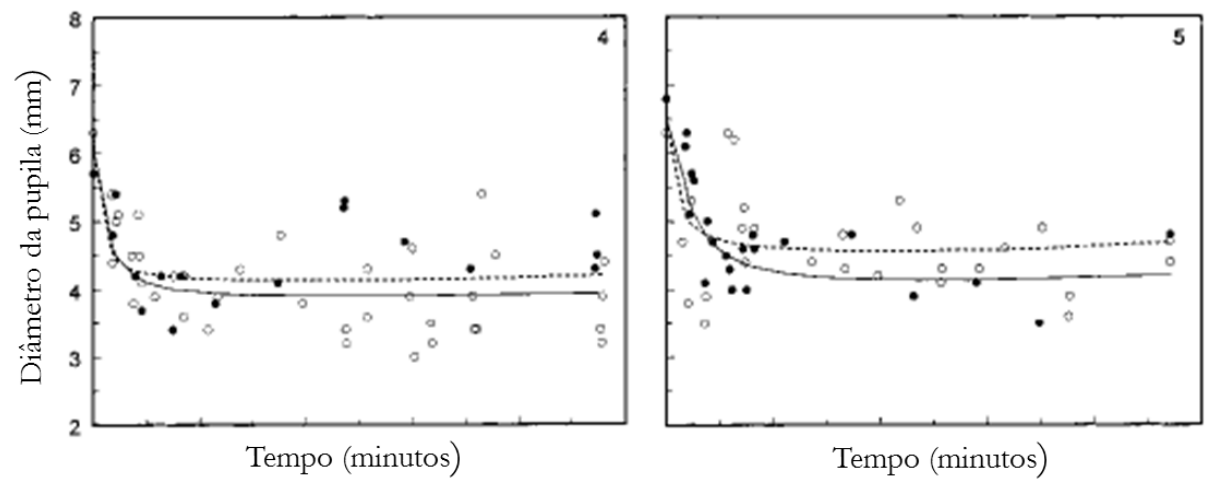

Figura 8: Variação do diâmetro da pupila em função do tempo em dois pacientes. Os círculos fechados e linhas sólidas se referem à inalação e os círculos abertos e linhas tracejadas a injeção intravenosa. As linhas representam os valores calculados pelo modelo sigmoidal, da Equação 3.4

\subsubsection{Modelo de Hunault et al. (2010)}

O modelo desenvolvido por Hunault et al. (2010) visou prever o comportamento farmacocinético e a disposição de $\Delta$-tetrahidrocanabinol (THC) no organismo após o fumo de Cannabis sativa em alta dose. A Cannabis sativa é uma droga ilícita consumida na forma de ervas ou de um sólido compacto chamado hashishe. A absorção do THC por inalação é muito rápida, com uma biodisponibilidade entre 18 e 50 \%. O THC rapidamente se distribui aos tecidos altamente vascularizados, incluindo o cérebro e devido a seus metabólitos serem lipofílicos, estes conseguem penetrar tecidos com menor perfusão sanguínea. Os cigarros comuns contém uma dose de aproximadamente 900 mg de cannabis contendo uma quantidade que varia entre 9 e $16 \mathrm{mg}$ de THC para doses baixas e acima de $34 \mathrm{mg}$ para doses elevadas (BARNETT et al., 1982; HUESTIS et al., 1992; LINDGREN et al., 1981; OHLSSON et al., 1982; PEREZ-REYES, 1982). Hunault et al. (2010) citam que existem modelos farmacocinéticos da cannabis em animais e em humanos após injeção intravenosa, administração oral ou inalação em doses pequenas, mas no modelo apresentado, são utilizados cigarros contendo cannabis com elevada concentração de THC (acima de 23 por cento), misturada com tabaco. A estrutura do modelo foi feita por meio de dois compartimentos, um referindo-se ao fígado e outros tecidos vascularizados nos quais a distribuição ocorre de maneira rápida e o outro aos tecidos nos quais ocorre uma absorção mais lenta, como por exemplo, o tecido adiposo. A fração de THC 
adentra ao compartimento dos tecidos vascularizados, com taxa de dosagem dependente do tempo, conforme mostra a Figura 9. As constantes $k_{12}$ e $k_{21}$ referem-se às trocas entre os compartimentos e a constante $k_{c l, 1}$ à eliminação, sendo que os valores destas foram obtidos por meio de ajuste de curva. Os cigarros fumados foram compostos de uma mistura de $300 \mathrm{mg}$ de cannabis e $700 \mathrm{mg}$ de tabaco. As amostras de sangue foram feitas 5, 10, 15, 20, 25, 30, 42 e 55 minutos e 8 horas após a inalação e as concentrações foram determinadas por extração da fase sólida e por cromatografia. A Figura 10 mostra os resultados obtidos com o modelo, onde se observa a rápida absorção seguida de uma fase de declínio acentuada.

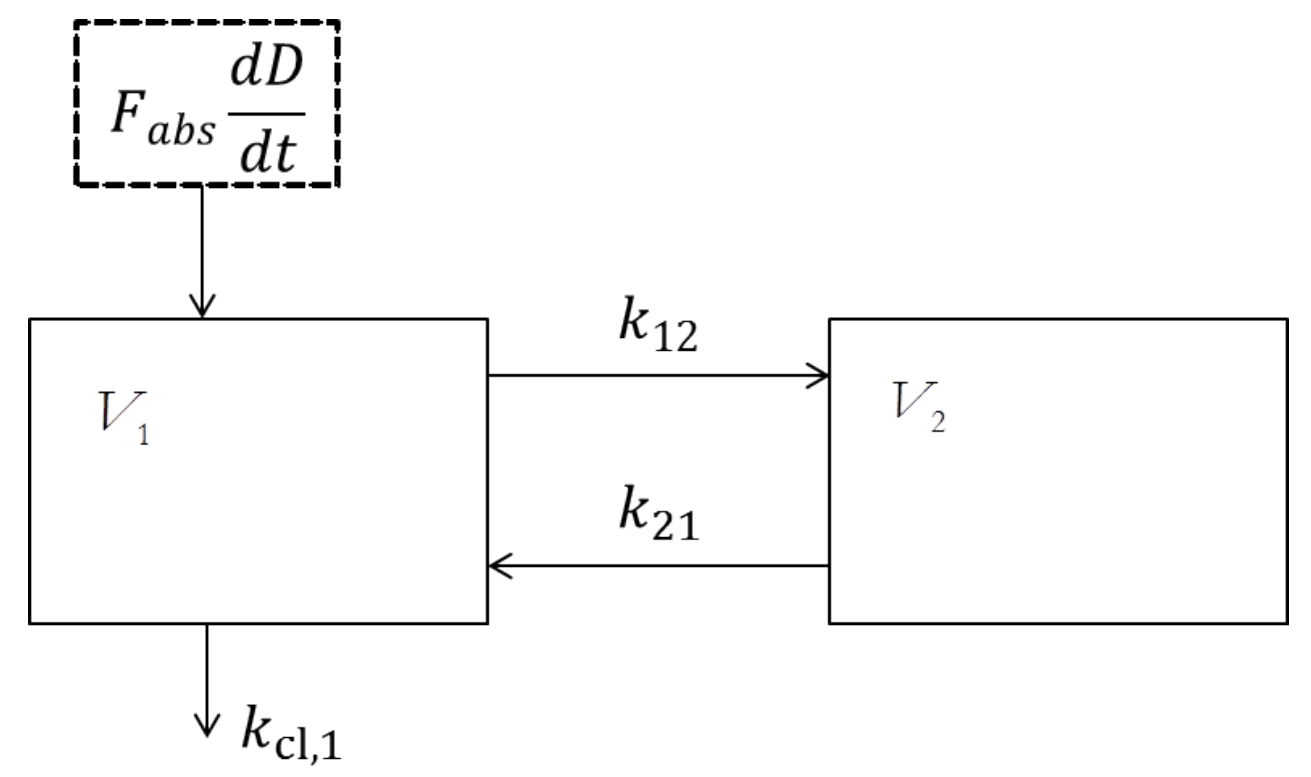

Figura 9: Modelo bicompartimental. O primeiro compartimento refere-se aos tecidos com alta perfusão e o segundo aos tecidos com menor vascularização. Redesenhado de Hunault et al. (2010)

\subsection{Modelos Farmacocinéticos Baseados em Fisiologia}

Nesta seção serão abordados modelos farmacocinéticos baseados em fisiologia. Estes modelos foram desenvolvidos a partir da divisão do organismo em compartimentos representativos dos órgãos e tecidos.

O objetivo deste tipo de abordagem é verificar não somente a concentração plasmática das drogas, mas também as concentrações atingidas em locais específicos. Isto possibilita a otimização do tratamento. 


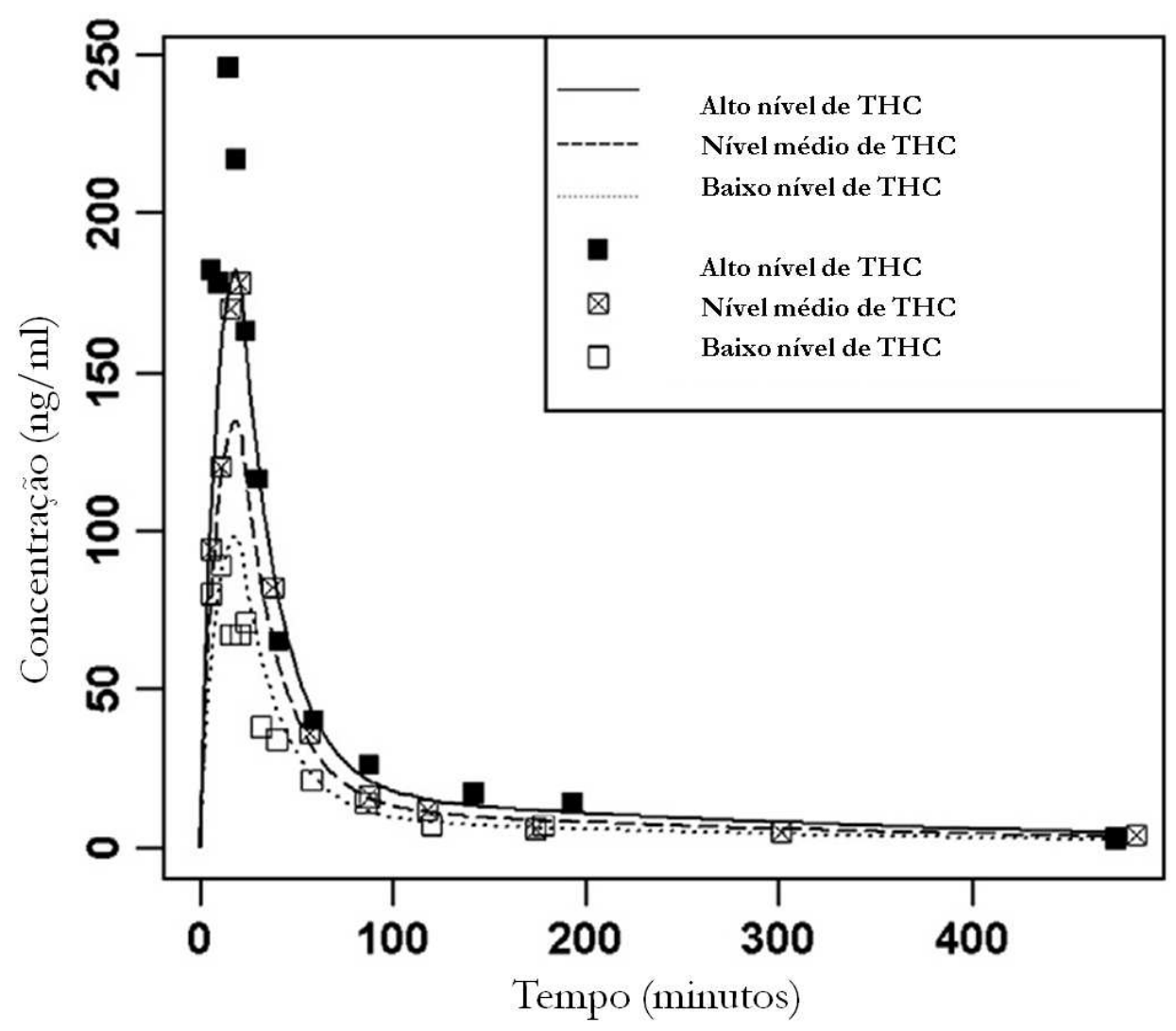

Figura 10: Níveis de THC no plasma calculados pelo modelo (linhas) e obtidos experimentalmente (quadrados). Adaptado de Hunault et al. (2010)

Em geral o desenvolvimento destes modelos é feito da seguinte forma: é desenvolvido um modelo matemático com balanços de massa em cada órgão ou tecido. Após isso são feitas infusões em cobaias. Destas cobaias são retirados órgãos para análise da concentração da droga em intervalos de tempo variados, que são utilizados para a validação do modelo matemático. Posteriormente, estes resultados são utilizados para que seja feito um aumento de escala possibilitando a previsão da concentração em seres humanos.

\subsubsection{Modelo de Granero et al. (1993)}

O modelo de Granero et al. (1993) consistiu na divisão do organismo em 10 compartimentos referentes aos órgãos e tecidos desenvolvido para avaliar a concentração do antibiótico ceftazidima após a infusão por meio de injeção intravenosa em ratos. Este modelo objetivou também que após a obtenção dos dados fosse feito um aumento de escala dos resultados obtidos nos ratos para prever o que ocorreria no organismo de seres humanos, segundo métodos propostos por Boxenbaum e D’Souza (1988). Tal aumento 
de escala é útil quando desejasse alterar os parâmetros farmacocinéticos, simulando uma situação de doença que influenciam estes parâmetros. A Tabela 2 mostra os parâmetros fisiológicos de ratos e a Tabela 3 mostra os parâmetros de seres humanos.

Tabela 2: Parâmetros fisiológicos de ratos (GRANERO et al., 1993).

\begin{tabular}{cccc}
\hline Tecido & Volume $(\mathrm{ml})$ & Vazão de plasma $(\mathrm{ml} / \mathrm{min})$ & Coeficiente de partição tecido plasma \\
\hline Gastrointestinal & $8.9 \pm 1.68$ & $8.22^{b}$ & $0.41 \pm 0.08$ \\
Coração & $1.02 \pm 0.14$ & $0.67^{b}$ & $0.22 \pm 0.08$ \\
Rins & $2.50 \pm 0.16$ & $5.89 \pm 1.73$ & $4.84 \pm 1.02$ \\
Fígado & $14.10 \pm 1.73$ & $9.99^{b}$ & $0.25 \pm 0.04$ \\
Pulmão & $1.74 \pm 0.53$ & $27.35^{c}$ & $0.44 \pm 0.09$ \\
Pele & $40.50 \pm 2.51$ & $3.10^{b}$ & $0.39 \pm 0.09$ \\
Gordura & $21.70^{b}$ & $3.05^{b}$ & $0.16 \pm 0.05$ \\
Músculos & $127.10^{b}$ & $4.65^{b}$ & $0.19 \pm 0.05$ \\
Plasma Arterial & $4.60^{e}$ & $27.35^{c}$ & \\
Plasma Venoso & $9.20^{e}$ & $27.35^{c}$ & \\
\hline
\end{tabular}

Tabela 3: Parâmetros fisiológicos de humanos (GRANERO et al., 1993).

\begin{tabular}{lcc}
\hline Tecido & Volume $(\mathrm{ml})$ & Vazão de plasma (ml/min) \\
\hline Gastrointestinal & $2400^{d}$ & $670^{d}$ \\
Coração & $300^{d}$ & $130^{d}$ \\
Rins & $300^{d}$ & $700^{d}$ \\
Fígado & $1500^{d}$ & $840^{d}$ \\
Pulmão & $600^{d}$ & $2670^{c}$ \\
Pele & $4000^{f}$ & $220^{g}$ \\
Gordura & $10000^{d}$ & $110^{d}$ \\
Músculos & $30000^{d}$ & $670^{d}$ \\
Plasma Arterial & $780^{d}$ & $2670^{c}$ \\
Plasma Venoso & $2200^{d}$ & $2670^{c}$ \\
\hline${ }^{a}$ Valores experimentais de Granero et al. (1993). \\
${ }^{b}$ Valores de Pierson et al. (1978) adaptados para um rato de 310 g. \\
${ }^{c}$ Vazão de plasma total. \\
${ }^{d}$ Dados de Gibaldi e Perrier (1982). \\
${ }^{e}$ Calculados com a Equação de Bischoff et al. (1971), sendo Var/Vve=0.5 (IGARI et al., 1982). \\
${ }^{f}$ Dados de Litter (1975). \\
$g$ De Guyton (1981) e assumindo um valor hematócrito de 0.44. \\
\hline
\end{tabular}

Segundo Richards e Brogden (1985), a ceftazidima é caracterizada por baixo metabolismo, baixo valor de associação protéica e excreção por meio da filtração glomerular, sendo que sua distribuição é limitada a fluidos extracelulares, como verificado por Schen$\operatorname{tag}(1989)$.

O procedimento experimental para avaliação das concentrações do antibiótico consistiu em utilizar a ceftazidima comercializada em ratos Wistar machos, submetidos a uma canulação na veia jugular. Além da canulação da jugular, alguns ratos foram submetidos 
também a canulação da artéria carótida e da bexiga urinária. Aplicou-se uma infusão constante de $15 \mathrm{mg} / \mathrm{h}$ (de uma solução de $15 \mathrm{mg} / \mathrm{ml}$ ) através da veia jugular. As taxas de remoção renal e total (clearance) foram obtidas a partir da relação entre a taxa de infusão e a concentração plasmática de estado estacionário. Foi feita uma amostragem adicional de sangue arterial após 90 minutos do início da infusão e o animal foi sacrificado com uma injeção de iodeto de potássio (70\%) através da cânula da veia jugular. Após isso, foram extraídas amostras do pulmão, do coração, dos músculos esqueléticos, do duodeno, do fígado, dos rins e do tecido adiposo. Assim, os coeficientes de partição tecido-plasma foram calculados para a amostragem de sangue retirada após 90 minutos. Foram feitas amostras também de urina.

Além da amostragem do plasma com o antibiótico em regime permanente, foram feitas amostras de sangue a partir da canulação da artéria carótida, nos períodos de 2, 5, 15, 30, 60, 90 e 120 minutos após a infusão de 5 mg e 2, 5, 15, 30, 75, 120 e 165 minutos após a dosagem.

O modelo matemático consistiu na divisão compartimental, mostrada na Figura 11, sendo que cada compartimento apresenta um balanço de massa baseado nas concentrações, nos fluxos de sangue, nos volumes de sangue venoso e arterial e nos coeficientes de partição tecido plasma. Considerou-se que a eliminação da droga ocorre completamente nos rins. Os volumes dos tecidos muscular e adiposo foram obtidos de Pierson et al. (1978), o volume total de plasma foi calculado de acordo com o proposto por Bischoff et al. (1971) e os volumes de plasma venoso e arterial foram estimados segundo a hipótese de que a razão entre o plasma arterial e venoso é 0.5 conforme verificado em Igari et al. (1982). Os fluxos sanguíneos para os tecidos foram retirados de Pierson et al. (1978), com exceção do renal que foi assumido como sendo equivalente a taxa de remoção do ácido p-aminohipúrico. O coeficiente de partição tecido plasma dos rins foi calculado segundo uma equação proposta por Lam, Chen e Chiou (1982). A solução dos balanços de massa de cada compartimento foi feita numericamente por meio do método de Runge-Kutta.

Uma vez validado com base em dados clínicos, foi feito o aumento de escala para seres humanos saudáveis e com insuficiência renal, com a hipótese de que os rins são os únicos 


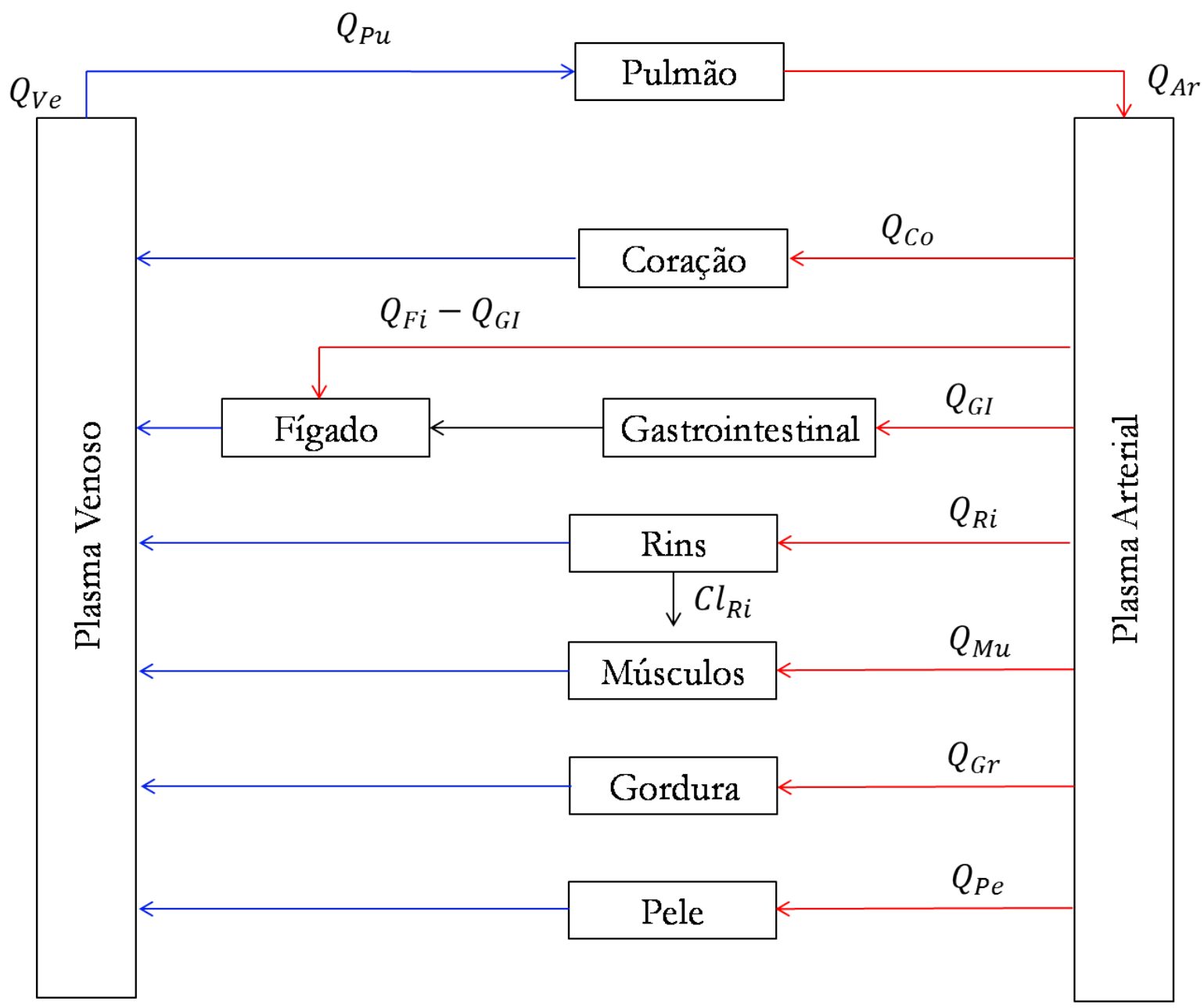

Figura 11: Divisão em compartimentos do modelo para infusão do antibiótico ceftazidima. Redesenhado de Granero et al. (1993)

órgãos responsáveis pela eliminação da droga. Assim, este modelo pode ser utilizado para prever as concentrações em seres humanos. Os resultados são mostrados nas Figuras 12 e 13.

\subsubsection{Modelo de Kwon e Bourne (1987)}

No modelo de Kwon e Bourne (1987), foi feito um levantamento experimental da concentração plasmática e da distribuição do fármaco tenoxicam em ratos. Cada tipo de tecido foi representado por um compartimento com rotas de eliminação que levam a substância para fora do organismo. Para a análise dos dados, foram retirados sangue e amostras dos tecidos em diferentes períodos de tempo. Este tipo de modelo é um modelo multi-compartimental, com o equacionamento matemático de cada compartimento, sendo feita uma comparação entre o previsto pelo modelo matemático e o medido experimental- 

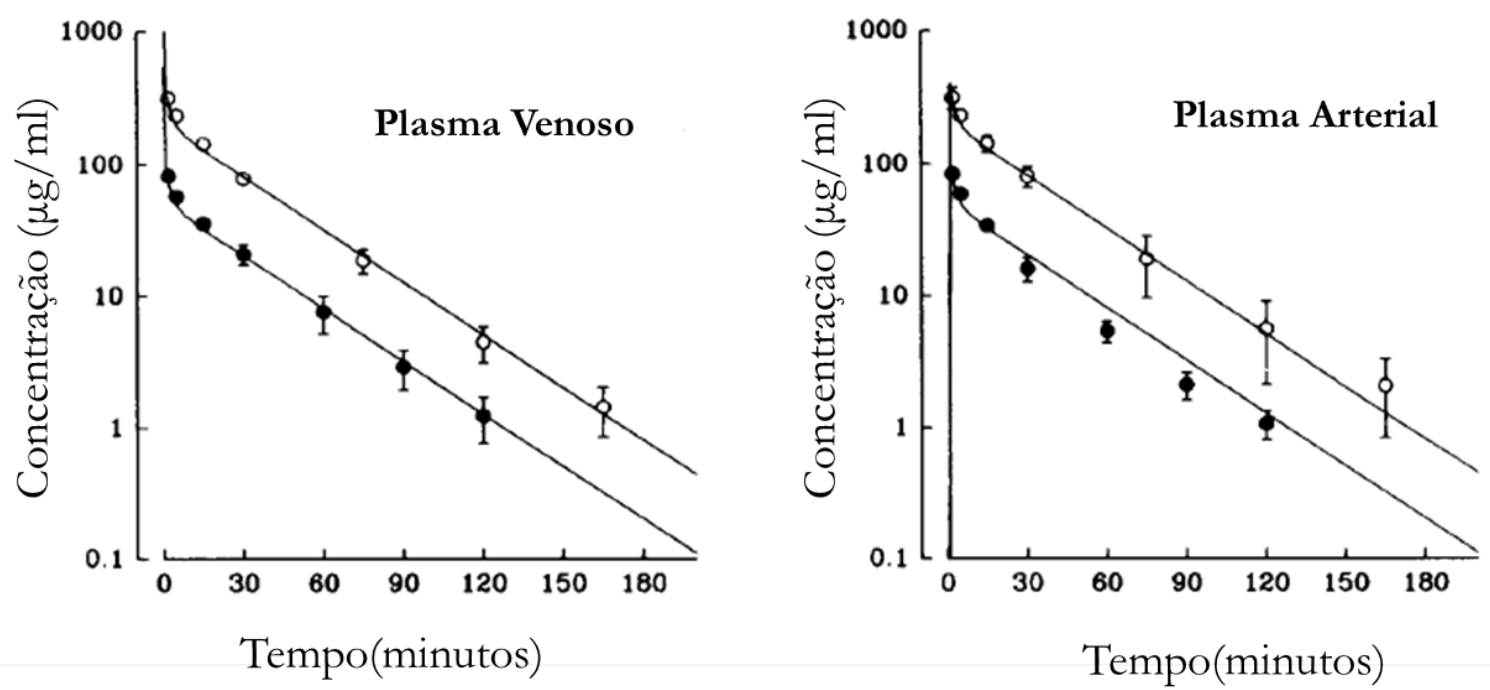

Figura 12: Valores calculados pelo modelo matemático (linhas) e medidos experimentalmente (pontos) após injeção intravenosa de $5 \mathrm{mg}$ e $20 \mathrm{mg}$. Adaptado de Granero et al. (1993).

mente. O tenoxicam é um medicamento não esteróide anti-inflamatório e analgésico que começava a ser utilizado na época em que o modelo foi desenvolvido, conforme verificado por Kirchheiner et al. (1982). Ele inibe a síntese da prostaglandina e possui meia vida de 50 horas (BIRD et al., 1983), possibilitando a aplicação de uma dosagem única ao dia.

Diferentemente de modelos baseados na concentração plasmática, como os modelos de Pickup e Lowe (1981), Dixon e Lowe (1984) e Joly (1984), o modelo de Kwon foi desenvolvido no intuito de possibilitar a verificação da concentração do tenoxicam em órgãos e tecidos, como feito por Fujio et al. (1983; 1984) e Farris et al. (1985).

A dose administrada foi de $4,5 \mathrm{mg} / \mathrm{kg}$ por meio de infusão intravenosa na veia caudal de ratos machos albinos do tipo Wistar. A amostra de sangue foi coletada do coração, com os animais anestesiados, e foi feita a extração do cérebro, do coração, do pulmão, do estômago, do baço, do pâncreas, das vísceras, do fígado, dos rins e dos testículos para a análise da concentração da droga em cada um destes órgãos. Também foi retirada a quantidade de $1 \mathrm{~g}$ de músculo, gordura, pele com pelos e osso com medula. Cinco ratos foram utilizados para cada período de amostragem, que foram os seguintes: 15 e 30 minutos e $1,1.5,3,6,12,18$ e 24 horas. De outro grupo de 5 ratos foram analisadas a urina e as fezes, coletadas nos períodos de 6, 24 e 48 horas para a urina e 48 horas para as fezes. A Figura 14 mostra o modelo multicompartimental. Para cada compartimento foi feito um 




Figura 13: Concentrações nos compartimentos do modelo após injeção intravenosa de 5 mg (•) e 20 mg (o). Adaptado Granero et al. (1993).

equacionamento, contendo as propriedades específicas de cada tecido ou órgão. As hipóteses feitas no equacionamento foram: a distribuição uniforme em cada compartimento; distribuição da droga limitada pela vazão sanguínea; as constantes de transferência entre o tecido e o plasma são independentes do tempo e da concentração plasmática; o compartimento carcaça inclui todos os órgãos não incorporados ao modelo; as taxas de remoção consideradas foram a metabólica, a renal, a biliar e a fecal e o fluxo de sangue ao fígado foi definido como a soma dos fluxos sanguíneos do estômago, do baço, do pâncreas, do intestino e o fluxo direto vindo da artéria hepática. As Equações 3.5, 3.6, 3.7, 3.8, 3.9, 3.10, 3.11, 3.12, 3.13 e 3.14 referem-se aos balanços de massa dos compartimentos.

\section{- Sangue Venoso:}

$$
\begin{aligned}
V_{v e} \frac{d C_{v e}}{d t}=Q_{c e} \frac{C_{c e}}{R_{c e}}+Q_{c o} & \frac{C_{c o}}{R_{c o}}+Q_{m u} \frac{C_{m u}}{R_{m u}}+Q_{f i} \frac{C_{f i}}{R_{f i}}+Q_{r i} \frac{C_{r i}}{R_{r i}}+Q_{g r} \frac{C_{g r}}{R_{g r}} \\
& +Q_{t e} \frac{C_{t e}}{R_{t e}}+Q_{p e} \frac{C_{p e}}{R_{p e}}+Q_{o s} \frac{C_{o s}}{R_{o s}}+Q_{c a} \frac{C_{c a}}{R_{c a}}-Q_{v e} C_{v e}
\end{aligned}
$$

- Sangue Arterial:

$$
V_{a r} \frac{d C_{a r}}{d t}=Q_{p u} \frac{C_{p u}}{R_{p u}}-Q_{a r} C_{a r}
$$




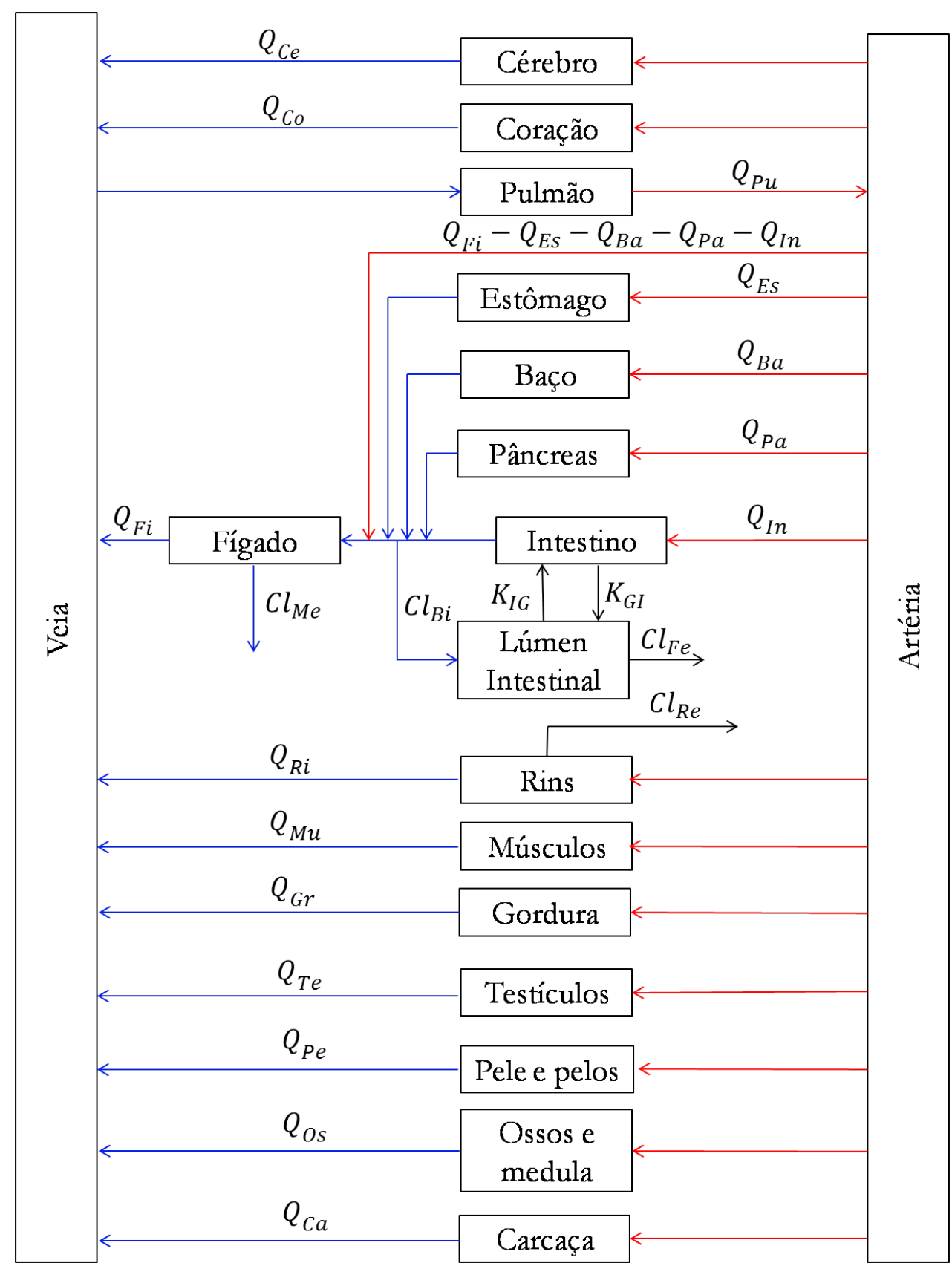

Figura 14: Modelo de Kwon e Bourne (1987).

- Testículos:

$$
V_{t e} \frac{d C_{t e}}{d t}=H_{t e}\left(C_{a r}-\frac{C_{t e}}{R_{t e}}\right)
$$

- Pulmão:

$$
V_{p u} \frac{d C_{p u}}{d t}=Q_{v e} C_{v e}-Q_{p u} \frac{C_{p u}}{R_{p u}}
$$


- Fígado:

$$
\begin{aligned}
V_{f i} \frac{d C_{f i}}{d t}=C_{a r}\left(Q_{f i}-\right. & \left.Q_{e s}-Q_{b a}-Q_{p u}-Q_{i n}\right)+Q_{e s} \frac{C_{e s}}{R_{e s}} \\
& +Q_{b a} \frac{C_{b a}}{R_{b a}}+Q_{p u} \frac{C_{p u}}{R_{p u}}+Q_{i n} \frac{C_{i n}}{R_{i n}}+Q_{f i} \frac{C_{f i}}{R_{f i}}-C l_{f i} C_{a r}
\end{aligned}
$$

- Rins:

$$
V_{r i} \frac{d C_{r i}}{d t}=Q_{r i}\left(C_{a r}-\frac{C_{r i}}{R_{r i}}\right)-C l_{r i} C_{a r}
$$

- Intestino:

$$
V_{i n} \frac{d C_{i n}}{d t}=Q_{i n}\left(C_{a r}-\frac{C_{i n}}{R_{i n}}\right)-K_{g i} V_{l i} C_{l i}-K_{i g} V_{i n} C_{i n}
$$

- Lúmen Intestinal:

$$
V_{l i} \frac{d C_{l i}}{d t}=C l_{b i} C_{a r}+K_{i g} V_{i n} C_{i n}-C l_{f e} C l i
$$

- Estômago, Baço, Pâncreas, Músculos, Gordura, Cérebro, Pele e pelos, Ossos e medula (órgãos sem eliminação):

$$
V_{i} \frac{d C_{i}}{d t}=Q_{i}\left(C_{a r}-\frac{C_{i}}{R_{i}}\right)
$$

- Urina:

$$
\frac{d C_{u}}{d t}=C l_{r i} C_{a r}
$$

em que:

$V_{i}=$ volume de tecido $(\mathrm{ml})$

$C_{i}=$ concentração plasmática da droga $(\mu \mathrm{g} / \mathrm{ml})$;

$Q_{i}=$ fluxo de plasma $(\mathrm{ml} / \mathrm{h})$;

$R_{i}=$ coeficiente de partição tecido plasma;

$C l_{i}=$ taxa de remoção da droga $(\mathrm{ml} / \mathrm{h}) ;$

$H_{i}=$ coeficiente de transferência de massa $(\mathrm{ml} / \mathrm{h})$;

$K_{g i}=$ constante de primeira ordem relativa à secreção do lúmen intestinal $\left(\mathrm{h}^{-1}\right)$; 
$K_{i g}=$ constante de primeira ordem relativa à absorção do lúmen intestinal $\left(\mathrm{h}^{-1}\right)$.

e o índice $i$ pode ser ve referindo-se ao compartimento venoso, ar ao arterial, ce ao cerebral, $c o$ ao do coração, $f i$ ao do fígado, $r i$ ao dos rins, $m u$ ao dos músculos, gr ao das gorduras, te ao dos testículos, pe ao da pele e pelos, os ao dos ossos e medula, ca ao da carcaça, $p u$ ao do pulmão, es ao do estômago, $p a$ ao do pâncreas, in ao do intestino, $l i$ ao do lúmen intestinal, $b i$ à bile, $f e$ às fezes, ur à urina e me metabolismo.

\subsubsection{Modelo de Chen e Andrade (1976)}

Chen e Andrade (1976) desenvolveram um modelo numérico e experimental para a obtenção dos níveis de concentração de drogas no sangue, nos órgãos e nos tecidos, para um cachorro de $15 \mathrm{~kg}$. Este modelo, segundo os autores, seria uma extensão do modelo de Bischoff et al. (1971) usado para prever as concentrações em função do tempo no sangue e em órgãos e tecidos de interesse.

Os modelos farmacocinéticos convencionais visam prever a concentração plasmática de determinada droga no organismo, como o desenvolvido por Rescigno e Segre (1966). Os modelos convencionais levam em consideração todos os fatores que alteram a concentração da droga, utilizando coeficientes que são obtidos experimentalmente. Na maioria dos casos, analisar a concentração plasmática é suficiente, já que a obtenção das concentrações em órgãos e tecidos é algo complexo de ser feito e resultados podem ser obtidos analisando-se apenas a concentração plasmática. No entanto, existem drogas como tiopental, utilizado no modelo, que necessitam da análise de concentração da distribuição da droga no sangue, nos órgãos e nos tecidos, para que ocorra a otimização do tratamento. O tiopental é um depressor do sistema nervoso central utilizado para anestesia e hipnose.

No modelo, foi feita a divisão do organismo nos seguintes compartimentos: cérebro, fígado, tecido magro, tecido adiposo e reservatório de sangue, correspondente ao sangue contido nos vasos sanguíneos. Foi feita a hipótese de que todo o metabolismo do tiopental ocorre no fígado. 
Os balanços de massa dos compartimentos seguem os mesmos princípios do modelo de Kwon e Bourne (1987). A Figura 15 mostra o modelo compartimental utilizado com dados fisiológicos de um cachorro de $15 \mathrm{~kg}$. Nos compartimentos divididos em dois, a parte superior é relativa ao volume de sangue do compartimento e a inferior ao volume de tecido. Cada compartimento possui uma vazão específica. O detalhadamento de cada compartimento é mostrado na Figura 16.

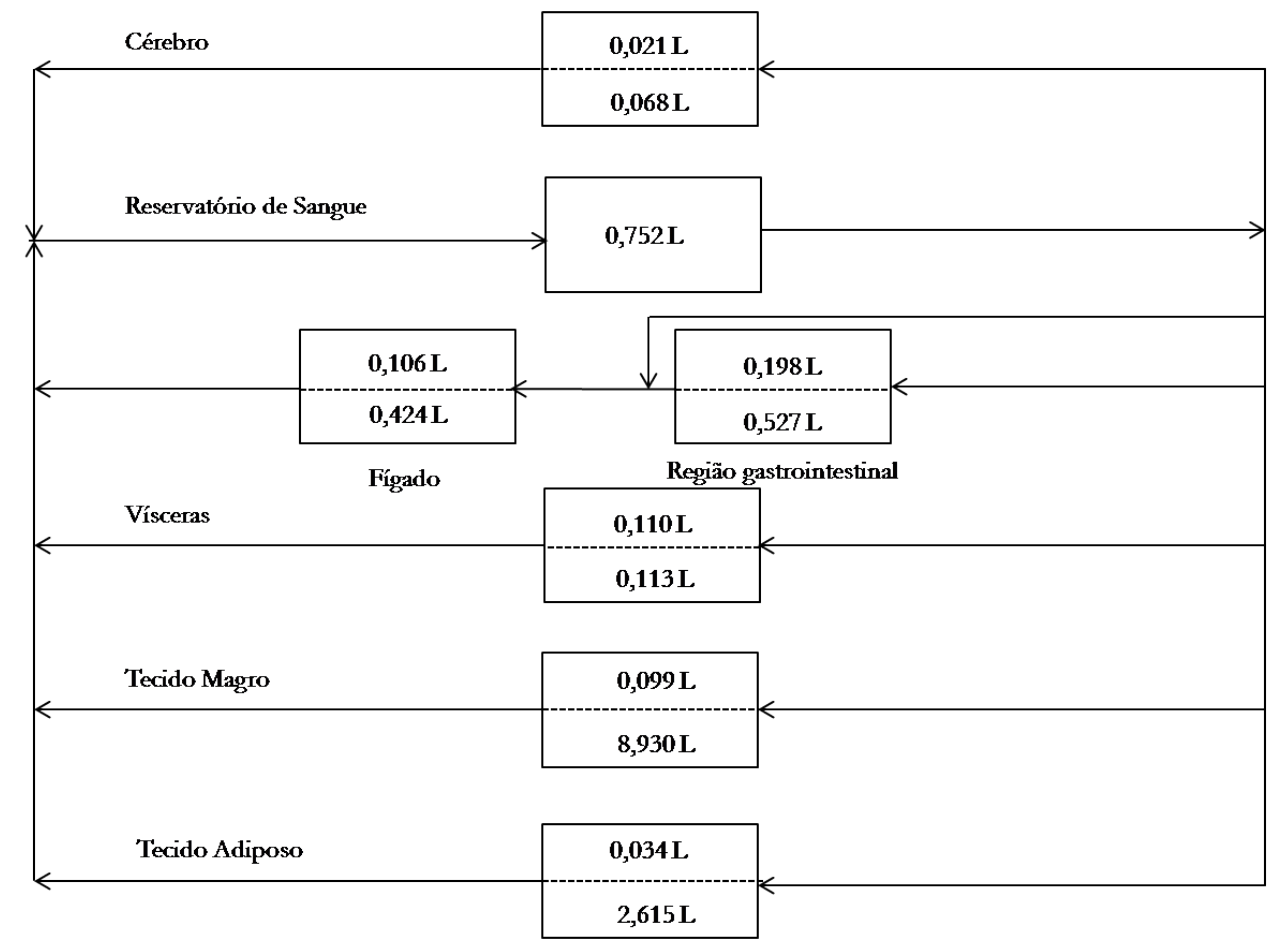

Figura 15: Divisão compartimental do modelo de Chen e Andrade (1976).

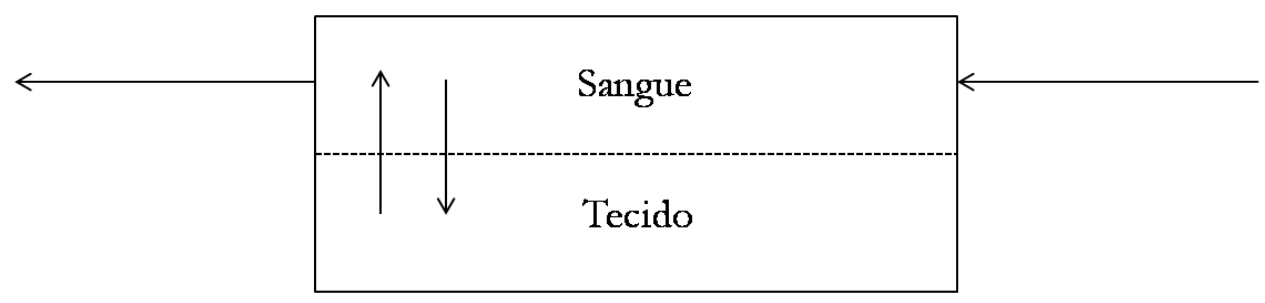

Figura 16: Detalhadamento de cada compartimento Y. Redesenhado de Chen e Andrade (1976).

Os autores sugerem que a partir deste modelo, desenvolvido com cães, seja possível prever as concentrações em seres humanos se alguns parâmetros farmacocinéticos e bioquímicos forem alterados. 


\subsubsection{Outros Modelos Farmacocinéticos Baseados em Fisiologia}

Além dos modelos citados e discutidos, existem na literatura outros tipos de aplicações para os modelos multi-compartimentais. Todos estes modelos levam em consideração os mesmos tipos de parâmetros. Considera-se a divisão do organismo em compartimentos representativos de órgãos e tecidos.

Em modelos mais simples, agrupam-se tecidos altamente vascularizados em um tipo de compartimento e os com menor perfusão em outro, ou seja, coloca-se mais de um órgão ou tecido no mesmo compartimento. Já nos modelos complexos, cada compartimento representa um tipo de órgão.

A utilização de um ou de outro depende do tipo de resultado que se deseja obter ou ainda do tipo de droga inserida no organismo. Visto que algumas drogas distribuem-se mais rapidamente para um tipo de órgão do que outro, a divisão em compartimentos é feita levando-se em conta quais órgãos ou tecidos que tem maior importância para a farmacocinética da droga.

Ainda considera-se o tipo de infusão. Em uma infusão por inalação, o pulmão é representado por um único compartimento, podendo existir a interação deste com outro compartimento onde ocorre a troca com o sangue. É o que nota-se no modelo de Ramsey e Andersen (1984) mostrado na Figura 17. Neste modelo existe a interação entre o compartimento alveolar e o representativo do sangue que é oxigenado no pulmão, recebendo conseqüentemente a droga, no caso o estireno, por inalação. Os compartimentos foram divididos em quatro tipos: com alta perfusão sanguínea, perfusão intermediária (músculos), baixa perfusão (gordura) e órgãos que metabolizam o estireno. Os dados experimentais foram obtidos a partir de ratos, submetidos a câmaras de exposição durante 24 horas, com extração de sangue para análise do estireno em estado estacionário. Foi feito também um aumento de escala para prever o comportamento em seres humanos.

O modelo de Harrison e Gibaldi (1977) foi desenvolvido para prever a disposição da digoxina em cães, com aumento de escala para prever a farmacocinética em seres humanos. 


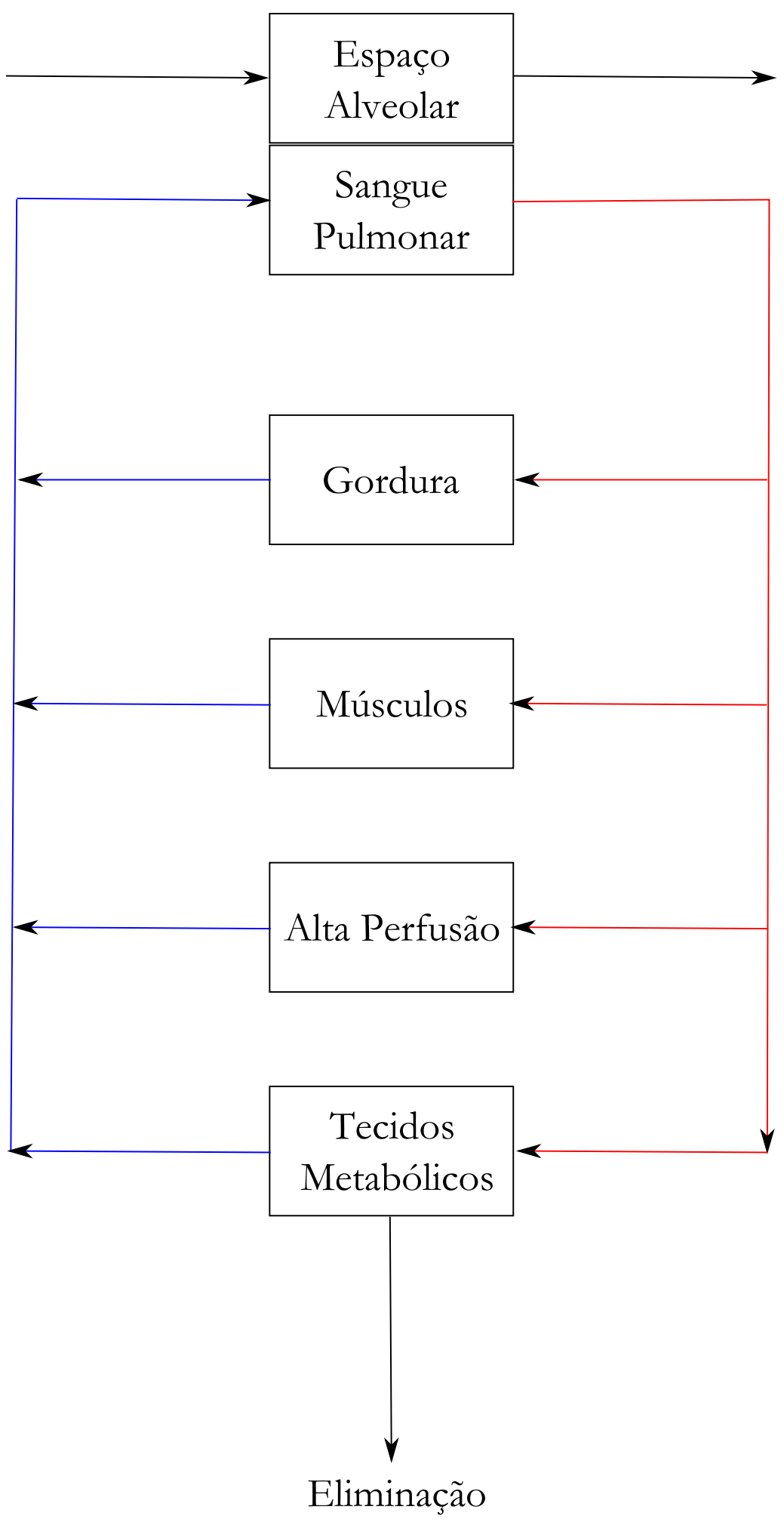

Figura 17: Divisão compartimental do modelo de Ramsey e Andersen (1984). Redesenhado de Ramsey e Andersen (1984).

Os compartimentos utilizados foram o sanguíneo, o coração, os músculos, a pele e o tecido adiposo, os rins, o fígado, a parede intestinal e o interior do intestino.

Farris, Dedrick e King (1988) desenvolveram um modelo farmacocinético para a cisplatina, considerando os compartimentos plasma (venoso e arterial), fígado, intestino, pele, 
músculo, carcaça(ossos, gordura e órgãos menores) e rins. O modelo foi utilizado para simulação da disposição da cisplatina e de seus metabólitos após injeção intravenosa em ratos, coelhos, cães e seres humanos, podendo ser utilizado em diversas outras espécies de mamíferos. Neste modelo não ocorreu a obtenção de constantes por meio de experimentos in vivo e sim por análise in vitro, devido ao fato dos metabólitos formados durante a incubação serem idênticos aos encontrados na administração in vivo, conforme verificado por Dalley, Gupta e Hung (1990). Um dos métodos citados para a análise in vitro é isolar o órgão a ser estudado em um sistema de recirculação entre este e um reservatório.

Chiu e Ginsberg (2011) objetivaram analisar a disposição do percloroetileno em ratos e humanos, substancia utilizada na limpeza de ambientes. Este modelo é chamado de tóxico cinético, uma vez que busca a obtenção da concentração de uma substância tóxica nos órgãos e tecidos.

Dalley, Gupta e Hung (1990) buscaram identificar a concentração do acido l-ascórbico em diversos tecidos durante um período de 120 horas após administração infra-venosa, com analise experimental in vivo utilizando ratos e divisão de compartimentos em plasma, fígado, ossos, rins, carcaça, pulmão e urina.

Fujio et al. (1984) estudaram a farmacocinética da pentazocina, um analgésico opioide em coelhos, por meio da infusão periódica durante 2 minutos através da veia femoral e extração de amostras de sangue pela artéria femoral. Os compartimentos utilizados no modelo matemático foram o cerebral, pulmonar, do coração, do lúmen intestinal, da parede do intestino, do fígado, dos rins, dos músculos, da pele e da gordura.

Plowchalk, Andersen e Debethizy (1992) investigaram a farmacocinética da disposição de nicotina em ratos por meio da infusão intra-arterial, com análise também dos metabólitos da nicotina.

Existe ainda o modelo toxicocinético desenvolvido por Lin et al. (2011) para verificar a farmacocinética do herbicida atrazina em ratos. Pesquisas indicam que a exposição a altos níveis deste herbicida são prejudiciais ao sistema reprodutor, imunológico e nervoso (HESSEL et al., 2004). No modelo matemático foi considerado além da atrazina, a farma- 
cocinética de seus principais metabólitos, separados em submodelos ligados entre si pela circulação sistêmica em um modelo integrado. Os parâmetros utilizados são os mesmos dos modelos citados anteriormente (como volume de compartimentos, vazão de sangue, coeficientes de partição tecido-plasma). No modelo experimental in vivo, o herbicida foi administrado oralmente, dissolvido em óleo de milho, em ratos adultos em doses únicas. Com a validação do modelo matemático por meio dos dados experimentais, foram feitas simulações para doses menores. 


\section{MODELAGEM MONOCOMPARTIMENTAL}

Neste capítulo será apresentado o desenvolvimento de um modelo farmacocinético monocompartimental utilizado para prever concentrações de susbtâncias no sangue. Este modelo é utilizado no caso de infusões intravasculares. A abordagem monocompartimental é utilizada quando a obtenção da concentração plasmática é suficiente para a análise farmacocinética. Os modelos experimentais, mostrados na seção 3.1 se utilizam desta hipótese, fazendo a análise apenas da concentração dos medicamentos no sangue.

\subsection{Balanço de massa do compartimento plasma}

A Equação 4.1 descreve o tipo de abordagem farmacocinética mais simples existente, em que existe uma concentração inicial no plasma e esta decai exponencialmente em função do tempo, com a hipótese de que a única rota de eliminação é via renal:

$$
V_{a p} \frac{d C_{p}}{d t}=-C l_{r e} C_{p}
$$

em que: $V_{a p}=$ volume aparente $(\mathrm{ml}) ; C l_{r e}=$ taxa de remoção renal $(\mathrm{ml} / \mathrm{h}) ; C_{p}=$ concentração plasmática $(\mathrm{mg} / \mathrm{ml}) ; t=$ tempo $(\mathrm{h})$.

A solução analítica da Equação 4.1 resulta na Equação 4.2:

$$
C_{p}(t)=C_{p 0} e^{\left(\frac{-C l_{r e}}{V_{p}}\right) t}
$$

O termo $C l_{r e}$ refere-se a soma de todas as rotas de eliminação do fármaco no organismo e o termo $C_{p 0}$ refere-se a quantidade de droga inicial presente no sangue. A limpeza do 
plasma é feita por diversos mecanismos, cada um com uma constante de eliminação, assim como a constante renal $k_{r e}$. Assim, a constante de eliminação total, $k_{e t}$ pode ser definida como a soma de todas as constantes de eliminação, por meio da Equação 4.3

$$
k_{e t}=\sum_{i} k_{i}=\frac{1}{V_{a p}} \sum_{i} C l_{i}=\frac{C l_{p}}{V_{a p}}
$$

sendo $i=$ renal, metabólico, respiratório e intestinal.

Assim, é obtida a Equação 4.4, análoga a Equação 4.2, considerando todas as rotas de eliminação e não somente a renal.

$$
C_{p}(t)=C_{p 0} e^{-k_{e t} t}
$$

Uma maneira de se obter a constante de eliminação total $k_{e t}$ é por meio do tempo de meia vida biológico, definido como tempo em que a concentração do fármaco cai à metade do seu valor inicial. Assim, a partir da Equação 4.4, fazendo $C_{p}(t)=0.5 C_{p 0}$, obtém-se o tempo de meia vida dado pela Equação 4.5:

$$
t_{1 / 2}=\frac{0,693}{k_{e t}}
$$

As Equações 4.1, 4.2, 4.3 e 4.4 referem-se a condições em que já existe uma quantidade inicial de droga no sangue, tida como concentração inicial $C_{p 0}$. A hipótese adotada é que esta concentração inicial é resultado da infusão. O modelo proposto neste trabalho possibilitará que a infusão de medicamento seja uma dose em função do tempo $D(t)$. Sendo assim, tem-se a Equação 4.6:

$$
V_{a p} \frac{d C_{p}}{d t}=D(t)-C l_{r e} C_{p}
$$


Sendo que $k_{e t}=\frac{C l_{r e}}{V_{a p}}$, tem-se a equação monocompartimental geral (Equação 4.7) em termos da concentração $C_{p}$ e da eliminação total $k_{e t}$.

$$
\frac{d C_{p}}{d t}=\frac{D(t)}{V_{a p}}-k_{e t} C_{p}
$$

\subsection{Parâmetros farmacocinéticos utilizados}

Nesta seção será discutida a maneira de obtenção dos parâmetros farmacocinéticos utilizados na modelagem monocompartimental.

\subsubsection{Volume aparente}

O valor do volume aparente $V_{a p}$ pode ser obtido nas bulas dos medicamentos. Se trata de um valor médio obtido a partir da análise clínica em pacientes. No modelo serão utilizados valores encontrados na literatura para cada tipo de droga em questão.

\subsubsection{Constante de eliminação total}

A constante de eliminação total $k_{e t}$ será calculada a partir da Equação 4.5, uma vez que o tempo de meia vida plasmático pode ser obtido a partir da bula do medicamento em questão. Assim, tem-se a Equação 4.8:

$$
k_{e t}=\frac{0,693}{t_{1 / 2}}
$$

\subsubsection{Dosagem em função do tempo}

O parâmetro $D(t)$ representa a infusão de medicamento em função do tempo. Os modelos discutidos no Capítulo 3 apresentam soluções para infusão constante ou a partir de uma quantidade inicial de droga no sangue. A utilização da dosagem em função do tempo permitirá infusões a cada período de tempo, como por exemplo uma infusão intravenosa a cada 8 horas. 


\section{MODELAGEM BICOMPARTIMENTAL}

A modelagem bicompartimental é utilizada quando o medicamento adentra ao organismo por outra via que não seja a intravenosa. Esta abordagem permite que se obtenha concentrações plasmáticas a partir da infusão de medicamentos por via oral, por inalação, transdermal, retal, entre outras apresentadas no Capítulo 2. Uma vez adentrando no sangue, a droga é distribuída para todo o organismo, sendo metabolizada em alguns órgãos como o fígado e eliminada pelos rins. O esquema desta abordagem é mostrado na Figura 18. A vantagem da infusão extra vascular é sua administração não invasiva e conveniente, sendo a uma das formas de administração mais utilizadas (ROSENBAUM, 2011).

Existe a dependência de dois fatores, a biodisponibilidade $\beta$ e a constante de absorção de primeira ordem $k_{a}$, que variam conforme o tipo de dosagem da droga, variando muito de uma substância para outra.

No modelo desenvolvido serão feitas simulações para infusão oral e inalação apenas. Assim o compartimento central poderá ser gastrointestinal ( $g i)$, pulmão $(p u)$ ou pele $(p e)$.

\subsection{Balanço de massa nos compartimentos}

Nesta modelagem considera-se dois compartimentos:

- Compartimento central: Trata-se do local onde a droga será administrada. Este compartimento realizará trocas com o compartimento sanguíneo.

- Compartimento plasmático: Refere-se ao compartimento relacionado ao sangue. Após ser administrado no compartimento central, a droga passa para o compartimento plasmático onde é distribuida e eliminada. 


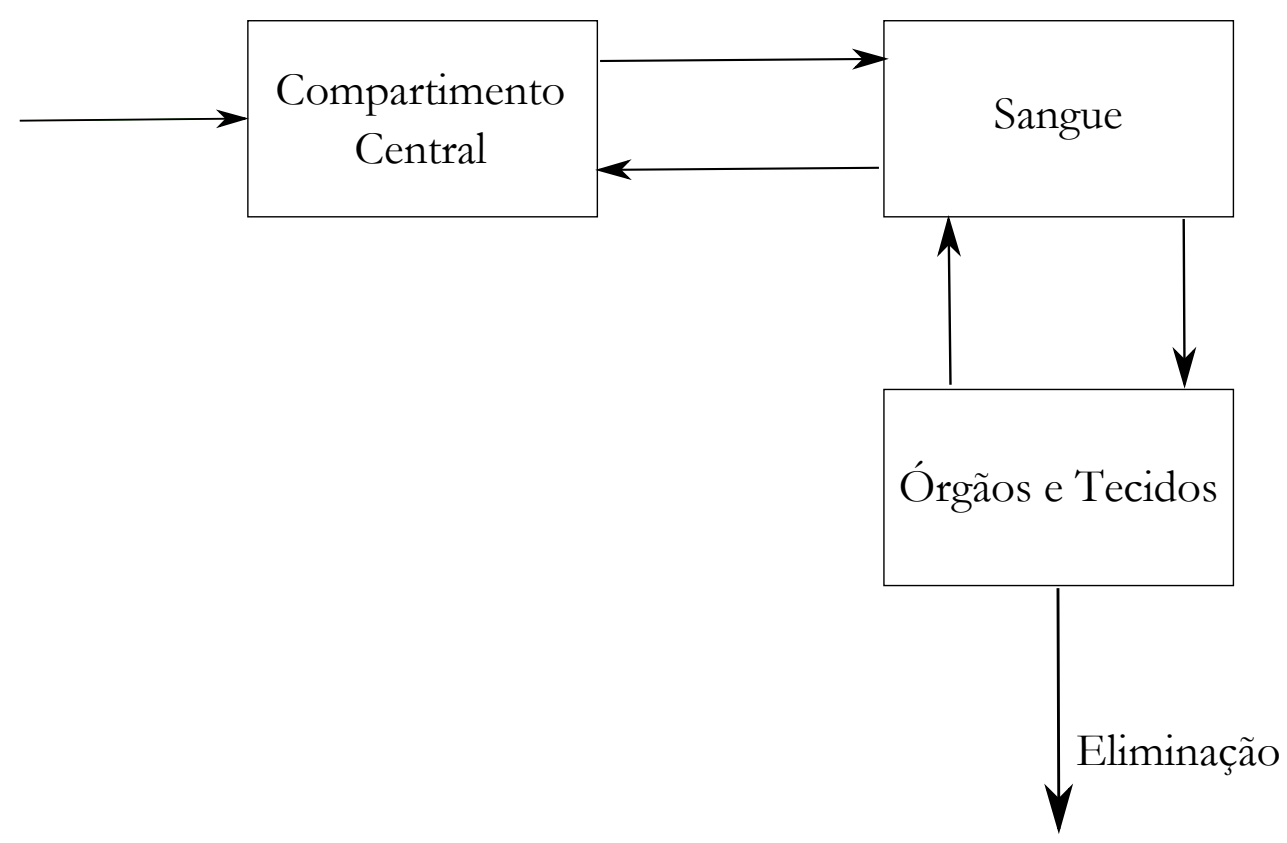

Figura 18: Esquema da distribuição das substâncias pelo sangue.

Neste modelo bicompartimental, analogamente ao que ocorre no modelo monocompartimental, considera-se que a droga é removida no compartimento plasmático. Fica implícito portanto, o fato de que a droga é filtrada nos rins quando utiliza-se a variável $k_{e t}$. O modelo simplificado é mostrado na Figura 19. É feita a hipótese de que a o maior fluxo de droga ocorre do compartimento central para o sangue. Assim, o retorno da droga pelo compartimento pode ser desprezado, conforme mostrado na Equação 2.2.

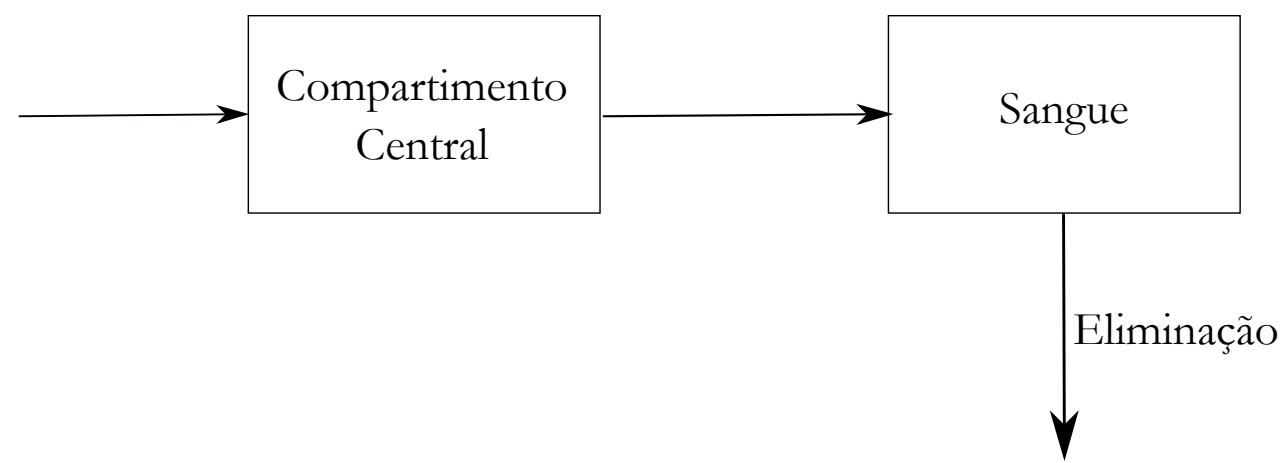

Figura 19: Modelo bicompartimental.

Diferentemente dos modelos apresentados no Capítulo 4 , neste modelo é proposto um equacionamento em termos de massa e não de volume. A concentração pode ser obtida 
dividindo-se a massa pelo volume do compartimento em questão. Os balanços de massa no compartimento central e plasmático são mostrados nas Equações 5.1 e 5.2:

$$
\begin{gathered}
\frac{d m_{i}}{d t}=D(t)-k_{a} m_{i} \\
\frac{d m_{p}}{d t}=k_{a} m_{i}-k_{e t} m_{p}
\end{gathered}
$$

sendo que o subscrito $i$ pode ser gi referindo-se ao compartimento gastro-intestinal, $p u$ referindo-se ao pulmonar ou pe referindo-se a pele, e $k_{a}$ e $k_{e t}$ referem-se às constantes de absorção e eliminação respectivamente, $m_{i}(\mathrm{mg})$ é a massa presente no compartimento central e $m_{p}(\mathrm{mg})$ é a massa no compartimento plasmático.

A Figura 20 mostra os compartimentos com suas respectivas entradas e saídas.

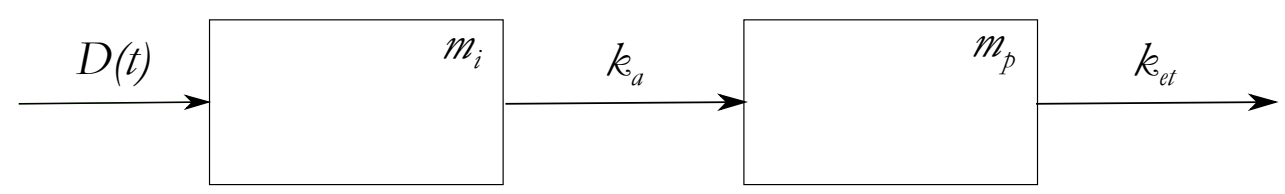

Figura 20: Diagrama de blocos do modelo bicompartimental.

\subsection{Parâmetros utilizados}

Nesta seção serão discutidos os parâmetros necessários para solucionar o modelo bicompartimental.

\subsubsection{Massa no compartimento central}

Com a hipótese de que a dose de medicamento $D(t)$ seja única (um único comprimido , inalação ou adesivo transdermal), existirá uma quantidade inicial de massa no compartimento $m_{i 0}(\mathrm{mg})$. A solução analítica do balanço de massa para o compartimento central (Equação 5.1) é mostrado na Equação 5.3 e a solução analítica para o compar- 
timento plasmático (Equação 5.2) é mostrado na Equação 5.4, para a condições iniciais $m_{i}(0)=m_{i 0}$ e $m_{p}(0)=0 \mathrm{mg}$ :

$$
\begin{gathered}
m_{i}(t)=m_{i 0} e^{-k_{a} t} \\
m_{p}(t)=m_{i 0}\left(\frac{k_{a}}{k_{a}-k_{e t}}\right)\left(e^{-k_{e t} t}-e^{-k_{a} t}\right)
\end{gathered}
$$

\subsubsection{Constante de absorção de primeira ordem}

A constante de absorção de primeira ordem $k_{a}$ refere-se a transferência de massa do compartimento central para o plasmático. Ela pode ser obtida a partir de do tempo em que a concentração plasmática é máxima, presente nas bulas dos medicamentos. A obtenção deste parâmetro será discutida no Capítulo 6. 


\section{SOLUÇÃO DO MODELO}

Os balanços de massa propostos no capítulo anterior são equações diferenciais ordinárias (EDO). Neste capítulo será explanada a solução destas equações, utilizando o método da transformada de Laplace.

\subsection{Modelagem Farmacocinética Utilizando a Transfor- mada de Laplace}

O comportamento do organismo sujeito a uma infusão de droga pode ser representado como um sistema, sendo que este está caracterizado por produzir uma saída para determinados estímulos na entrada (NISE, 2010).

Segundo Haykin e Venn (1999), um sistema pode ser definido como um agente que transforma um ou mais sinais, em outros tipos de sinais. Sendo assim, no sistema farmacocinético, a entrada seria considerada um tipo de sinal, sendo que este é definido como uma função que carrega informação de uma determinada grandeza. Neste caso específico a entrada seria o sinal da concentração em função do tempo na dosagem e a saída seria o sinal da concentração plasmática ou compartimental em função do tempo. Esta relação é mostrada na Figura 21.

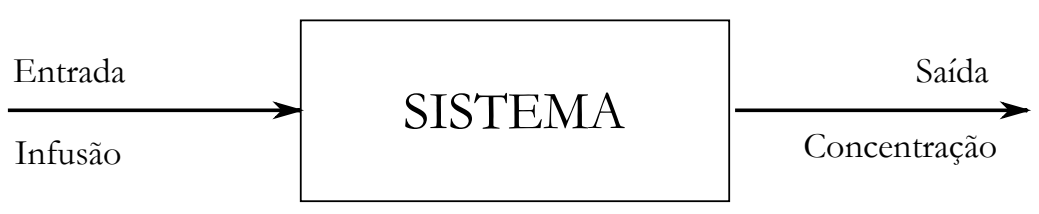

Figura 21: Representação de um modelo farmacocinético como sistema.

Ainda tem-se que o sistema em questão trata-se de um sistema linear invariante no tempo (LTI - linear time invariant). 
Define-se um sistema como sendo linear se ao multiplicar-se a entrada por uma constante $a_{1}$, tendo-se na entrada $a_{1} x(t)$, será obtida uma saída $a_{1} y(t)$. Ainda neste tipo de sistema, para a entrada $a_{1} x_{1}(t)+a_{2} x_{2}(t)$ a saída será $a_{1} y_{1}(t)+a_{2} y_{2}(t)$, conforme mostrado na Figura 22.

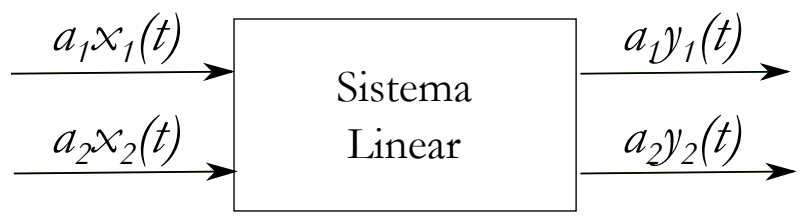

Figura 22: Sistema Linear.

No sistema invariante no tempo, uma entrada com atraso $x(t+\delta)$ produzirá a saída com atraso $y(t+\delta)$, devido ao sistema não mudar de comportamento no decorrer do tempo, conforme mostrado na Figura 23.

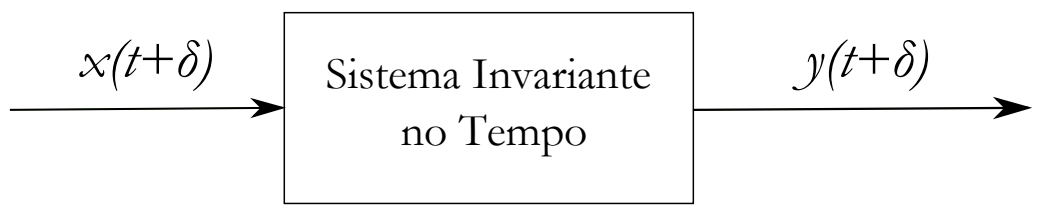

Figura 23: Sistema Invariante no Tempo.

Assim o sistema linear invariante no tempo combina as características de linearidade e invariância no tempo, podendo ser representado com funções de transferência (HAYKIN e VAN VEEN, 1999; PROAKIS e MANOLAKIS, 2007).

A utilização da transformada de Laplace em um sistema de equações diferenciais faz com que estas se tornem equações algébricas, facilitando a solução do modelo. O uso da transformada consiste em mudar o domínio do problema em questão. A mudança é feita do domínio do tempo $t$ para o domínio da frequência $s$. Posteriormente, volta-se para o domínio do tempo que é o foco da modelagem. A transformada de Laplace de uma função no domínio do tempo é definida pela Equação 6.1

$$
F(s)=\mathcal{L}\{f(t)\}(s)=\int_{0-}^{+\infty} e^{-s t} f(t) \mathrm{d} t
$$

A notação do limite inferior significa que mesmo ocorrendo descontinuidade em $t=0 s$, pode ser feita a integração normalmente, desde que a integral convirja. A obtenção da 
transformada inversa de Laplace, que traz novamente ao domínio do tempo é dada pela Equação 6.2.

$$
\mathcal{L}^{-1}\{F(s)\}=\frac{1}{2 \pi j} \int_{\sigma-j \infty}^{\sigma+j \infty} F(s) e^{s t} \mathrm{~d} s=f(t) u(t)
$$

sendo que $u(t)$ que representa a função degrau:

$$
u(t)= \begin{cases}1 & , \text { se } t>0 \\ 0 & , \text { se } t<0\end{cases}
$$

\subsubsection{Utilização da Transformada de Laplace na Solução de Sis- temas regidos Equações Diferenciais Ordinárias}

De uma maneira geral, uma equação diferencial simples na forma (Equação 6.3):

$$
\frac{\mathrm{d} y}{\mathrm{~d} t}=x
$$

cuja solução analítica pode ser obtida por integração, como mostrado na Equação 6.4:

$$
y(t)=\int_{0}^{t} x(t) \mathrm{d} t
$$

pode ser representado por um sistema onde a saída $y=y(t)$ dependa de uma entrada $x=x(t)$. Assim, em termos de sistema, tem-se a Figura 24:

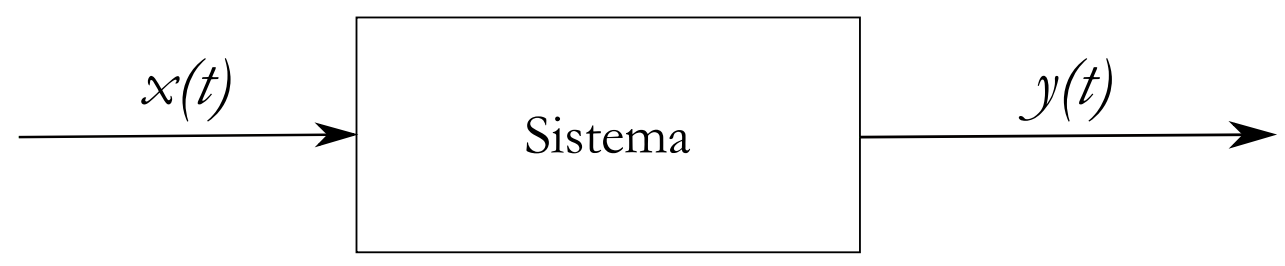

Figura 24: Representação do sistema referente a Equação 6.3. 
Utilizando as propriedades discutidas anteriormente, pode-se transformar a Equação 6.3 em uma equação algébrica, dada pela Equação 6.5:

$$
s Y(s)=X(s)
$$

Assim, pode-se obter a função de transferência que relaciona a entrada com a saída (Equação 6.6):

$$
G(s)=\frac{Y(s)}{X(s)}=\frac{1}{s}
$$

A partir da Equação 6.6, chega-se ao sistema em termos de variáveis no domínio $s$, mostrado na Figura 25:

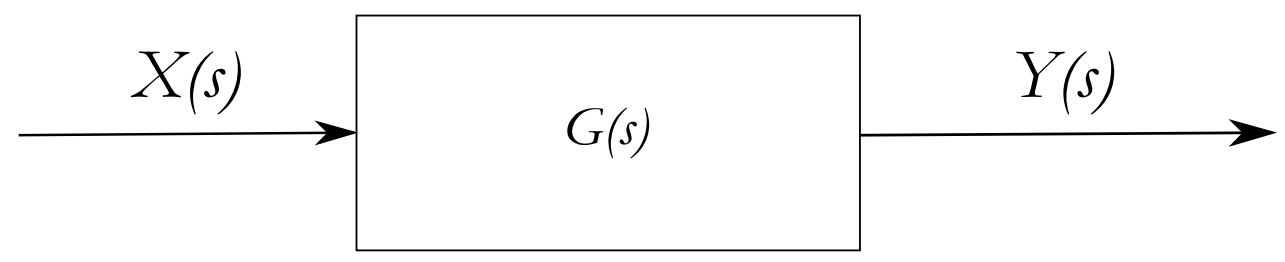

Figura 25: Representação de um sistema no domínio $s$.

A vantagem deste tipo de abordagem é verificada quando a entrada $x(t)$ é uma função com maior grau de complexidade. Além disso, podem-se inserir diversos tipos de entradas sem que a integração tenha que ser feita cada vez que se deseje obter a resposta $y(t)$. Por exemplo, se a entrada $x(t)$ for uma soma de exponenciais, quando esta entrada for levada ao domínio $s$, esta passará a ser uma soma de frações algébricas.

\subsubsection{Obtenção das Funções de Transferência no Modelo Farma- cocinético Monocompartimetal}

É possível ainda a obtenção de uma função de transferência no domínio s do modelo farmacocinético, relacionando a entrada infusão com a saída concentração, ambos no domínio da transformada. A equação básica que rege a farmacocinética da distribuição de anestésicos e outros fármacos no organismo é dada pela Equação 4.1, que descreve a eliminação do fármaco dada uma concentração inicial. A utilização da função de trans- 
ferência é útil no caso de uma dosagem que varie no tempo, como mostrado na Equação 4.6, fazendo com se possa calcular genericamente a resposta da concentração em função do tempo. Aplicando-se a Transformada de Laplace na Equação 4.7, que considera a eliminação total do organismo $\left(k_{e t}\right)$, tem-se que as variáveis em função de $t$, se tornam função de $s$, conforme a Equação 6.7:

$$
s C_{p}(s)+k_{e t} C_{p}(s)=\frac{D(s)}{V_{a p}}
$$

A partir da Equação 6.7 , pode-se obter a função de transferência (Equação 6.8) e a partir desta obter o comportamento do sistema para diferentes tipos de entrada. A saída do sistema $C(s)$ pode ser obtida a partir da função de transferência (Equação 6.9). O diagrama de blocos da Equação 6.8 é mostrado na Figura 26:

$$
\begin{gathered}
G(s)=\frac{C_{p}(s)}{D(s)}=\left(\frac{1}{V_{a p}}\right)\left(\frac{1}{s+k_{e t}}\right) \\
C_{p}(s)=D(s)\left(\frac{1}{V_{a p}}\right)\left(\frac{1}{s+k_{e t}}\right)
\end{gathered}
$$

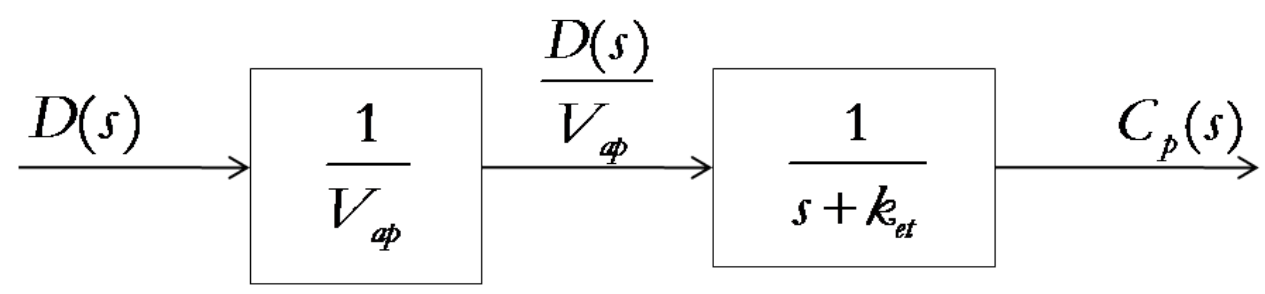

Figura 26: Diagrama de blocos da função de transferência. $D(s)$ corresponde a entrada dose e $C_{p}(s)$ a concentração no compartimento plasma.

\subsubsection{Obtenção das Funções de Transferência no Modelo Farma- cocinético Bicompartimental}

O modelo bicompartimental desenvolvido levará em consideração as massas que adentram nos compartimentos ao invés da concentração. A obtenção da concentração será feita 
posteriormente. Utilizando-se a Transformada de Laplace nas Equações 5.1 e 5.2 tem-se as Equações 6.10 e 6.11:

$$
\begin{gathered}
s M_{i}(s)=D(s)-k_{a} M_{i}(s) \\
s M_{p}=k_{a} M_{i}(s)-k_{e t} M_{p}(s)
\end{gathered}
$$

A partir destas Equações, podem-se obter as funções de transferência para os compartimentos central e plasmático (Equações 6.12 e 6.13):

$$
\begin{gathered}
G_{i}(s)=\frac{M_{i}(s)}{D(s)}=\frac{1}{s+k_{a}} \\
G_{p}(s)=\frac{M_{p}(s)}{k_{a} M_{i}(s)}=\frac{1}{s+k_{e t}}
\end{gathered}
$$

Com utilização das funções de transferência, podem ser obtidas as massas no compartimento central e plasmático em função de $s$ (Equações 6.14 e 6.15):

$$
\begin{gathered}
M_{i}(s)=D(s) \frac{1}{s+k_{a}} \\
M_{p}(s)=k_{a} M_{i}(s) \frac{1}{s+k_{e t}}
\end{gathered}
$$

A Figura 27 mostra o diagrama de blocos do modelo bicompartimental:

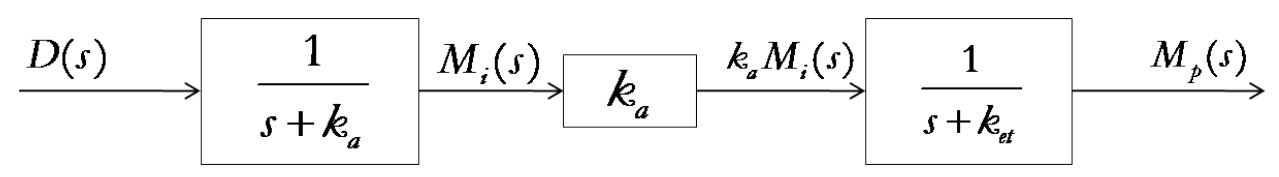

Figura 27: Diagrama de blocos das funções de transferência. $D(s)$ corresponde a entrada dose, $M_{i}(s)$ a massa no compartimento central e $M_{p}(s)$ a massa no compartimento plasmático. 


\subsubsection{Tipos de Infusões Utilizadas}

Com a obtenção das funções de transferência é possível que sejam utilizadas entradas diferentes no sistema, possibilitando diferentes infusões cujas soluções analíticas apresentam certo grau de complexidade. Nesta abordagem a função impulso $i(t)$ representa uma infusão intravenosa e a função degrau $u(t)$ representa uma infusão constante.

Sendo que a função $u(t)$ com atraso seja representada por $u(t-\delta)$ e sua Transformada de Laplace seja a Equação 6.16:

$$
\mathcal{L}\{(u(t-\delta))\}=\frac{1}{s}\left(e^{-\delta s}\right)
$$

sendo que $\delta(\min )^{-1}$ se refere a um atraso na entrada do sistema.

A obtenção de um pulso $p(t)$ pode ser feita com um degrau atrasado subtraído de um degrau, conforme determinado pela Equação 6.17 e sua Tranformada de Laplace pela Equação 6.18:

$$
\begin{gathered}
p(t)=u(t)-u(t-\delta) \\
P(s)=\frac{1}{s}\left(1-e^{-\delta s}\right)
\end{gathered}
$$

Ainda existe a possibilidade de infusões periódicas em intervalos de tempo, como nos casos de injeções intravenosas a cada certa quantidade de horas. A Transformada de Laplace de uma série de pulsos consecutivos pode ser obtida pela Equação 6.19:

$$
W(s)=\frac{1}{s}\left(\sum_{0}^{n}(-1)^{n} e^{-\delta_{n} s}\right)
$$

sendo que $W(s)$ se refere a série de pulsos consecutivos (Trem de Pulsos) em função de $s$ e $n \in \mathcal{N}$ ao índice de cada atraso. 
A Tabela 4 relaciona sinais no domínio do tempo com o tipo de infusão que este pode representar.

Tabela 4: Relação dos sinais com os tipos de infusões.

\begin{tabular}{ccc}
\hline$x(t)$ & $X(s)$ & Infusão \\
\hline Impulso & 1 & Intravenosa \\
Degrau & $\frac{1}{s}$ & Constante \\
Pulso & $\frac{1}{s}\left(1-e^{-\delta s}\right)$ & Periódica \\
Trem de pulsos & $\frac{1}{s}\left(\sum_{0}^{n}(-1)^{n} e^{-\delta_{n} s}\right)$ & Infusões Múltiplas Periódicas \\
\hline
\end{tabular}

\subsection{Obtenção do Parâmetro Farmacocinético Cons- tante de Absorção $\boldsymbol{k}_{a}$.}

Nesta seção será descrito o método utilizado para a obtenção do parâmetro farmacocinético $k_{a}$. Nos livros de Rosenbaum (2011), Makoid, Vuchetich e Banakar (1999), Bauer (2008) e Jambhekar e Brenn (2009) é proposto que se obtenha o valor da constante $k_{a}$ por meio da análise gráfica. Desta forma, é necessária a obtenção das concentrações dos medicamentos para certos intervalos de tempo após a infusão. A maneira como é feita esta obtenção é mostrada na Figura 28.

Neste trabalho é proposto um método para o cálculo da constante $k_{a}$, que utiliza apenas dados presentes na bula de medicamentos, não necessitando da análise clínica e de amostras de concentração plasmática. Isto torna o método mais simples que os propostos na literatura.

Não existem nas bulas dados referentes à absorção do medicamento. Os fabricantes fornecem apenas o tempo $t_{\max }$ em que ocorre a concentração plasmática máxima $C_{p \max }$ e o tempo de meia vida a partir do qual se obtém a constante de eliminação total $k_{e t}$. A quantidade de medicamento presente no plasma após uma única dose de medicamento é dada pela Equação 5.4. A curva obtida a partir desta equação para valores arbitrários de $M_{g i 0}, k_{e t}$ e $k_{a}$ é mostrado na Figura 29 , somente para visualização do tempo de máximo. 


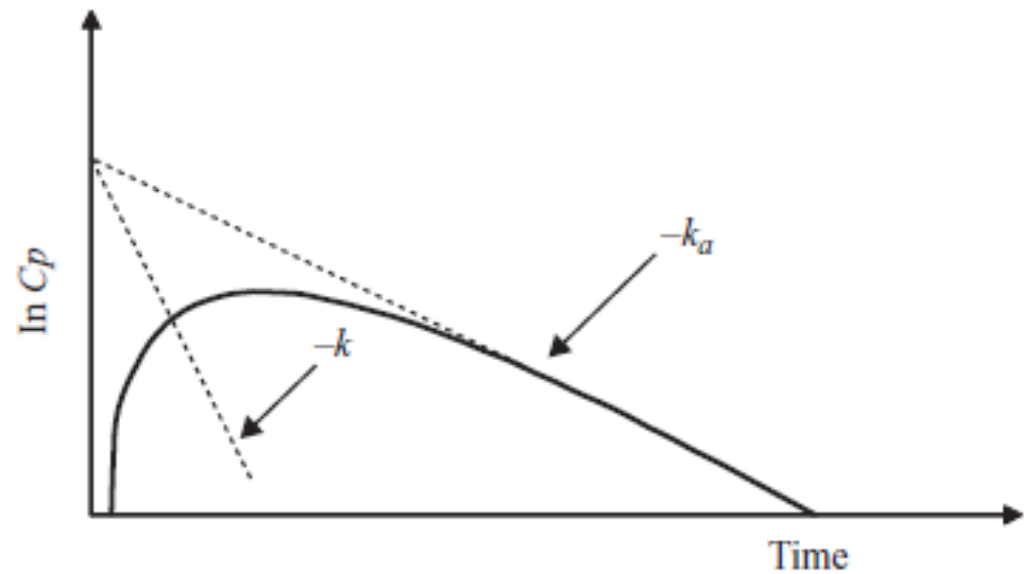

Figura 28: Obtenção de $k_{a}$ por meio da análise gráfica (ROSENBAUM, 2011).

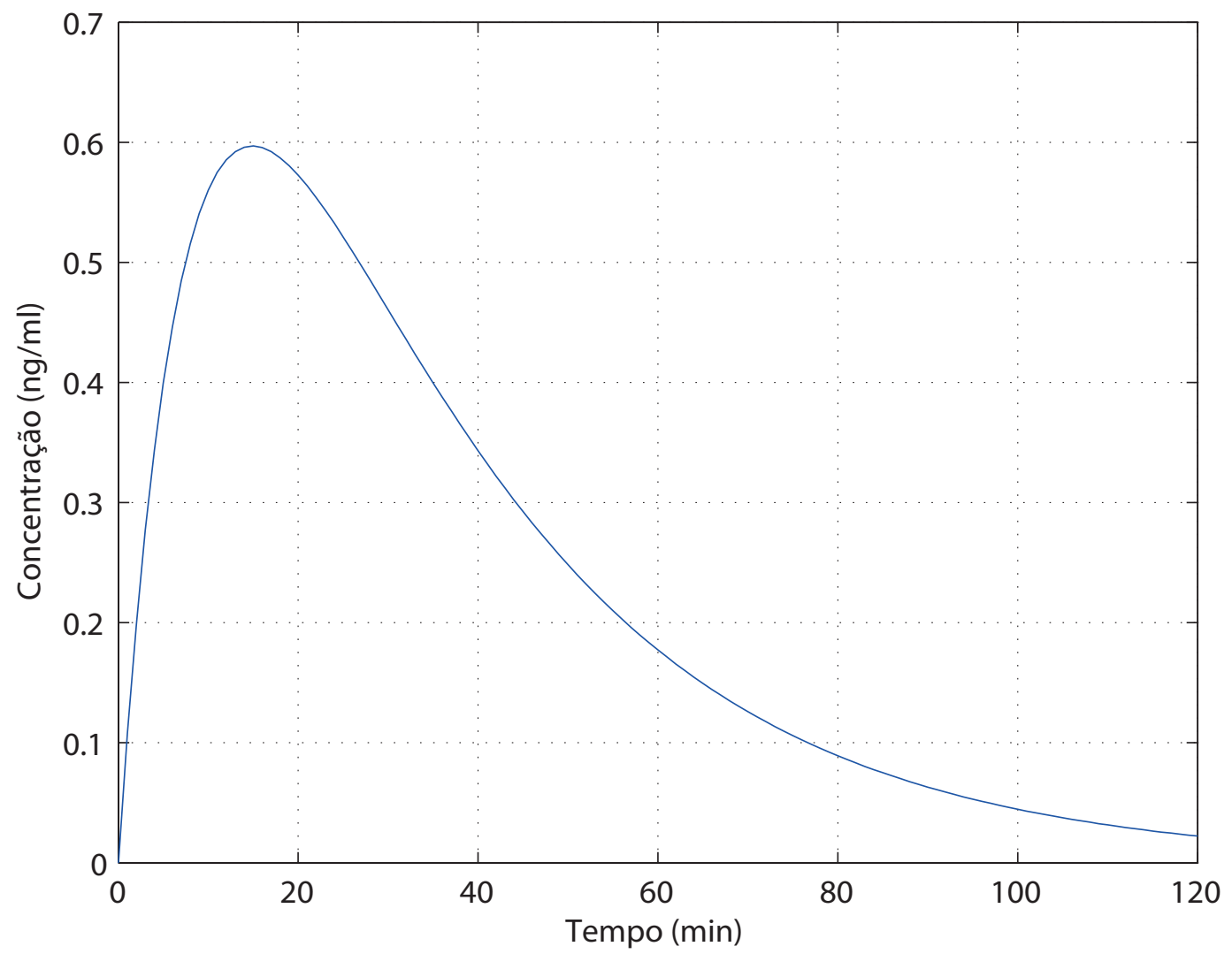

Figura 29: Absorção e eliminação de um medicamento.

É possível se obter o ponto de máximo da função dada pela Equação 5.4 por meio da derivada desta função que resulta na equação 6.20 :

$$
M_{i}^{\prime}=\left(\frac{k_{a}}{k_{a}-k_{e} t}\right)\left(-k_{e} e^{-k_{e t}}+k_{a} e^{-k_{a} t}\right)
$$


Sabe-se que quando $t=t_{\max }$, a Equação 6.20 assume valor 0. Então tem-se a Equação 6.21

$$
-k_{e t} e^{\left(-k_{e t} t_{\max }\right)}+k_{a} e^{\left(-k_{a} t_{\max }\right)}=0
$$

Sendo os valores de $k_{e t}$ e $t_{\max }$ conhecidos, a Equação 6.21 pode ser solucionada para obtenção do valor da constante $k_{a}$. Tem-se uma função $f\left(k_{a}\right)$ dada pela Equação 6.22 e deve ser obtida a raíz desta função.

$$
f\left(k_{a}\right)=-k_{e t} e^{\left(-k_{e t} t_{\max }\right)}+k_{a} e^{\left(-k_{a} t_{\max }\right)}=0
$$

Não existe uma solução analítica simples para obtenção desta raiz, por isso é proposto o método de Newton-Raphson para obtenção de $k_{a}$. Neste método, a partir de uma função $f(x)$ e de sua derivada $f^{\prime}(x)$, é possível estimar o valor da raíz a partir de um valor inicial $x_{0}$, como mostrado na Equação 6.23:

$$
x_{0}=x_{1}-\frac{f(x)}{f^{\prime}(x)}
$$

A raiz pode ser obtida por iteração, conforme Equação 6.24

$$
x_{n}=x_{n+1}-\frac{f(x)}{f^{\prime}(x)}
$$

Sendo a derivada da função 6.22, dada pela Equação 6.25, tem-se a Equação 6.26 para estimação do valor de $k_{a}$.

$$
\begin{gathered}
f^{\prime}\left(k_{a}\right)=\left(1-t_{\max }\right) e^{\left(-k_{a} t_{\max }\right)} \\
k_{n+1}=k_{n}-\frac{f\left(k_{a}\right)}{f^{\prime}\left(k_{a}\right)}
\end{gathered}
$$




\subsection{Implementação Computacional}

Para obter as respostas das funções de transferência propostas será utilizado a ferramenta computacional simulink presente no software MATLAB. No ambiente do simulink é possível inserir no sistema entradas correspondentes às infusões e obter suas respostas em cada diagrama de bloco representativo das funções de transferência.

O método solucionado para solução das EDO foi ode45 (Dormand-Prince, passo variável). Este método pertence ao tipo de métodos Runge-Kutta para solucionar EDOs. 


\section{RESULTADOS}

Neste Capítulo serão apresentados e discutidos os resultados obtidos a partir do modelo proposto.

Inicialmente, será apresentada a validação do modelo com base em dados dos medicamentos presentes na literatura. Posteriormente, serão feitas simulações para situações como interrupção no tratamento, sobredosagem, variação na quantidade da dose e variação no intervalo da dose.

\subsection{Validação do Modelo Monocompartimental}

Nesta seção será verificada a validação do modelo monocompartimental. Para isso, serão comparados valores medidos experimentalmente com os obtidos pelo modelo.

\subsubsection{Comparação com o modelo de Hoskin et al. (1989)}

A partir da Equação 6.9 e do diagrama de blocos apresentado na Figura 26, foi feita a simulação para uma infusão intravenosa de morfina, com os parâmetros farmacocinéticos de indivíduos do experimento realizado por Hoskin et al. (1989). A Tabela 5 mostra os dados farmacocinéticos de cada indivíduo. A dose da injeção intravenosa foi de $D=10$ mg aplicada durante 2 minutos.

Tabela 5: Parâmetros farmacocinéticos de indivíduos (HOSKIN et al., 1989).

\begin{tabular}{cccc}
\hline Paciente & $t_{1 / 2}(\mathrm{~h})$ & $C_{\max }(\mathrm{ng} / \mathrm{ml})$ & $V_{a p}(\mathrm{ml})$ \\
\hline 1 & 1,5 & 276 & 3623 \\
2 & 2,5 & 314 & 3184 \\
3 & 1,5 & 574 & 1742 \\
4 & 1,7 & 274 & 3649 \\
\hline
\end{tabular}


Os resultado são mostrado na Figuras 30, 31, 32, 33. Os pontos marcados com (*) representam os valores medidos experimentalmente.

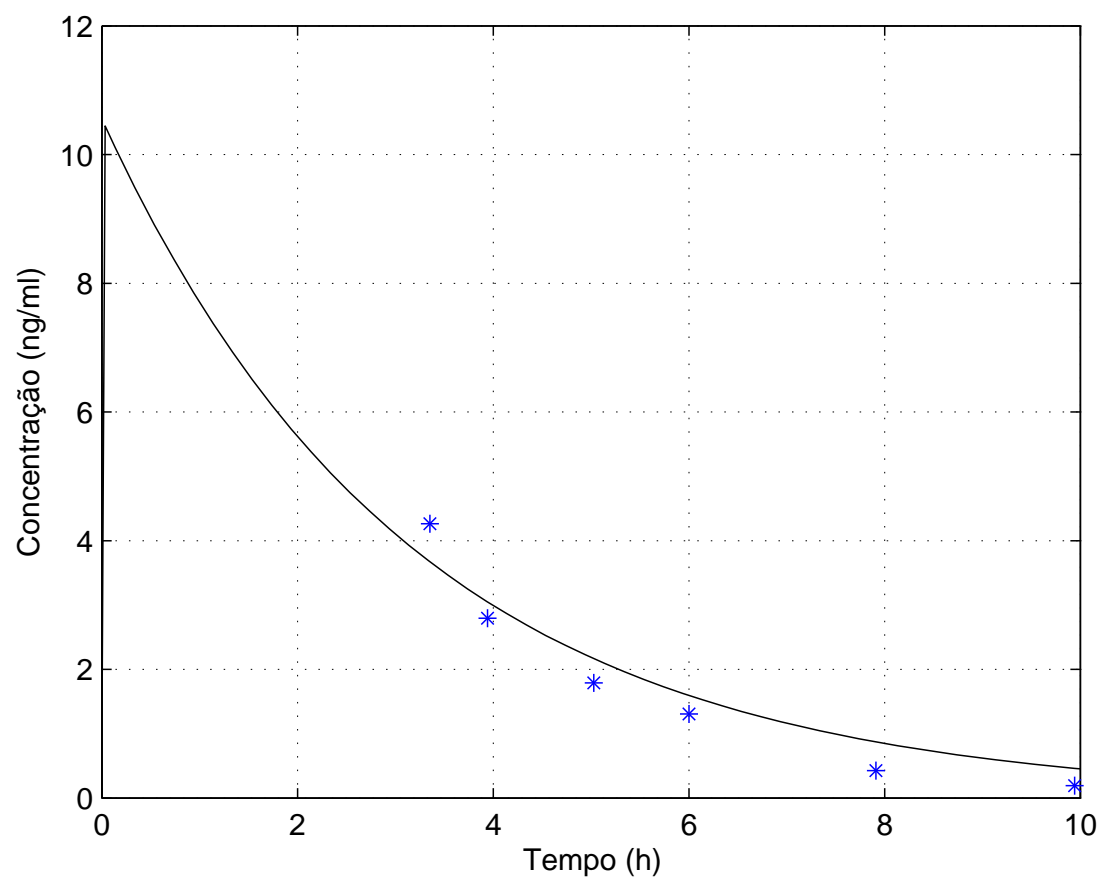

Figura 30: Resposta do modelo para o paciente 1.

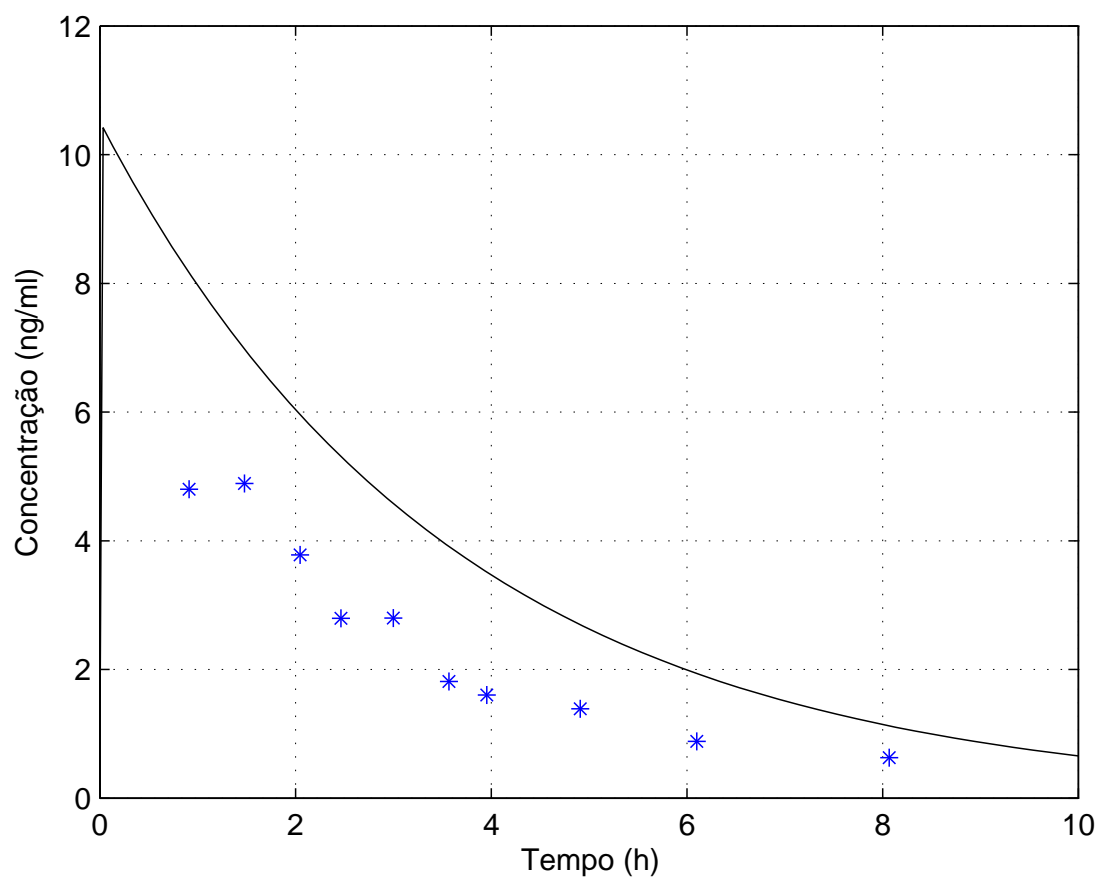

Figura 31: Resposta do modelo para o paciente 2.

A grande amplitude entre o mínimo e o máximo valor se deve ao fato de que os parâmetros farmacocinéticos variam muito de pessoa para pessoa. Esta variação esta 


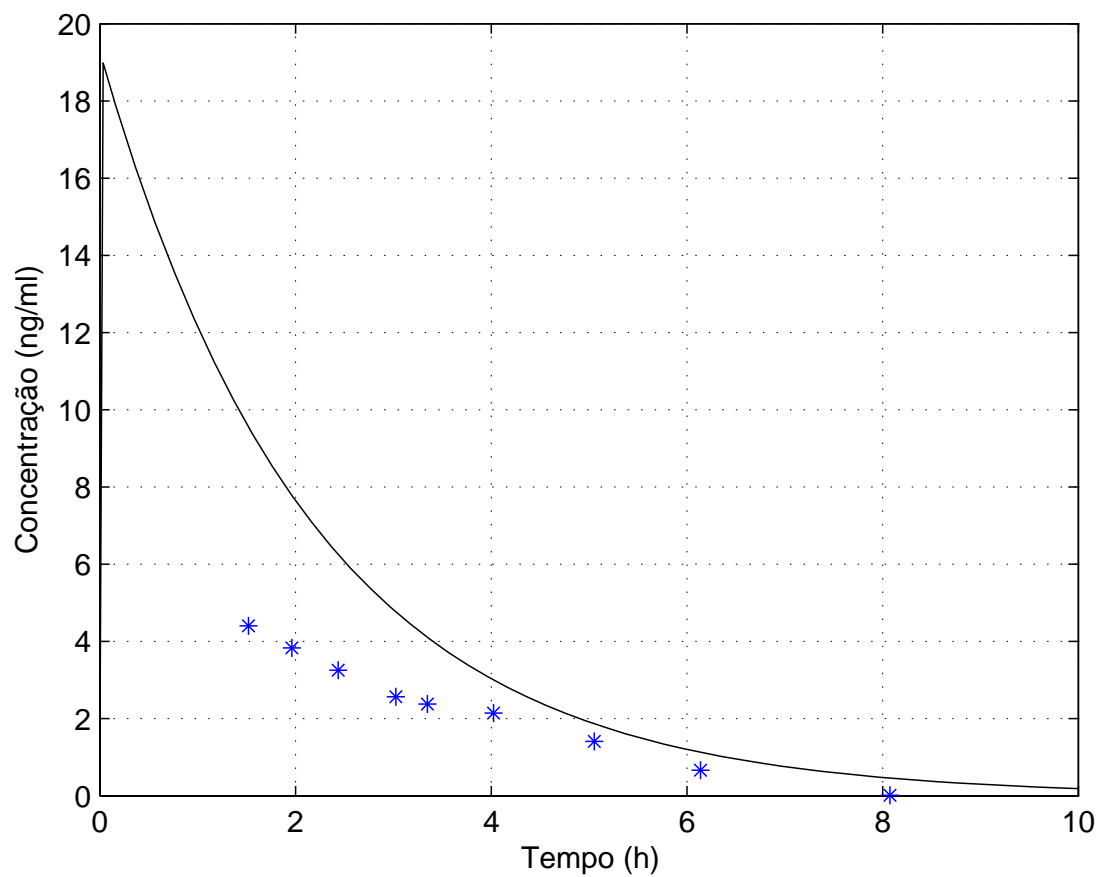

Figura 32: Resposta do modelo para o paciente 3.

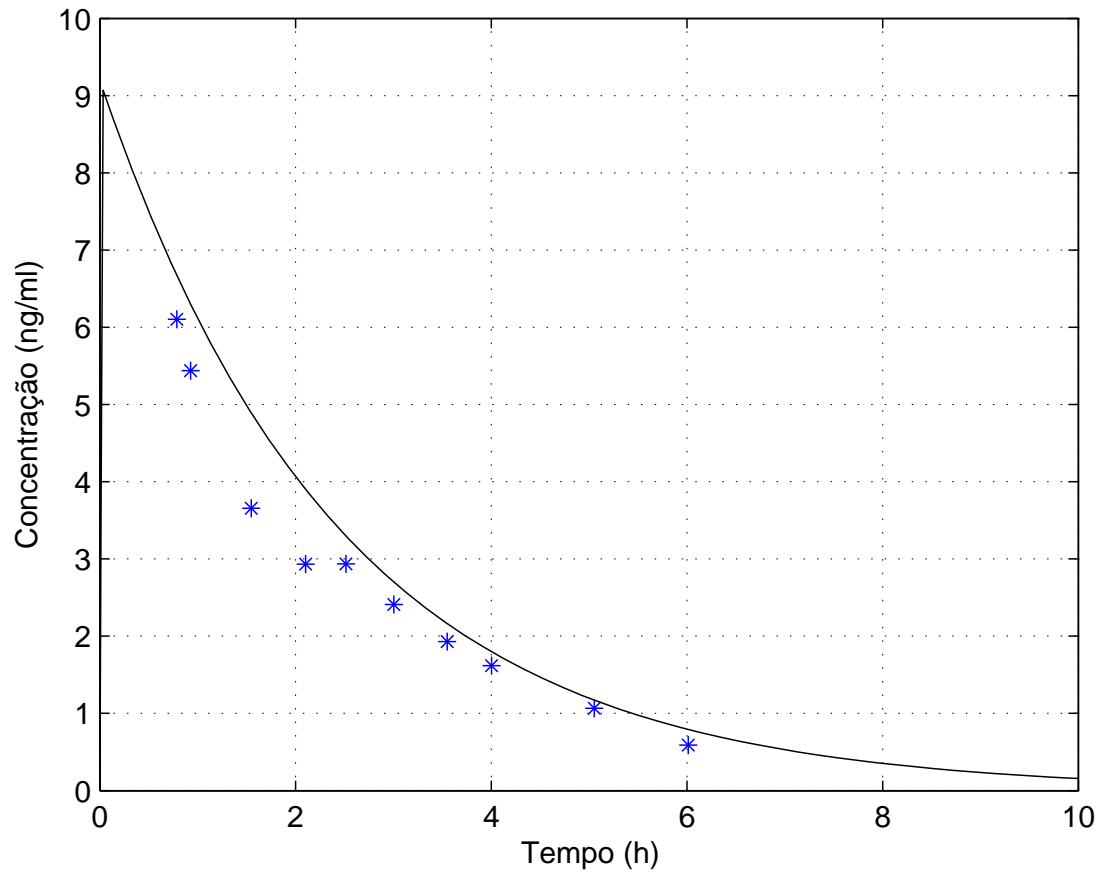

Figura 33: Resposta do modelo para o paciente 4.

associada a diferenças de idade, peso, metabolismo, taxa de remoção e sexo. Sendo assim, verifica-se que em alguns pacientes o modelo se aproximou mais dos valores experimentais do que em outros. 


\subsubsection{Comparação com o modelo de Granero et al. (1993).}

O modelo multicompartimental desenvolvido por Granero et al. (1993) apresenta medições experimentais das concentrações plasmáticas do sangue após infusões intravenosas de ceftazidima nas quantidade de $5 \mathrm{mg}$ e $20 \mathrm{mg}$. Os valores dos parâmetros farmacocinéticos utilizados foram $t_{1 / 2}=13,42$ min e $V_{a p}=2940 \mathrm{ml}$. Os resultados são mostrados nas Figuras 34 e 35.

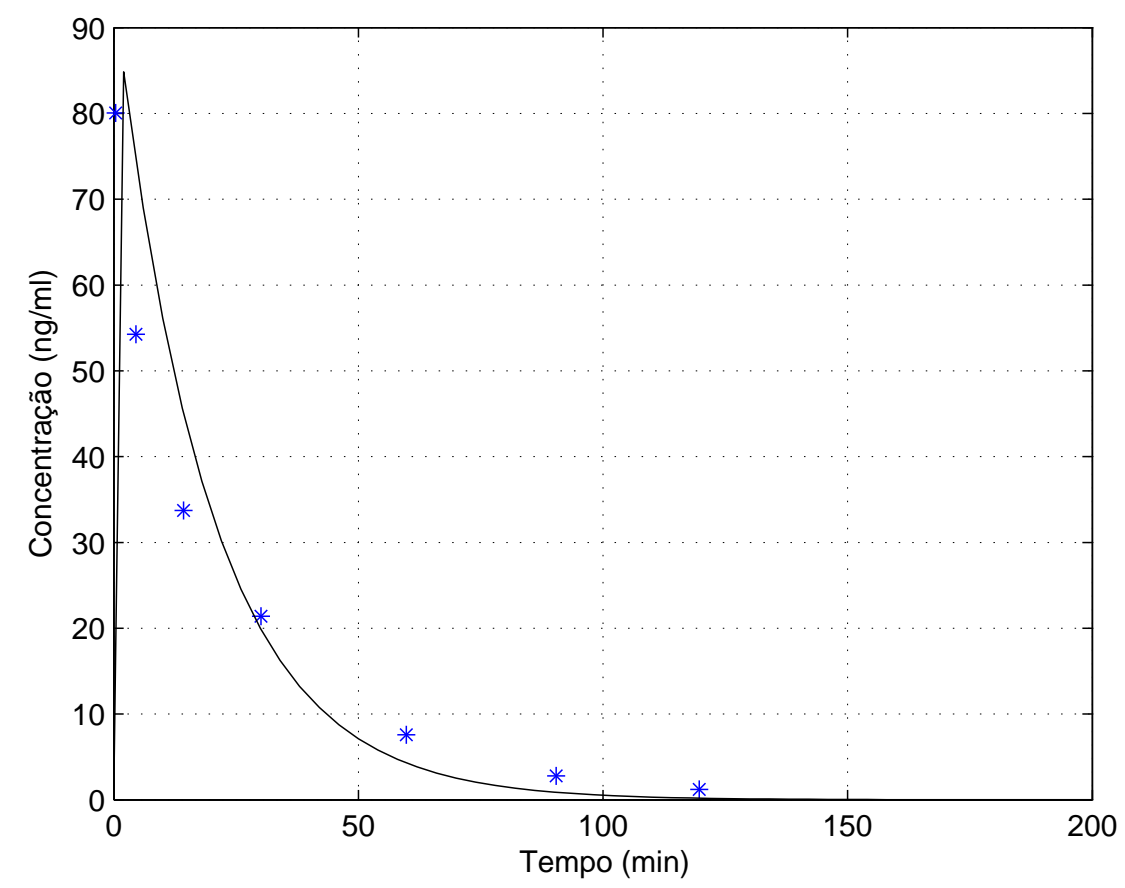

Figura 34: Comparação da concentração plasmática calculada pelo modelo e medida experimentalmente $\left(^{*}\right)$ por Granero et al. (1993) após dose de 5 mg.

\subsection{Validação do Modelo Bicompartimental}

Nesta seção será feita a comparação dos modelo bicompartimental com dados presentes na literatura.

Com a utilização da Equação 6.14 e 6.15, é possível que se obtenha a massa presente em cada compartimento após a infusão do medicamento. 


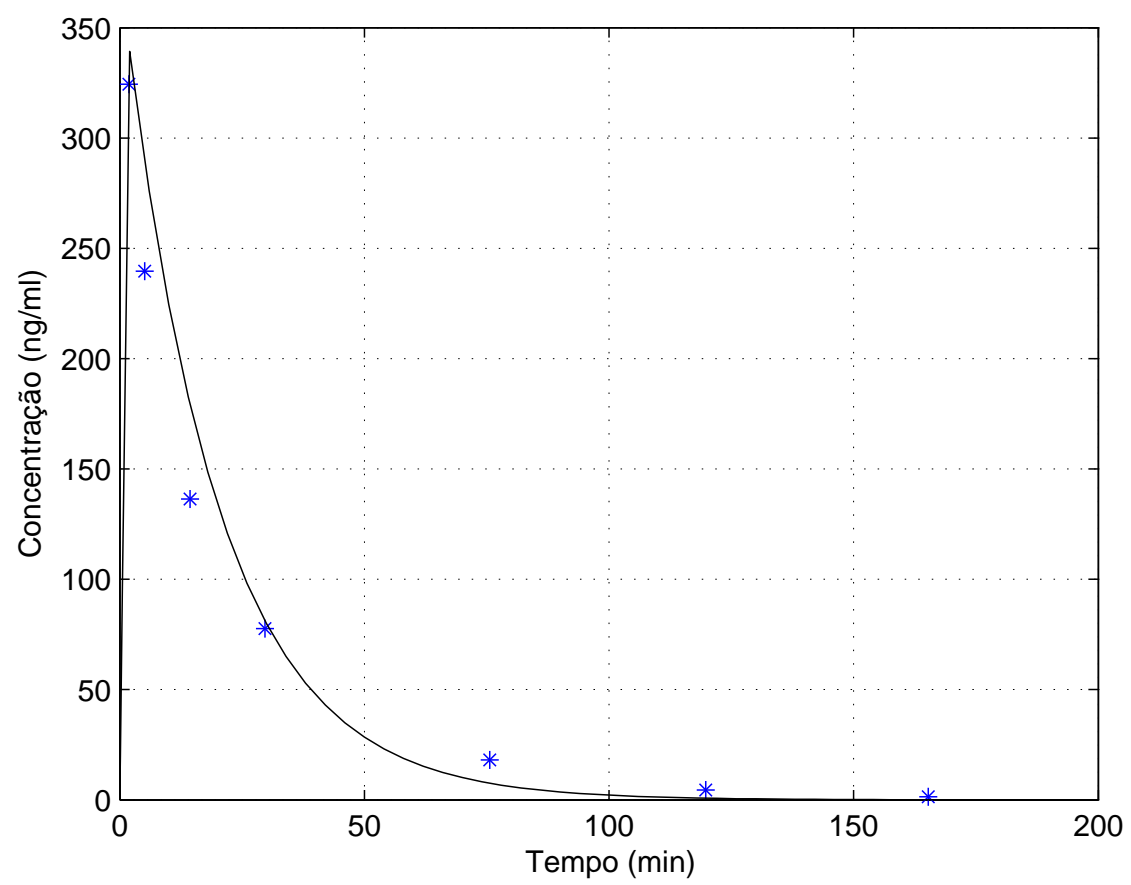

Figura 35: Comparação da concentração plasmática calculada pelo modelo e medida experimentalmente $(*)$ por Granero et al. (1993) após dose de $20 \mathrm{mg}$.

O foco da análise é a concentração plasmática, sendo que o compartimento central serve para simular a absorção do medicamento dependendo da maneira a qual ele é infundido. Assim tem-se a Equação 7.1:

$$
C_{p}=\frac{M_{p}}{V_{a p}}
$$

Conforme explanado no Capítulo 2, boa parte da dose pode ser perdida devido ao metabolismo hepático renal e ao fator salino. Sendo assim, a partir da Equação 2.5 e da Equação 7.1, chega-se a Equação 7.2 que refere-se a concentração real de droga no sangue, já levando-se em consideração a biodisponibilidade.

$$
C_{p e f}=\frac{D_{e f}}{V_{a p}}
$$

\subsubsection{Comparação com o modelo de Hunault et al. (2010).}

Nesta subseção será apresentada a comparação dos dados experimentais obtidos por Hunault et al. (2010) com os calculados pelo modelo. O compartimento central $i$ neste 
caso representa o pulmão $(p u)$. O resultado é mostrado na Figura 36. Os parâmetros farmacocinéticos utilizados foram $t_{1 / 2}=20$ minutos, $t_{\max }=13$ minutos, $\frac{D_{e f}}{V_{a p}}=14,56$ ng/ml. O valor de $k_{a}$, calculado conforme mostrado na subseção 6.2 foi de $0,14 \mathrm{~min}^{-1}$.

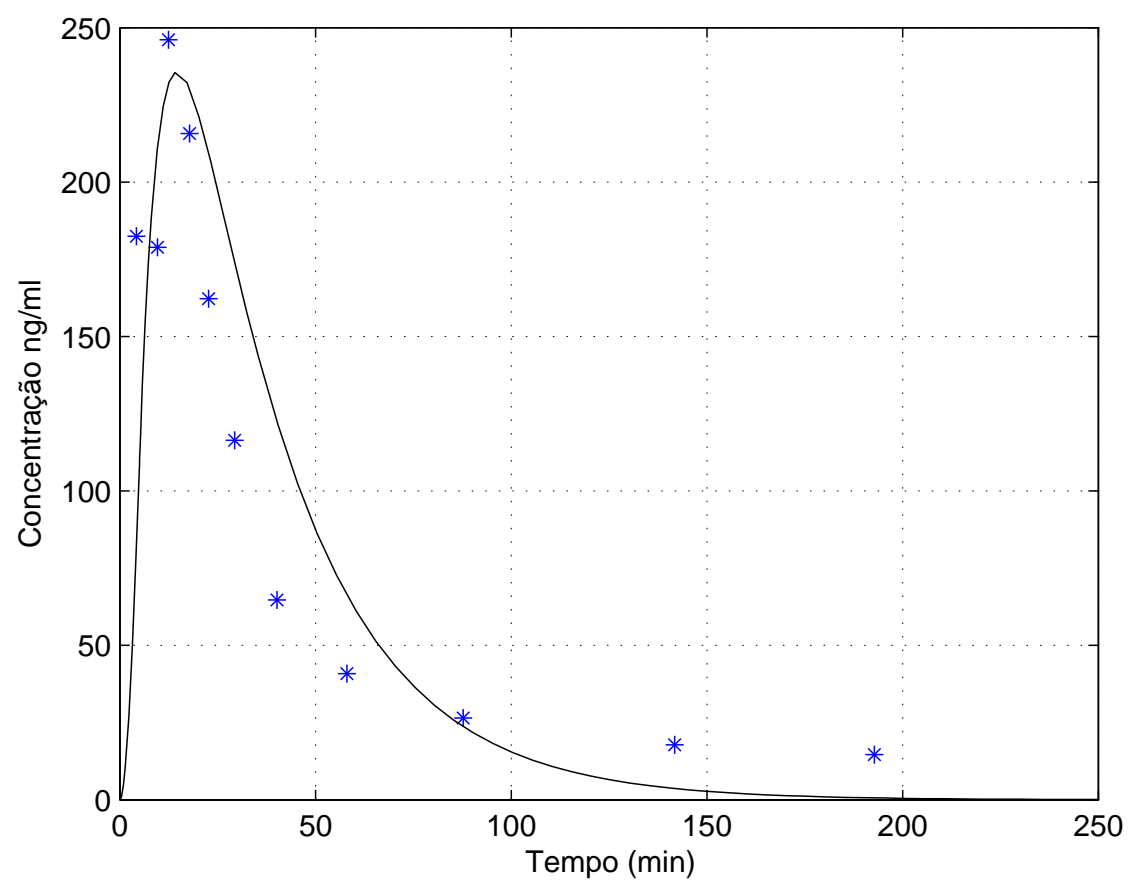

Figura 36: Comparação da concentração plasmática calculada pelo modelo e medida experimentalmente $(*)$ por Hunault et al. (2010).

\subsubsection{Comparação com o modelo de Foulds et al. (2003).}

No modelo de Foulds et al. (2003) foi feita a análise da concentração de nicotina no sangue após o fumo de um cigarro contendo dose efetiva de $D_{e f}=2 \mathrm{mg}$.

Sabe-se que a nicotina é uma droga que provoca dependência, sendo que seus usuários necessitam de consumo periódico de cigarros para manter uma concentração de regime permanente no sangue.

Os valores farmacocinéticos médios obtidos para o modelo foram $t_{1 / 2}=23$ minutos, $t_{\max }=5$ minutos, $D_{e f}=2 \mathrm{mg}$ e $V_{a p}=2939 \mathrm{ml}$. Os resultados são mostrados na Figura 37. 


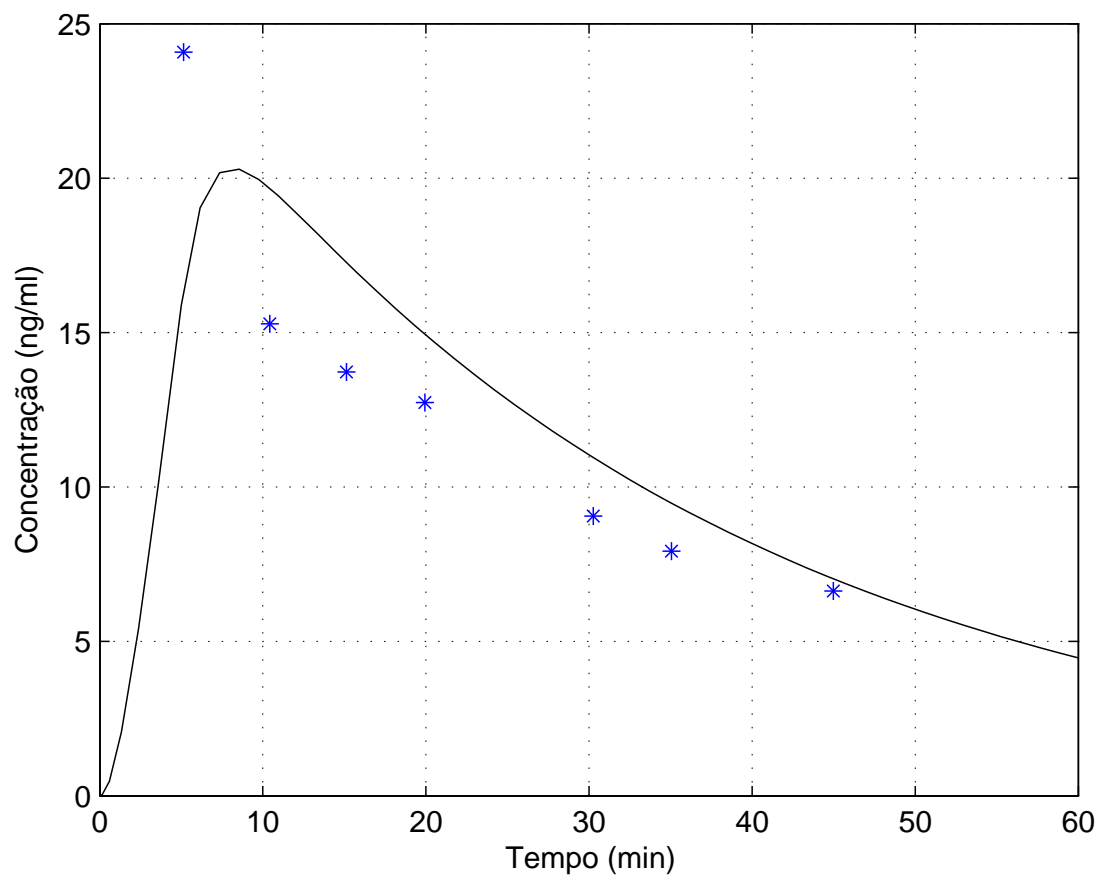

Figura 37: Comparação da concentração plasmática calculada pelo modelo e medida experimentalmente $\left(^{*}\right)$ por Foulds et al. (2003).

\subsubsection{Comparação com dados presentes em bulas de medicamen- tos}

Para validação do modelo foram utilizados parâmetros farmacocinéticos da paroxetina, um medicamento utilizado no combate a depressão, sendo estes:

- dosagem $\boldsymbol{D}(\boldsymbol{t}): 40 \mathrm{mg} / \mathrm{dia}$;

- biodisponibilidade $\beta$ : $50 \%$;

- tempo de $C_{p m a x}: 5 \mathrm{~h}$;

- volume aparente $\boldsymbol{V}_{a p}: 280 \mathrm{~L}$;

- período de infusão constante dos tabletes: $5 \mathrm{~h}$;

- regime de dosagem: $4 \mathrm{mg} / \mathrm{h}$ durante 5 horas a cada 24 horas;

- Tempo de meia vida: $t_{1 / 2}: 24 \mathrm{~h}$.

Os dados foram retirados da bula do medicamento (DRUGS INFORMATION ONLINE, 2012 ) e de Lima, Baumann e Bin (2008). 
O valor da constante de absorção $k_{a}$ foi obtido a partir de $t_{\text {max }}$ e $k_{e t}$, conforme proposto no Capítulo 6.

A Figura 38 mostra os resultados da simulação. Como a infusão foi simulada para cada 24 horas, tem-se que cada curva representa a concentração durante um dia.

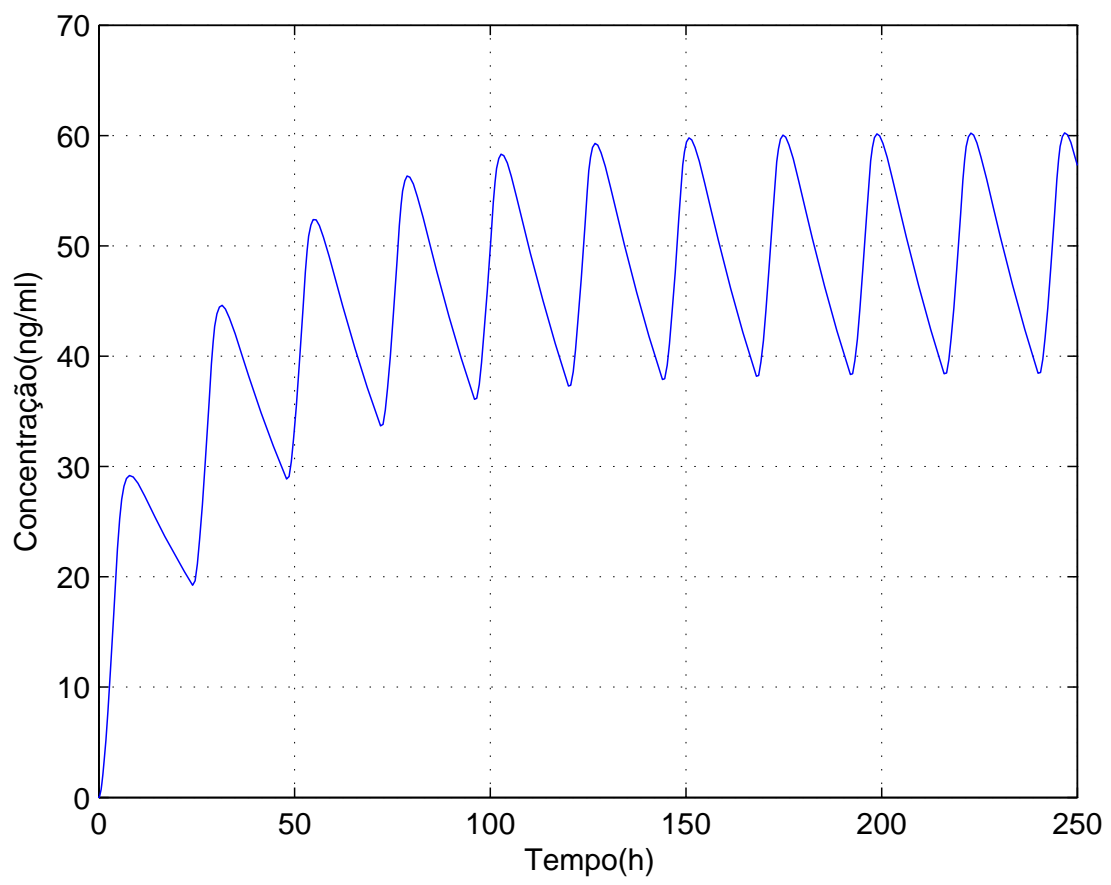

Figura 38: Resposta do modelo para consumo de tabletes de Paroxetina a cada 24 horas.

Segundo informações da bula (DRUGS INFORMATION ONLINE, 2012 ), a concentração de regime permanente média varia entre 48,7 ng/ml e $117 \mathrm{ng} / \mathrm{ml}$ e é atingida após 7 dias da primeira infusão.

Como o valor médio da concentração calculado pelo modelo é igual a aproximadamente $50 \mathrm{ng} / \mathrm{ml}$, o modelo apresentou uma resposta coerente com os dados farmacocinéticos apresentados. Observa-se que o tempo de regime permanente ocorre após aproximadamente 170 horas, ou cerca de 7 dias. Este valor também esta de acordo com os dados presentes na literatura. 


\subsection{Variação de Infusão de Morfina no Modelo Mono- compartimental}

Nesta seção serão apresentadas algumas variações possíveis no modelo monocompartimetal. Será comparada a infusão constante com diversas infusões periódicas.

\subsubsection{Comparação entre Infusão Constante e Injeções Intraveno- sas Periódicas.}

Foi feita a simulação para infusão constante de morfina na dose $D(t)=5 \mathrm{mg} / \mathrm{h}$. Segundo Bauer (2008), a administração de maneira intravenosa pode ser feita em dose única ou com várias infusões periódicas. Assim, uma dosagem constante de $5 \mathrm{mg} / \mathrm{h}$ pode ser feita com doses de $30 \mathrm{mg}$ a cada seis horas. Esta condição foi simulada, sendo que as injeções intravenosas foram infundidas com uma dose de $D(t)=15 \mathrm{mg} / \mathrm{min}$, durante dois minutos. O resultado pode ser observado na Figura 39. Pela análise do resultado, conclui-se que as dosagens constante ou feitas de maneira periódica não apresentam os mesmo resultados devido ao baixo tempo de meia vida da morfina que é de duas horas. Pode-se concluir que, através da análise utilizando modelos baseados em sistemas lineares invariantes no tempo, procedimentos recomendados na literatura não atingem os resultados esperados.

Desejando-se uma concentração de regime permanente no valor de 410 ng/ml é necessária que seja feita a infusão constante já que se for feita de maneira distribuída, a cada seis horas, não é possível que se atinja o valor desejado devido a meia vida da morfina ser muito baixa.

\subsubsection{Tentativa de Aproximação da Concentração de Regime Per- manente}

Na tentativa de se atingir a mesma concentração de regime permanente, foi simulada a mesma dose de infusão intravenosa a cada hora. O resultado é mostrado na Figura 40, onde observa-se que o mesmo valor também não é atingido. 


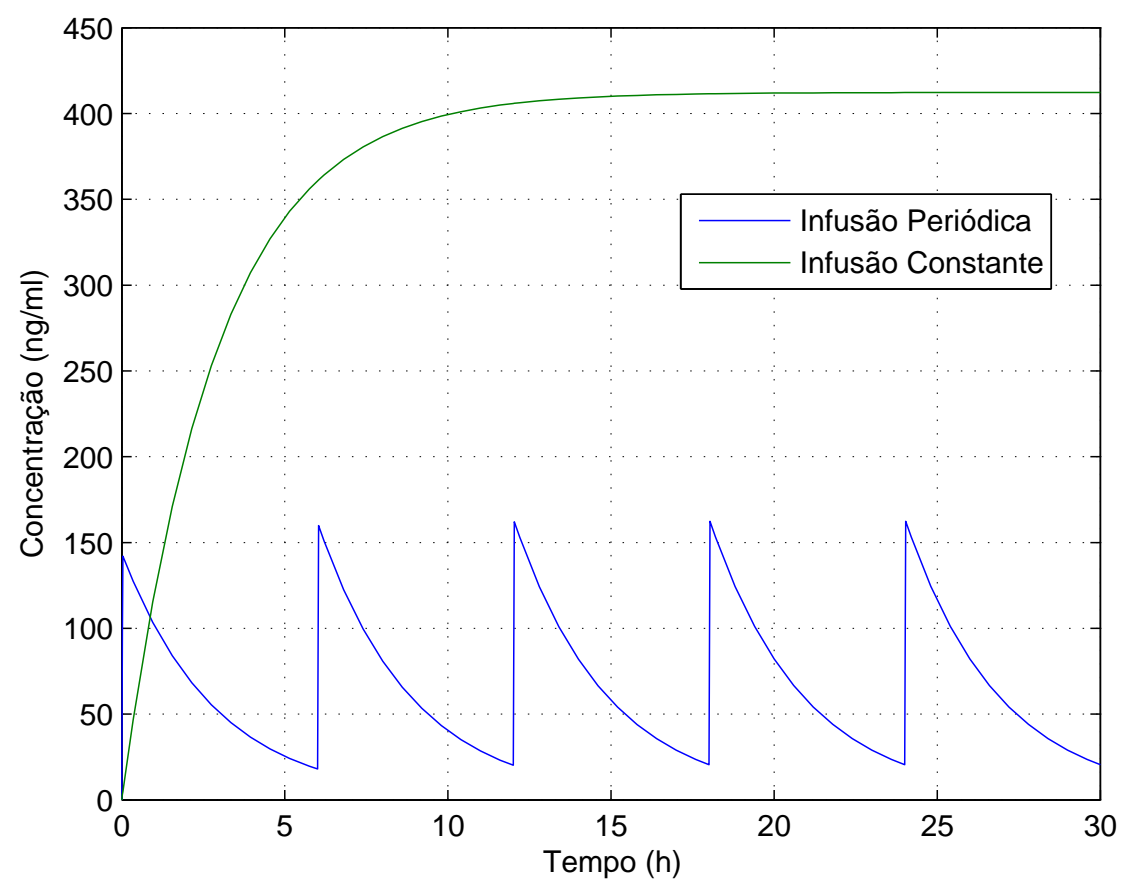

Figura 39: Comparação entre infusão constante $(5 \mathrm{mg} / \mathrm{h})$ e infusões periódicas múltiplas (30 mg a cada seis horas).

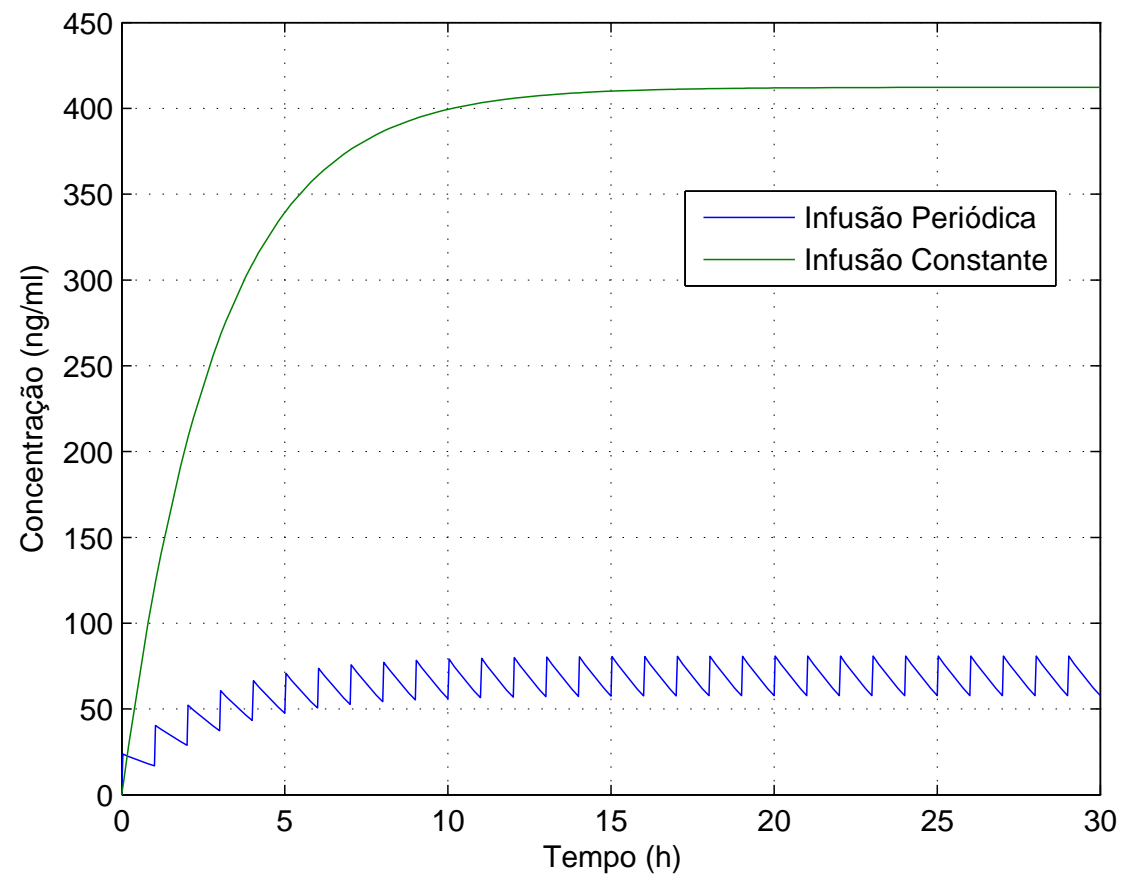

Figura 40: Comparação entre infusão constante $(5 \mathrm{mg} / \mathrm{h})$ e infusões periódicas múltiplas (30 mg a cada hora).

Outra tentativa de atingir o valor de regime permanente desejado é manter a dose da injeção intravenosa de $D(t)=300 \mathrm{mg}$ a cada hora. O valor da injeção periódica neste caso é seis vezes maior do que o valor da dose de infusão constante para que se atinja 
a mesma concentração de $410 \mathrm{ng} / \mathrm{ml}$. Sendo assim, é necessária uma quantidade muito maior de droga para que se atinja o mesmo resultado utilizando-se injeções intravenosas múltiplas. Este método portanto, acaba por sobrecarregar o fígado, já que existe uma quantidade muito maior de fármaco no organismo. O resultado é mostrado na Figura 41.

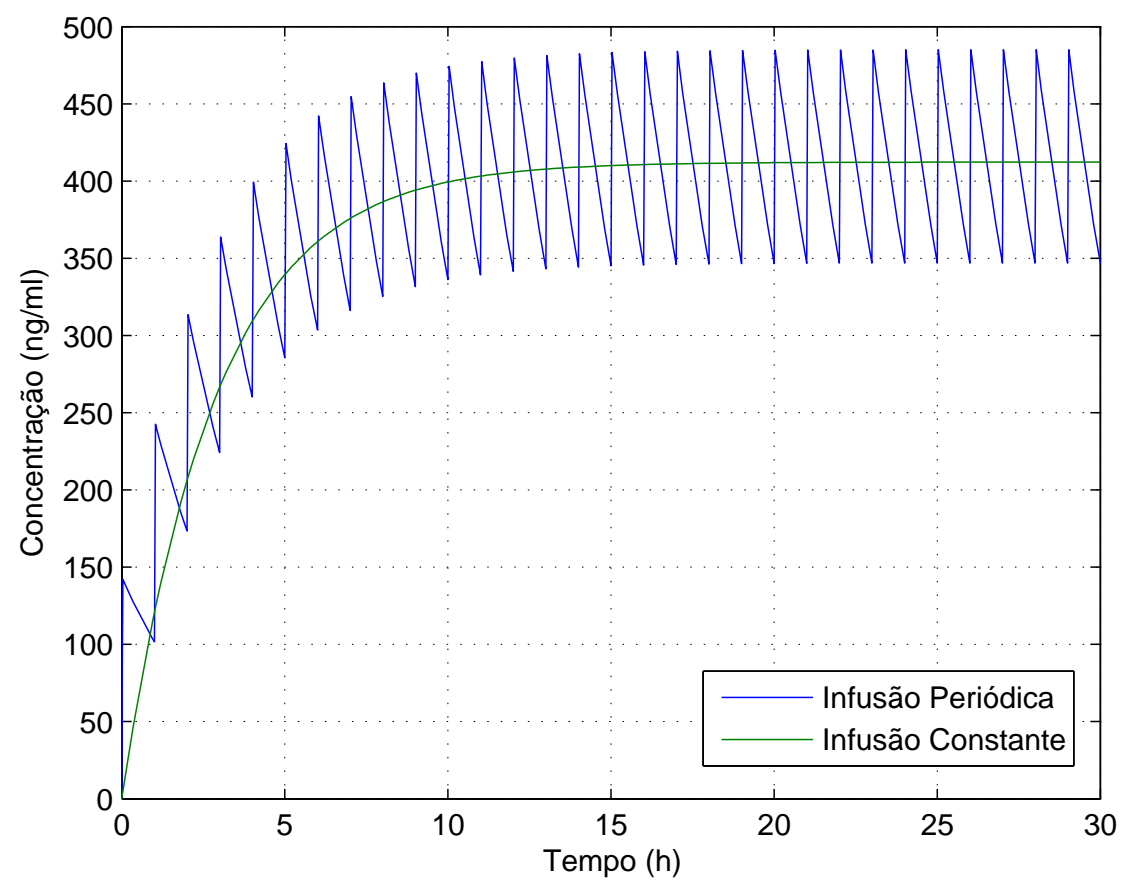

Figura 41: Comparação entre infusão constante $(5 \mathrm{mg} / \mathrm{h})$ e infusões periódicas múltiplas (300 mg a cada hora).

\subsection{Simulação de Condições Adversas no Modelo Bi- compartimental}

Uma vez validado, foram feitas novas simulações para prever as concentrações obtidas para o modelo quando o organismo se sujeita a outras formas de infusão diferentes das propostas no regime de tratamento. Estas situações são mostradas e discutidas nos itens a seguir.

\subsubsection{Alterações na Posologia de Paroxetina}

Nesta subseção são apresentados resultados do modelo para variações na posologia da Paroxetina. 


\subsubsection{Interrupção no Tratamento}

Conforme verificado na seção 7.1, verifica-se que o medicamento atinge regime permanente na corrente sanguínea após 7 dias, com uma concentração de regime permanente terapêutica no valor de $48 \mathrm{ng} / \mathrm{ml}$.

Foi feita uma simulação em que o indivídio não toma o medicamento no oitavo dia. A concentração plasmática é mostrada na Figura 42. Verifica-se que quando ocorre a interrupção no tratamento, a concentração de regime permanente leva aproximadamente 6 dias para ser atingida novamente.

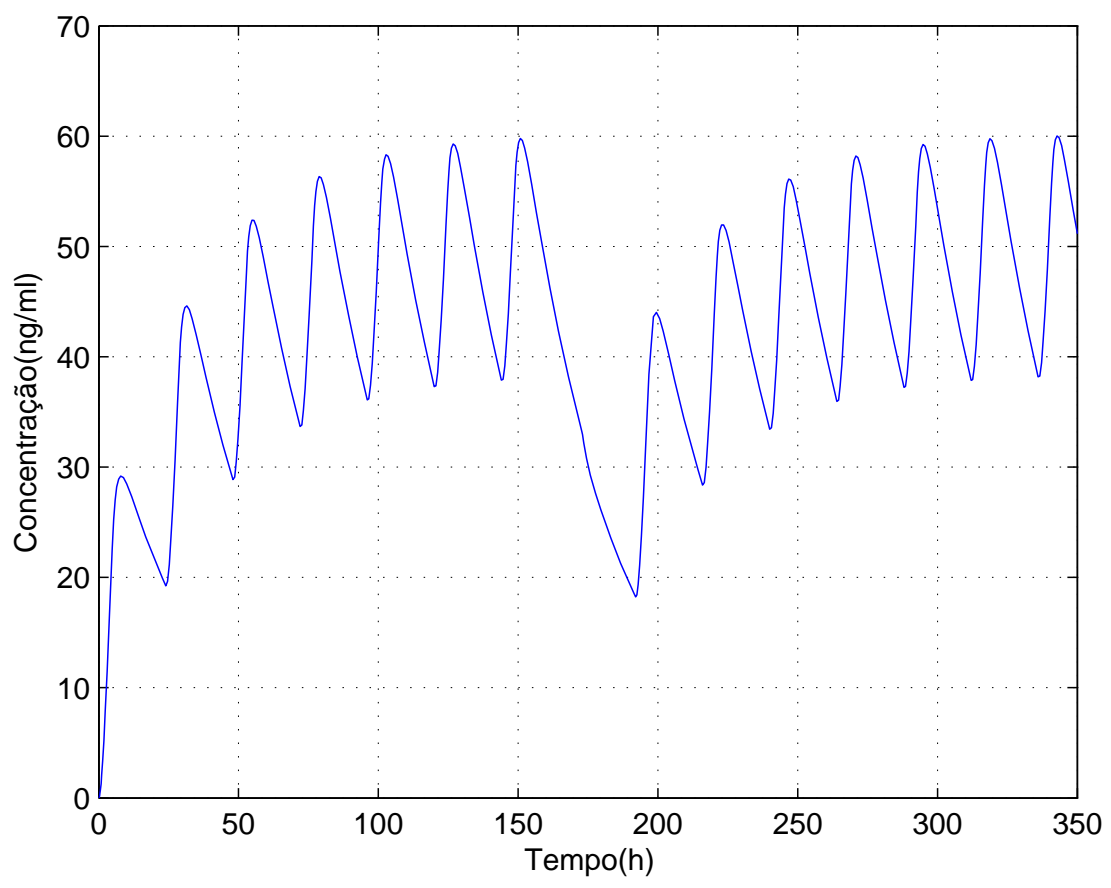

Figura 42: Interrupção no Tratamento de Paroxetina.

Uma tentativa de recuperar a concentração desejada é tomar no dia seguinte dois comprimidos. Neste caso, verifica-se que ocorre um pico de concentração e o regime permamente ocorre após cerca de 6 dias, conforme mostra a Figura 43. Sendo assim, é mais vantajoso não utilizar essa dosagem, já que na posologia normal a concentração retorna no mesmo intervalo de tempo, sem que se corram riscos de sobredosagem. 


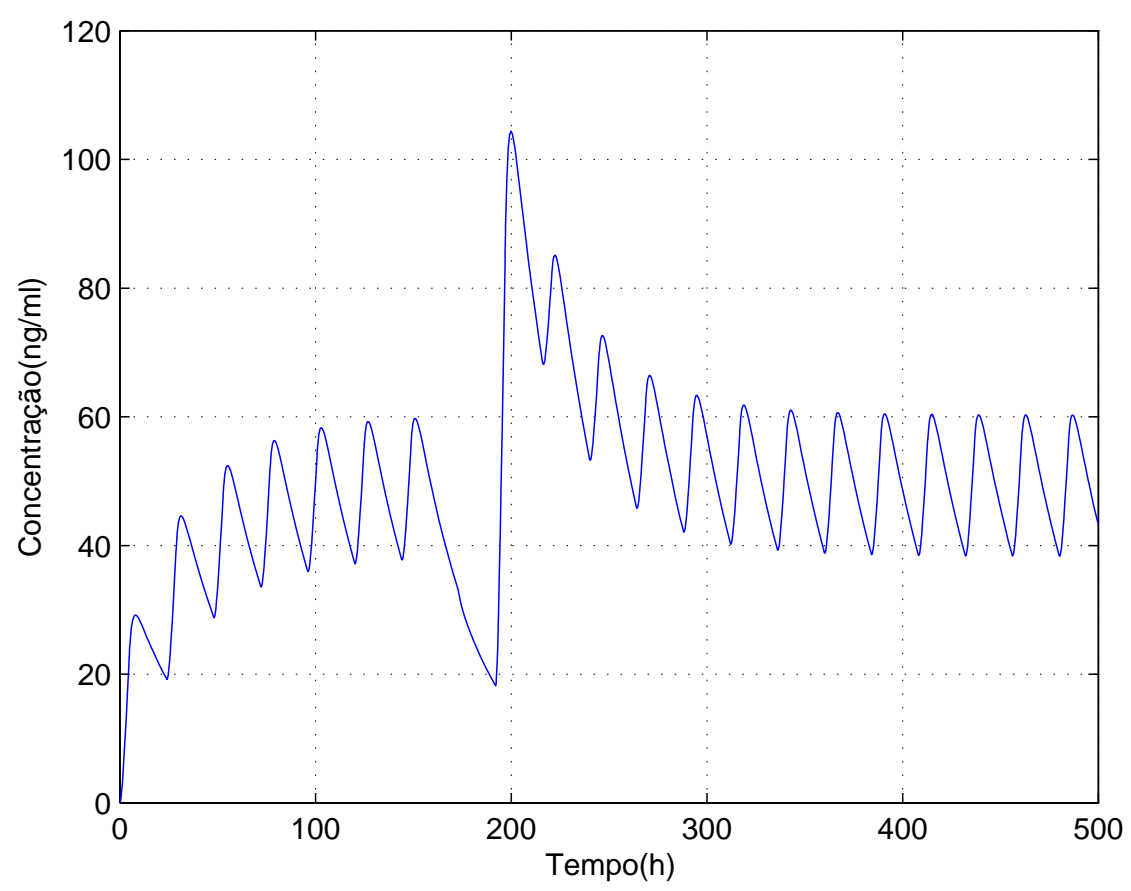

Figura 43: Dosagem de paroxetina dobrada para recuperar concentração de regime permanente.

\subsubsection{Aumento da Frequência de Dosagem com Dose Menor}

Usualmente pacientes consomem comprimidos pela metade na metade do regime de dosagem imaginando que o objetivo final seja alcançado, já que a quantidade de medicamento que adentra no organismo é a mesma.

Foi feita uma simulação de acordo com estas condições. A dose diária de 4 mg, sendo os comprimidos consumidos a cada $24 \mathrm{~h}$, foi reduzida para $2 \mathrm{mg}$, com ingestão de tabletes a cada 12 h. O resultado é mostrado na Figura 44. Verifica-se que no caso de tomar metade da dose, a concentração de regime permanente atinge apenas metade na desejada, estando em torno de $25 \mathrm{ng} / \mathrm{ml}$. Conclui-se que as duas posologias não apresentam o mesmo resultado de concentração final.

\subsubsection{Infusão Dobrada no Início do Tratamento}

Outra situação simulada é a infusão do dobro da quantidade $D(t)=80 \mathrm{mg}$ no início do tratamento para atingir regime permanente com maior rapidez. O resultado é mostrado 
na Figura 45. Verifica-se que a concentração de regime permanente, com valor médio de $48 \mathrm{ng} / \mathrm{ml}$, é atingida já no segundo dia.

\subsubsection{Eliminação Completa do Organismo}

Uma vez estabelecido o regime permamente, foi feita a simulação para determinar o tempo transcorrido para que a quantidade do medicamento no organismo atinja valor nulo. A simulação é mostrada na Figura 46. Verifica-se que levam cerca de 200 horas (aproximadamente 8 dias) para que a droga desapareça completamente do plasma sanguíneo.

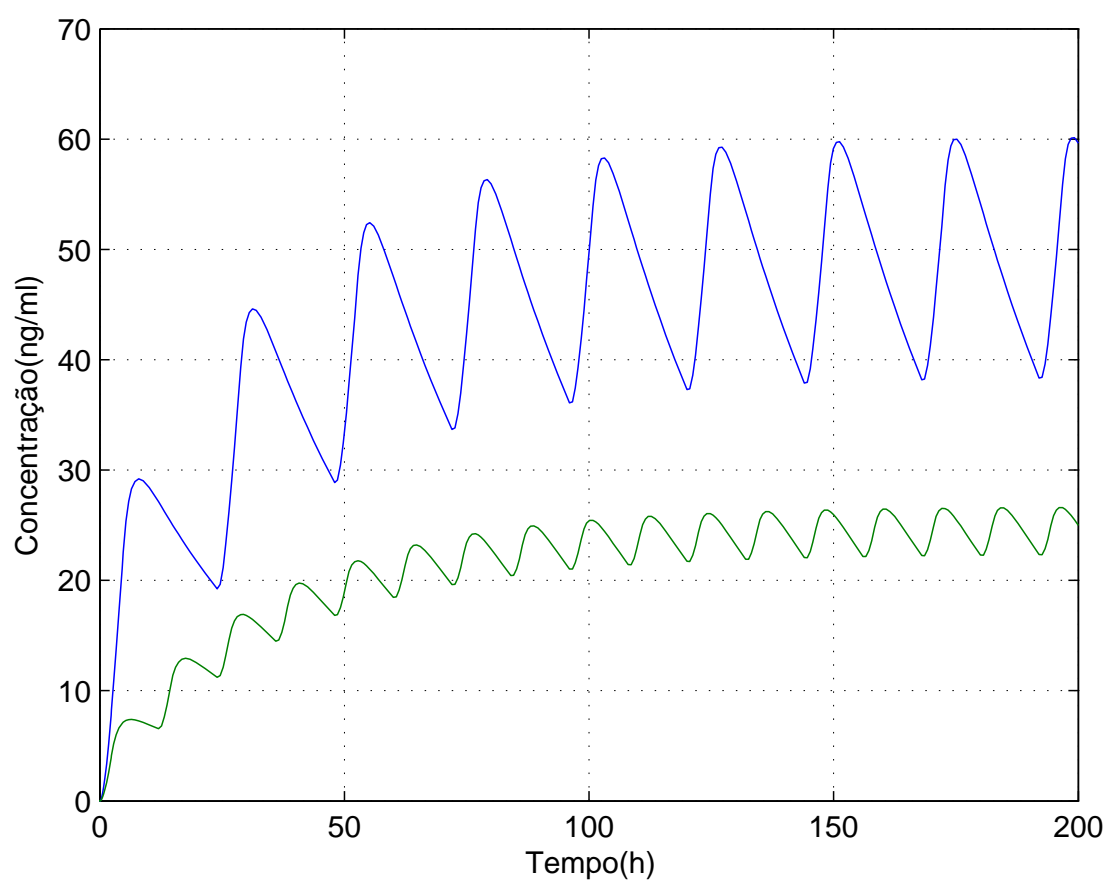

Figura 44: Comparação entre a dosagem normal e metade desta dosagem. Verifica-se que a metade da dosagem atinge uma concentração inferior a da dosagem inteira.

\subsubsection{Simulação para verificação da concentração de nicotina no plasma após o fumo de cigarros.}

Utilizandos os mesmo parâmetros farmacocinéticos da subseção 7.2.2, foram feitas simulações para o consumo de cigarros objetivando-se verificar as concentrações plasmáticas após o fumo de vários cigarros consecutivos. 


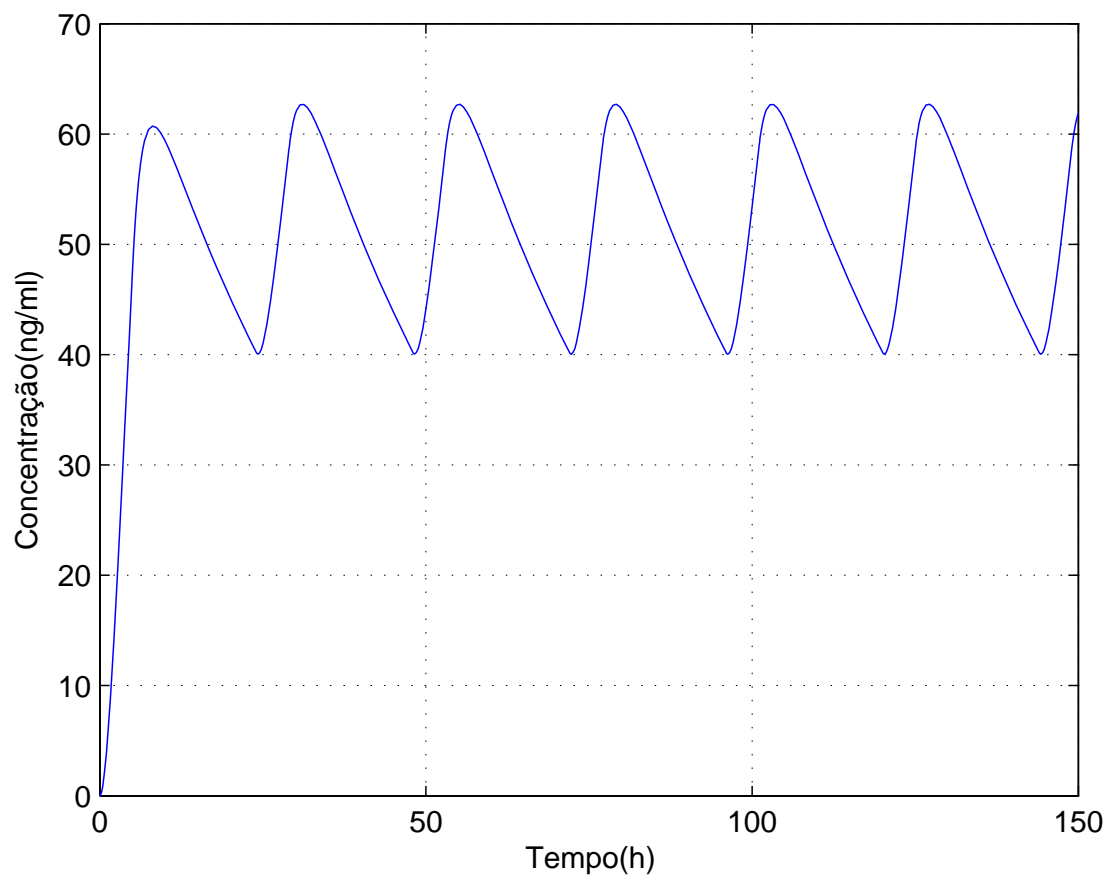

Figura 45: Dosagem de paroxetina dobrada no início do tratamento.

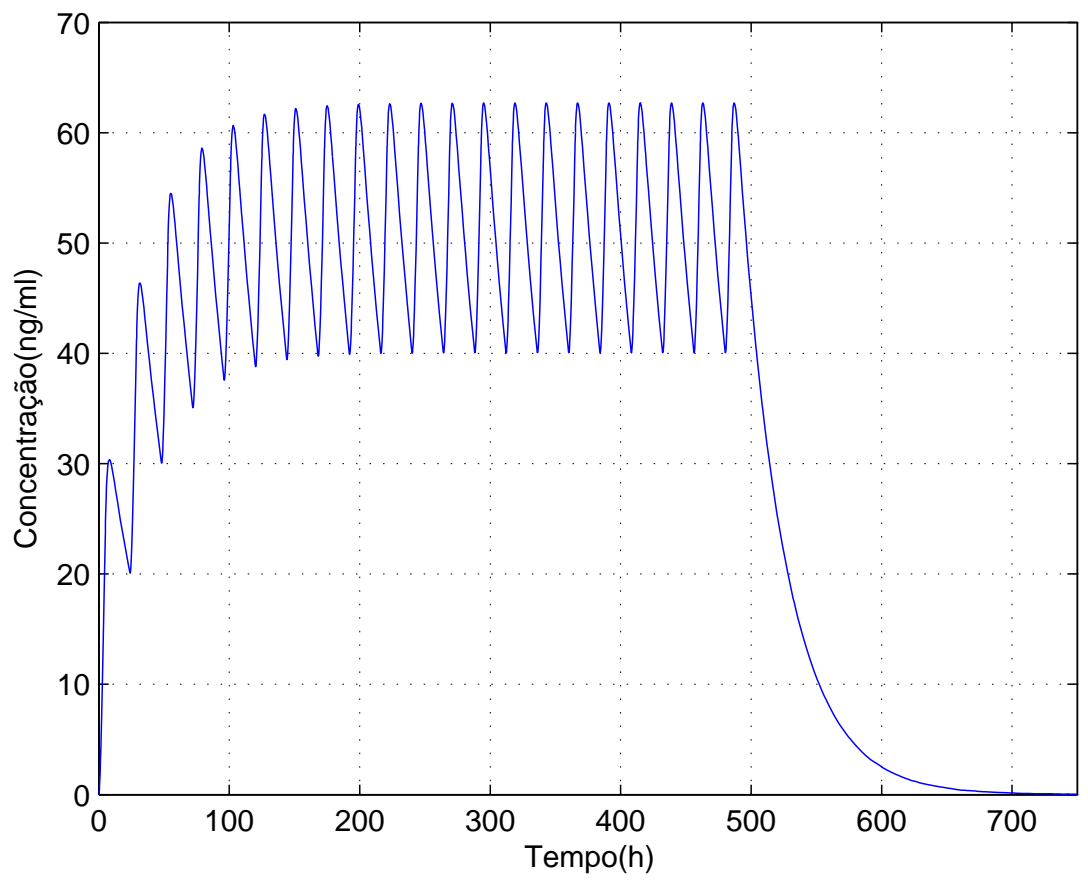

Figura 46: Eliminação da Paroxetina do Organismo.

Inicialmente, foi feita a simulação para verificar o decaimento da concentração de nicotina de uma pessoa que fumou um cigarro. O resultado é mostrado na Figura 47. Outra resposta inicial é mostrada na Figura 48, onde ocorre o fumo de um cigarro a 
cada 12 horas. Nestes dois casos se verifica que a nicotina é totalmente eliminada em um período de 5 horas, não existindo a ocorrência de uma concentração de regime permanente.

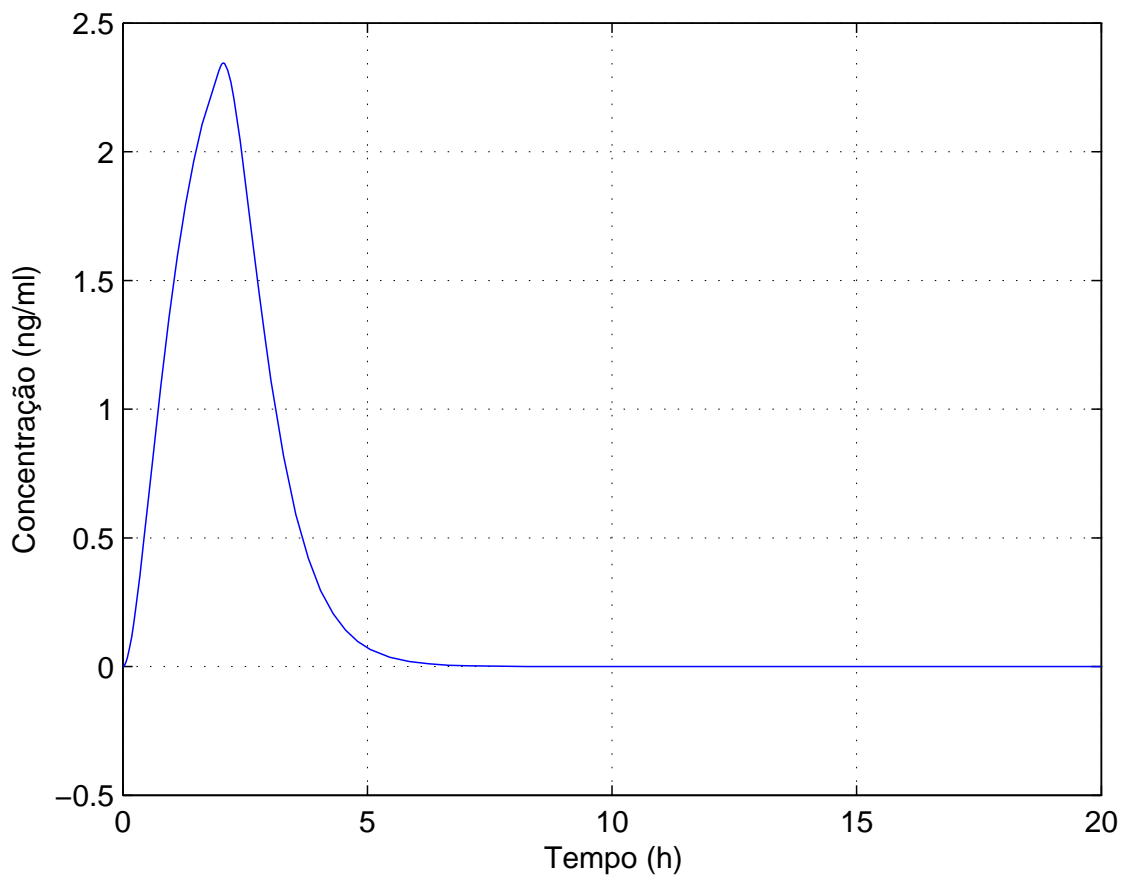

Figura 47: Concentração de nicotina após o fumo de um cigarro.



Figura 48: Concentração de nicotina após o fumo de um cigarro a cada 12 horas. 
A resposta do modelo para uma pessoa que fuma um cigarro a cada 3 horas é mostrada na Figura 49. Pode-se observar que a concentração não atinge mais o valor zero. Sendo assim, o corpo não consegue eliminar totalmente a nicotina.

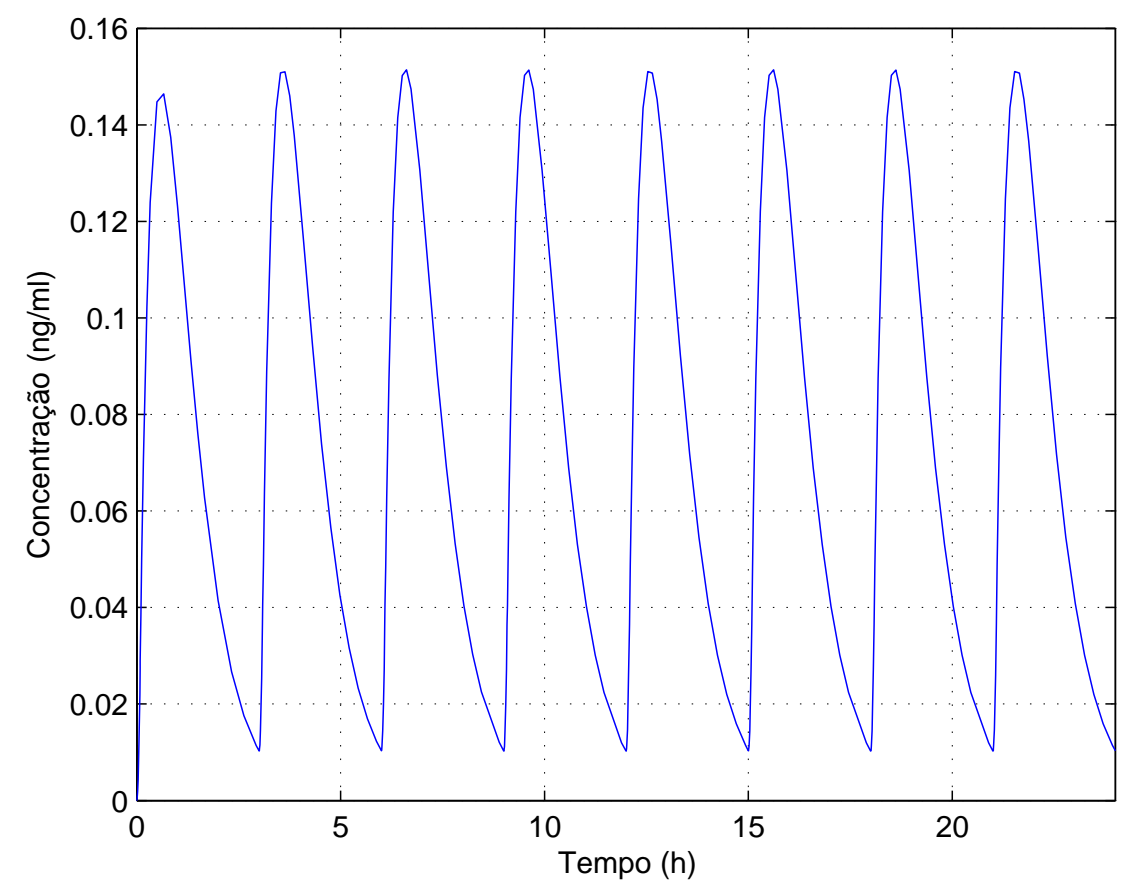

Figura 49: Concentração de nicotina após o fumo de um cigarro a cada 3 horas.

No caso de fumo de um cigarro a cada hora, verifica-se que ocorre a existência de uma concentração de regime permanente no sangue (Figura 50).

A Figura 51 mostra a diferença de concentrações para um cigarro fumado a cada 20 minutos e um fumado a cada 40 minutos. Devido ao tempo de meia vida da nicotina ser muito baixo, para que se obtenha uma concentração de regime permanente mais estável é necessária a ingestão de nicotina em menores intervalos de tempo. Pode-se notar analisando a figura que a amplitude entre a menor e a maior concentração no caso de fumar a cada 40 minutos é maior do que no caso de fumar a cada 20 minutos.

A Figura 52 mostra o consumo de três cigarros consecutivos seguidos de um tempo de abstinência. Esta situação se aplica, por exemplo, a um indivíduo que, devido a não poder fumar durante um período de seis horas ingere uma quantidade maior no início para tentar atingir a concentração de regime permanente e aliviar a dependência química provocada pela nicotina. 
A Figura 53 compara as concentrações de um cigarro que fornece $2 \mathrm{mg}$ de dosagem efetiva com um que fornece $4 \mathrm{mg}$. A simulação foi feita para um intervalo de tempo de 20 minutos entre cada cigarro de $2 \mathrm{mg}$ e de 40 minutos para cada cigarro de $4 \mathrm{mg}$. A concentração de regime permamente é maior no caso do cigarro de $4 \mathrm{mg}$ e apresenta uma maior amplitude entre o valor mínimo e máximo.

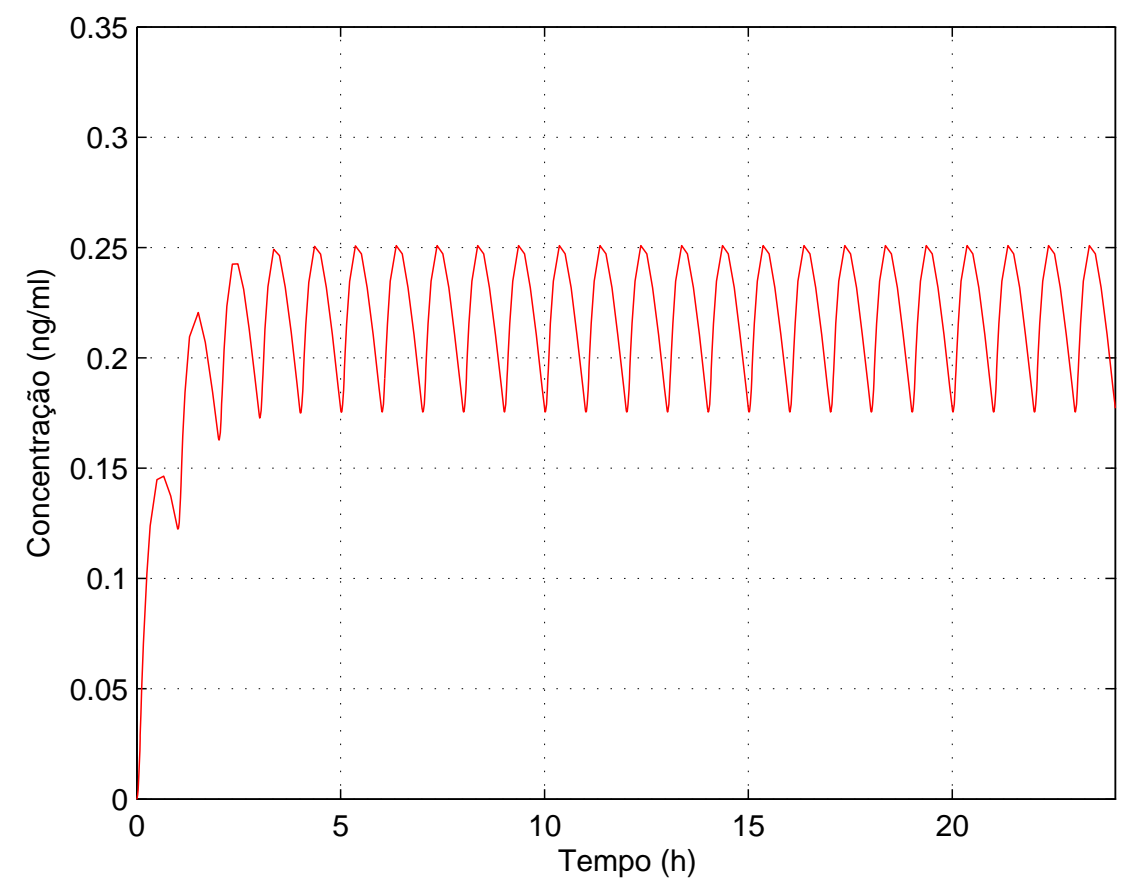

Figura 50: Concentração de nicotina após fumo de cigarros a cada hora.

\subsubsection{Utilização de medicamentos anti-concepcionais}

Nesta seção serão apresentados resultados do modelo para utilização de medicamentos anti-concepcionais. Inicialmente será mostrado uma comparação entre dois tipos de infusão: a constante (transdermal) e a via comprimidos.

\subsubsection{Comparação entre anti-concepcional transdermal e em comprimidos}

A utilização de medicamentos anti-concepcionais tem o objetivo de fazer com que se obtenha uma concentração de regime permanente de determinado hormônio no sangue. Isto pode ser feito via oral, com a utilização de comprimidos, ou via transdermal com a utilização de adesivo. 


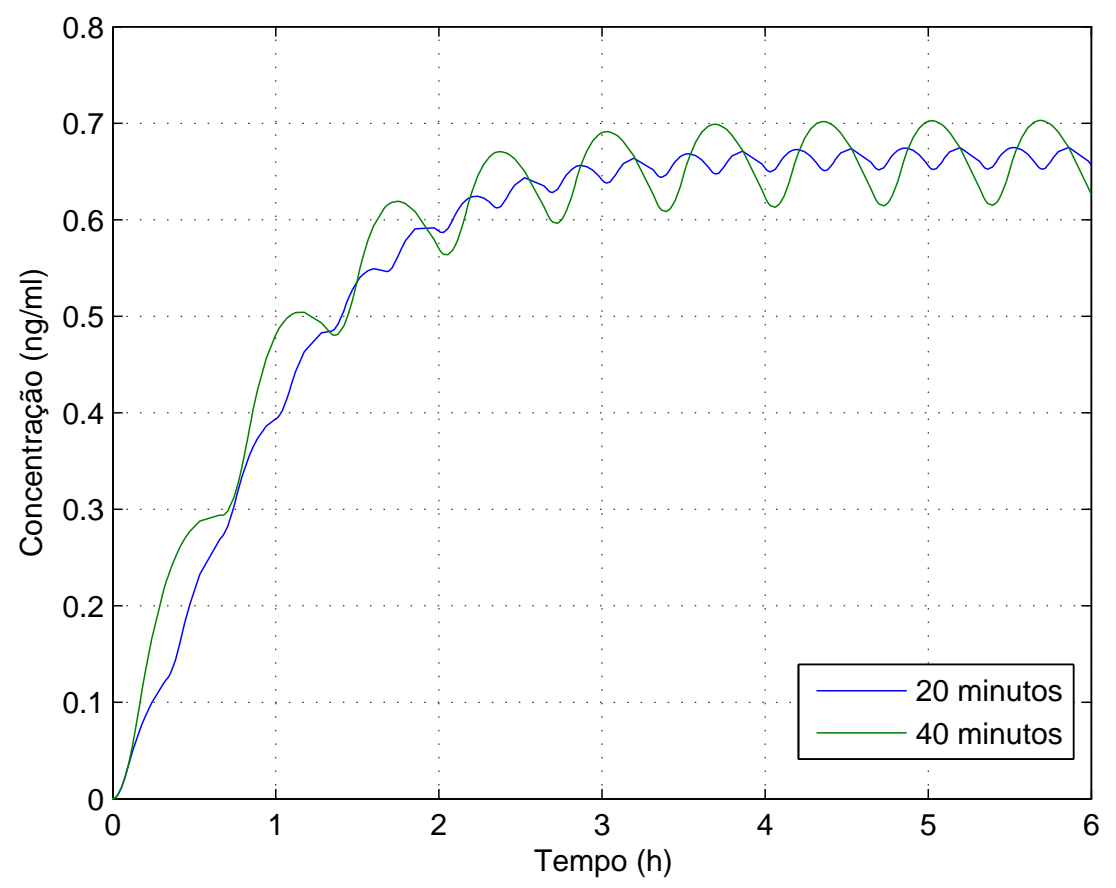

Figura 51: Concentração de nicotina após o fumo de cigarros a cada 20 minutos e a cada 40 minutos.

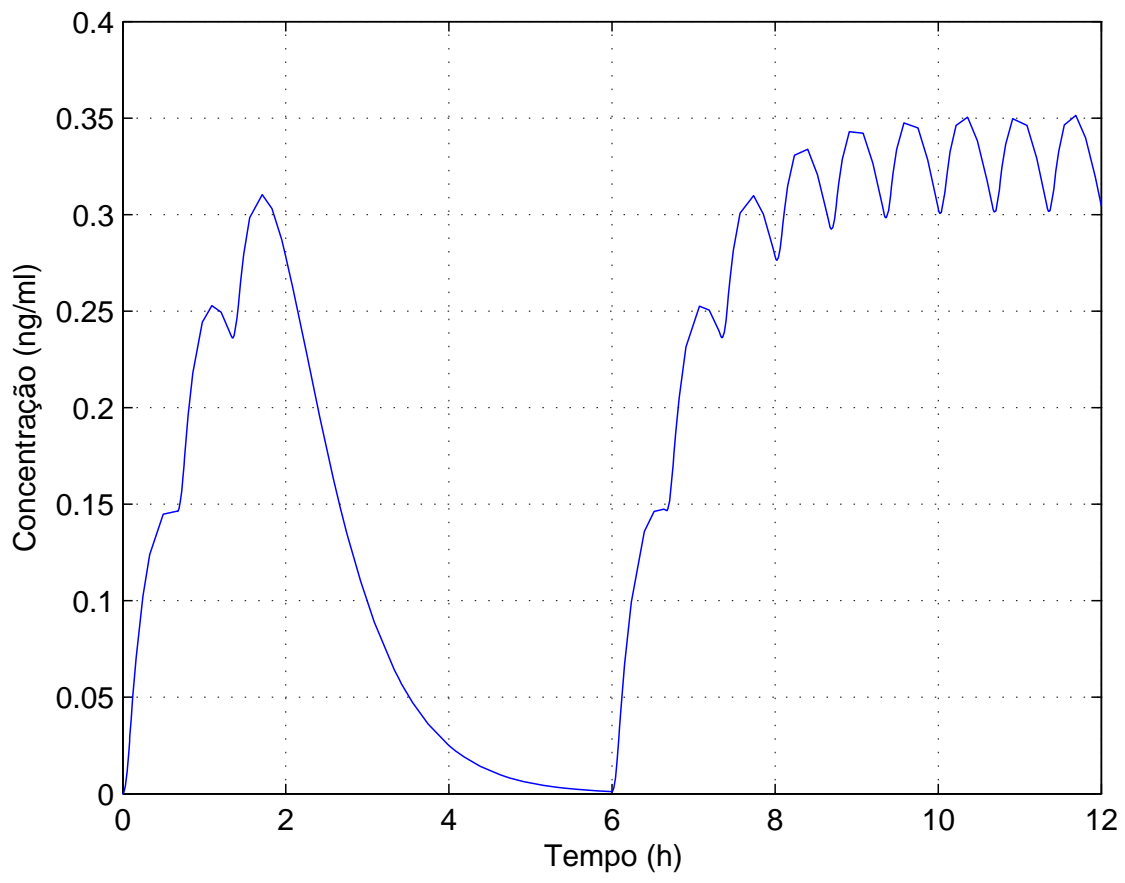

Figura 52: Concentração de nicotina após o fumo 3 cigarros seguidos.

Nesta subseção será comparada a resposta do modelo para ingestão de comprimidos com a resposta para utilização de adesivo transdermal. 


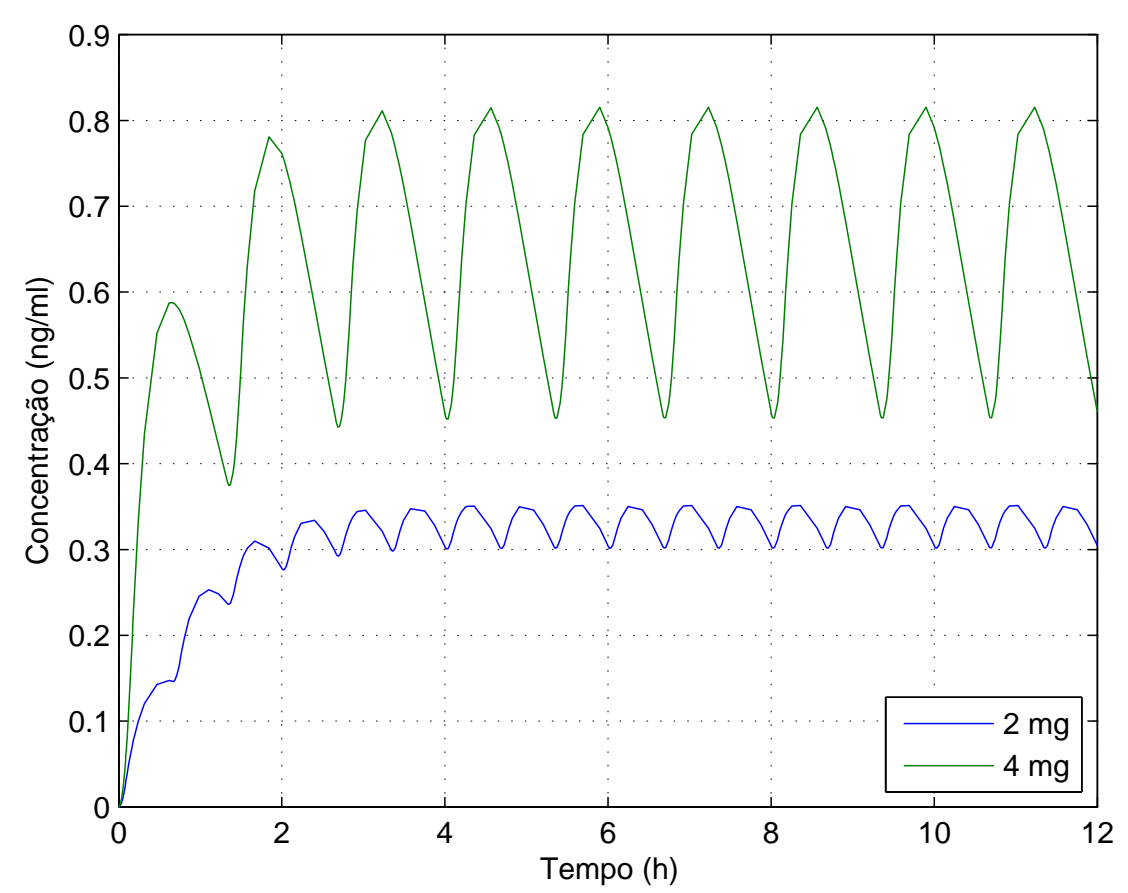

Figura 53: Comparação das concentrações de nicotina para cigarros de dosagens efetivas diferentes.

Os dados para a ingestão de comprimidos foram retirados da bula do medicamento Allestra 20 e os do adesivo transdermal do medicamento EVRA (BULA DE MEDICAMENTOS, 2012) . Ambos os medicamentos utilizam a substância etinilestradiol como contraceptivo.

Os parâmetros farmacocinéticos utilizados baseados em informações da bula foram:

- $t_{1 / 2}=28 \mathrm{~h}$;

- $k_{a}=1,3606 \mathrm{~h}^{-1}$

- $V_{a p}=100 \mathrm{ml}$

- $D(t)=0,0016 \mathrm{ng} / \mathrm{h}(\mathrm{EVRA})$

- $D(t)=20 \mathrm{ng} / \mathrm{h}($ Allestra 20);

Os resultados são mostrados na Figura 54. Verifica-se que uma menor quantidade de medicamento infundido constantemente atinge concentração de regime permanente pouco inferior a utilização de compridos, estando os dois valores dentro da faixa terapêutica. A infusão constante provoca menor sobrecarga ao fígado, já que existe uma menor 
quantidade de droga a ser metabolizada. Existe também a vantagem de não ocorrer a interrupção da posologia, já que o indivíduo pode esquecer de tomar um dos comprimidos.

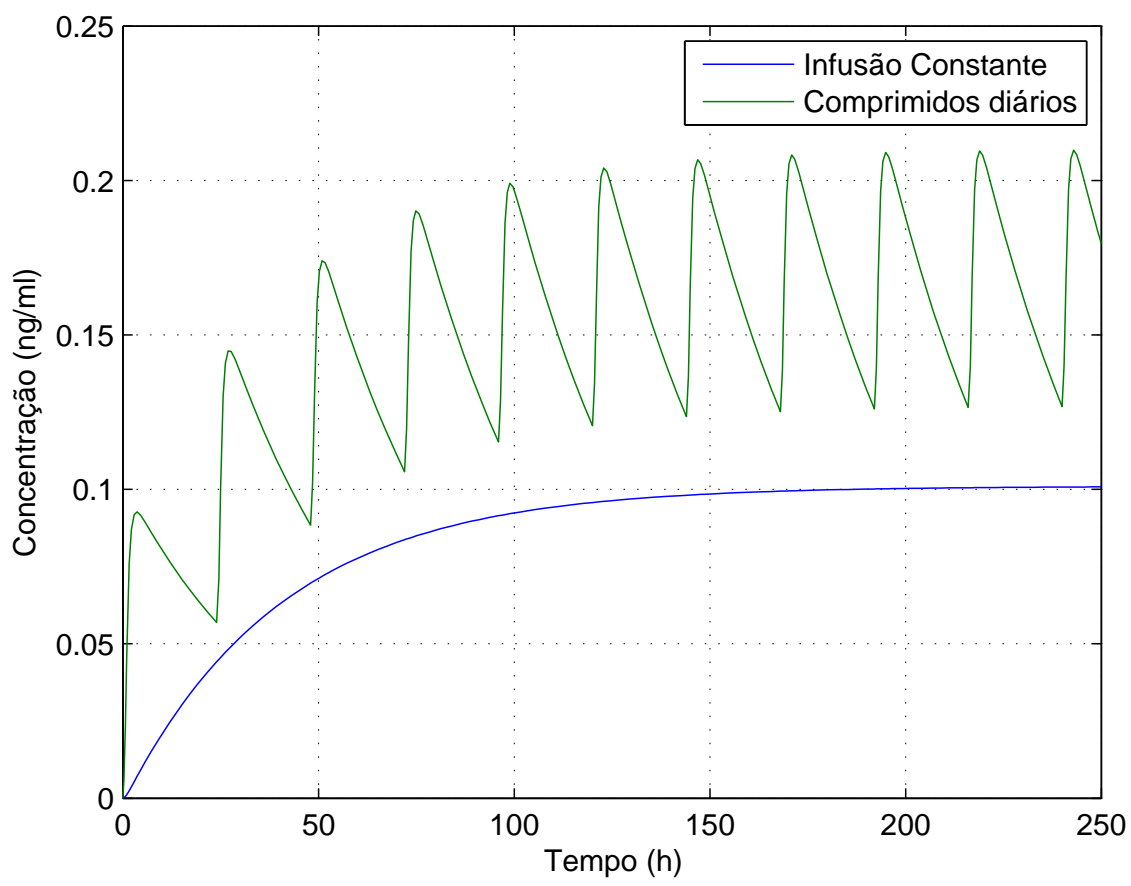

Figura 54: Comparação entre o anti concepcional transdermal e em comprimidos.

\subsubsection{Interrupção no tratamento}

No caso do consumo de comprimidos diariamente, pode ocorrer a interrupção da posologia no caso de o indivíduo se esquecer de tomar o medicamento. Esta situação foi simulada pelo modelo, sendo mostrado o resultado na Figura 55. Verifica-se que o regime permanente só é atingido novamente após 7 dias. Sendo assim, perde-se o efeito desejado pelo medicamento.

\subsubsection{Aumento da dosagem inicial}

Na tentativa de se atingir o regime permanente com maior rapidez, foram feitas simulações com maiores doses iniciais. A Figura 56 mostra o resultado destas simulações. Foram inseridas dosagens iniciais três vezes maior e duas vezes maior que a dose convencional. Verifica-se que nas doses maiores ocorre um aumento mais rápido da concentração, mas o regime é atingido praticamente no mesmo período. Como a faixa terapêutica deste 
medicamento é alta, dependendo do objetivo almejado, pode ser utilizada esta variação de dosagem para alcançar uma concentração maior mais rapidamente.

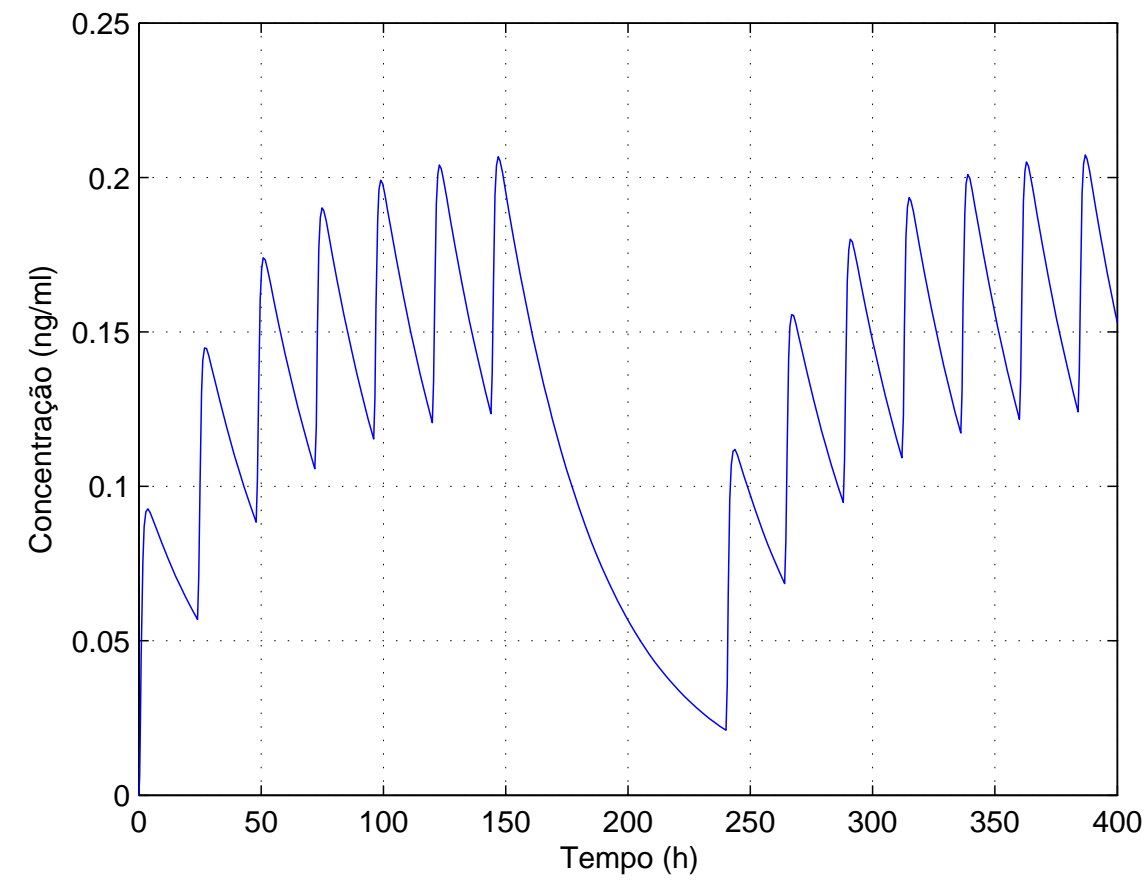

Figura 55: Interrupção na posologia do Allestra 20.

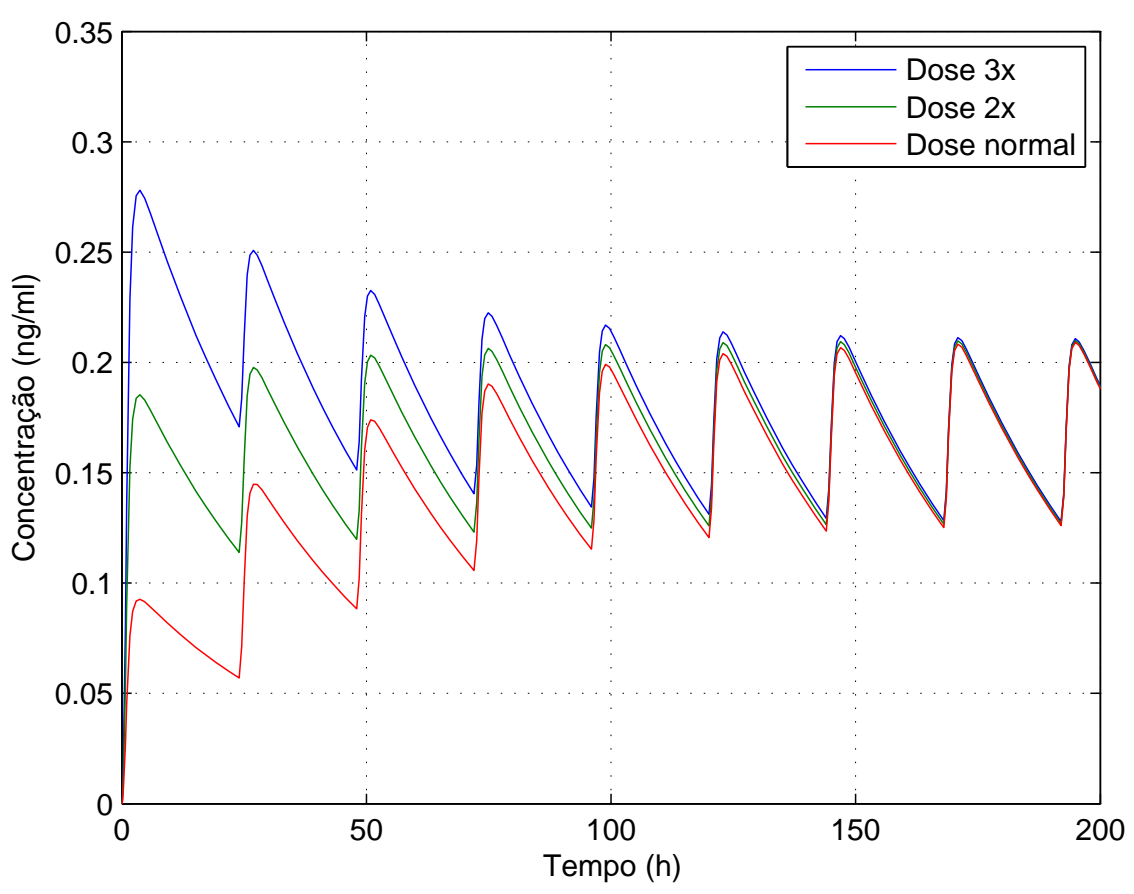

Figura 56: Aumento na dosagem inicial de Allestra 20. 


\subsubsection{Sobre dosagem de analgésicos}

Mais uma utilidade do modelo é verificar situações de sobre dosagem. É possível simular infusões de diversos comprimidos consecutivos e verificar qual o valor da concentração atingida.

Foram utilizados parâmetros farmacocinéticos da Nimesulida, uma droga que age no combate à inflamação, à dor e à febre. Cada comprimido fornece uma dose de 100 mg.

Os parâmetros farmacocinéticos utilizados no modelo foram os seguintes:

- $t_{\max }=2 \mathrm{~h}$;

- $t_{1 / 2}=2.36 \mathrm{~h}$;

- $V_{a p}=27300 \mathrm{ml}$;

- $D=100 \mathrm{mg}$.

A Figura 57 mostra a curva da concentração após o consumo de um comprimido. Verifica-se que a concentração sobe, atingindo o pico de concentração em cerca de duas horas. Após dez horas do consumo do comprimido ainda existe certa quantidade do medicamento no plasma sanguíneo.

A dosagem máxima permitida pelo medicamento é $200 \mathrm{mg}$ por dia. Foi feita a simulação para uma quantidade de 400 mg por dia, sendo esta uma situação de sobredosagem. O resultado é mostrado na Figura 58. Verifica-se se a concentração atinge o valor de 3500 $\mathrm{ng} / \mathrm{ml}$ e a droga fica no organismo durante trinta horas até ser totalmente eliminada.

A concentração máxima permitida pelo medicamento é de cerca de 2860 ng/ml. Assim, tem-se que durante um período aproximadamente igual a 5 horas, a concentração atinge um valor muito acima da concentração máxima, podendo ser prejudicial ao organismo durante este tempo. Conclui-se que a ingestão de 4 comprimidos já ultrapassa o valor máximo terapêutico permitido. 


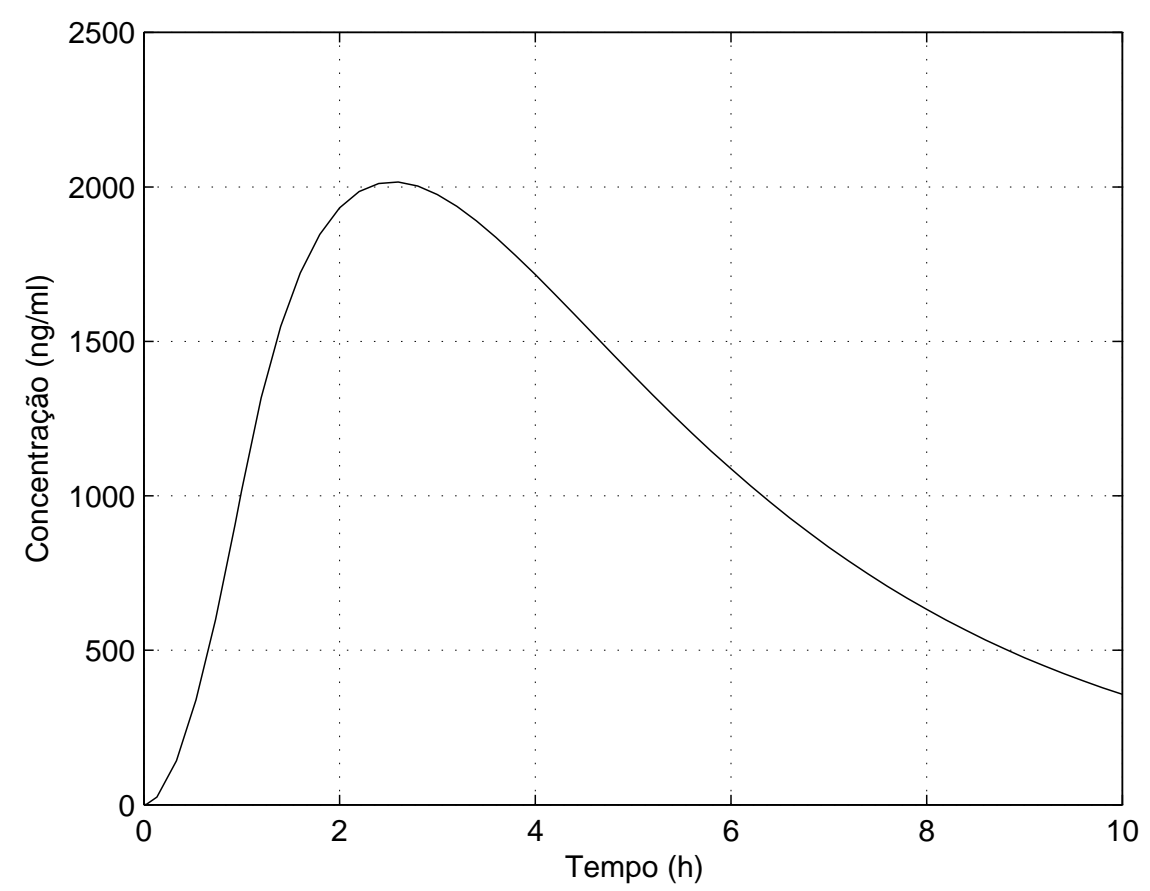

Figura 57: Concentração plasmática após o consumo de um comprimido de Nimesulida.

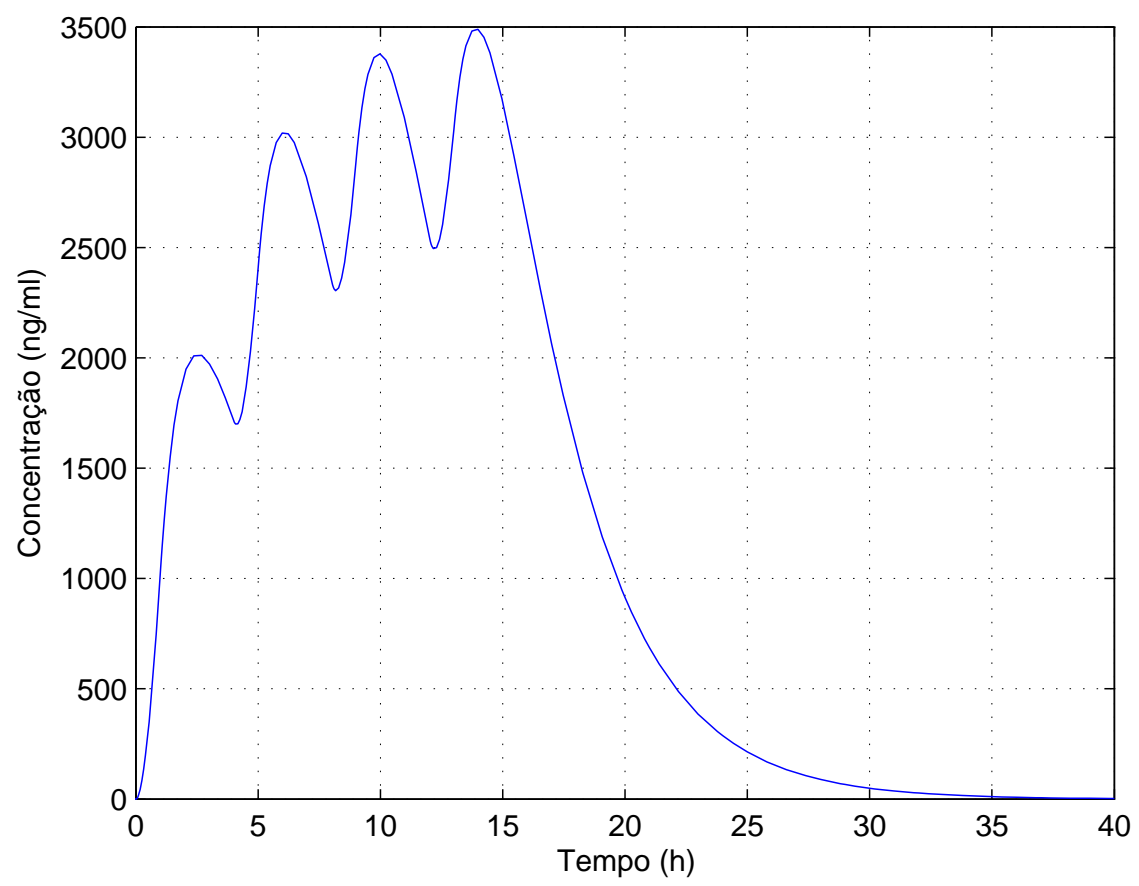

Figura 58: Sobre dosagem de Nimesulida. 


\section{CONCLUSÃO}

Neste trabalho foram desenvolvido modelos farmacocinéticos capazes de prever as concentrações plasmáticas de diversos tipos de drogas para infusões diferentes.

Com a utilização deste modelo foi possível verificar que alguns procedimentos recomendados por autores e comumente utilizados não atingem os efeitos de concentração desejados. Sendo assim, pode-se enfatizar a importância da utilização do modelo proposto neste trabalho para que se obtenham resultados que outros modelos não alcançam. Devido a modelagem ter sido feita com a utilização de sistemas lineares invariantes no tempo, tem-se que o modelo apresenta um grande dinamismo e permite a simulação de diferentes formas de procedimentos de infusão e dosagem. Além disso, a partir destas, pode-se tentar atingir as concentrações terapêuticas recomendadas na literatura.

Neste capítulo serão apresentadas as conclusões obtidas após a simulação destes modelos.

\subsection{Modelo Monocompartimental}

O modelo monocompartimental foi utilizado para injeção intravenosa sendo validado com base em dados experimentais para posterior simulação em condições diversas.

Os modelos experimentais presentes na literatura se baseiam apenas em administrar o medicamento e fazer coletas de sangue para verificar a concentração plasmática. Sendo assim, não existem disponíveis nos trabalhos os valores das constantes farmacocinéticas necessárias no modelo matemático. Estas constantes variam muito de pessoa para pessoa. Na validação, foram utilizados parâmetros de cada indivíduo analisado, sendo que alguns 
dados foram retirados das curvas experimentais fornecidas pelos autores dos trabalhos. Devido a estes fatos, alguns pontos medidos experimentalmente ficaram fora da curva, mas de maneira geral, o modelo respondeu com precisão para prever as concentrações.

No modelo monocompartimental, foi possível verificar que o organismo não responde da mesma maneira para infusões periódicas e constantes com o mesmo valor de dosagem, conforme afirmado por Bauer (2008). Isto se deve ao fato da meia vida do medicamento apresentar um valor baixo.

No caso simulado, como cada dose administrada de morfina tem um intervalo de 6 horas entre cada aplicação, observa-se que quando a nova infusão é feita, a quantidade de morfina praticamente chega ao valor zero devido a meia vida desta substância apresentar valor $t_{1 / 2}=2,5 \mathrm{~h}$, o que significa é que neste período metade da droga infundida já foi eliminada.

Neste caso, para que se tenha uma concentração de regime permanente equivalente a obtida por meio da infusão constante, a droga deve ser administrada em uma quantidade muito maior, fazendo com que o fígado tenha que realizar uma maior atividade metabólica.

Assim, verificou-se que a infusão constante é um método de infusão mais adequado quando deseja-se obter uma concentração de regime permanente estável que provoca menor sobrecarga ao fígado.

Não existem modelos matemáticos na literatura capazes de prever as concentrações plasmáticas para outras infusões que não sejam a intravenosa. Assim, a possibilidade de infusões diferentes faz com que o modelo seja útil na verificação da resposta do organismo para outros tipos de administração que não sejam a intravenosa.

\subsection{Modelo Bicompartimental}

O modelo bicompartimental foi desenvolvido para prever as concentrações plasmáticas de substâncias que sejam adminisnistradas por vias que não sejam a via intravenosa. Para isto foram modelados dois compartimentos: o compartimento central por onde a droga adentra no organismo (podendo representar o estômago, o pulmão ou a pele) e 
o compartimento plasmático que é o foco da análise. Analisar a concentração no compartimento central não apresenta utilidade clínica alguma, uma vez que o foco da análise farmacocinética é a concentração plasmática. Sendo assim, a utilização do compartimento central foi feita pare que este fosse apenas um meio intermediário entre a infusão e o sangue. Conforme mostrado na subseção 2.1.6, devido a diferença de concentração, pode-se considerar que o fluxo do medicamento é praticamente somente na direção do sangue. Por isto utilizou-se a constante $k_{a}$ e não foi utilizada uma constante de via inversa, devido a difusão ocorrer no sentido da concentração maior. No trabalho foi proposto uma equação para o cálculo de $k_{a}$, utilizando apenas o tempo de concentração máxima e a meia vida do medicamento. Os autores dos livros de farmacocinética citados no trabalho utilizam análise gráfica, necessitando de amostragem da concentração plasmática dos medicamentos em diversos intervalos de tempo. Assim, o método proposto no trabalho é mais simples do que os existentes na literatura e o valor da constante pode ser obtido apenas com os parâmetros fornecidos nas bulas.

A validação do modelo foi feita com a comparação de dados experimentais em que o compartimento central foi o pulmão. Não existem na literatura modelos matemáticos relacionados a ingestão de comprimidos sucessivos. Por isto foram utilizados dados médios encontrados nas bulas e resultados encontram-se dentro do valor médio esperado.

Na simulação de condições adversas utilizou-se o medicamento anti depressivo Paroxetina devido ao tratamento com esta droga necessitar de cuidados especiais pois erros na administração podem causar problemas sérios aos pacientes.

Verificou-se que se o indivíduo esquecer de tomar um comprimido, a concentração de regime permanente cai e só é atingida novamente após 7 dias. Sendo assim, quando ocorre interrupção é como se o paciente tivesse que iniciar o tratamento novamente.

Uma alternativa para subir a concentração mais rapidamente é consumir dois comprimidos no dia seguinte ao que ocorreu a interrupção. Foi observado que a concentração atinge um valor acima do regime permanente rapidamente e como o valor de sobre dosagem deste medicamento é alto, este método pode ser uma alternativa para corrigir a interrupção. 
O modelo também verificou que tomar meia dose de medicamento em intervalos de tempo menor não faz com que a concentração desejada seja atingida. Devido ao tempo de meia vida do medicamento ser baixo, consumir uma menor quantidade provoca uma concentração média inferior.

Para atingir a concentração desejada mais rapidamente foi simulada a condição de tomar uma dose dobrada no início do tratamento. Foi verificado que a concentração é atingida já no segundo dia. Isto pode ser útil quando deseja-se um efeito mais rápido na terapia. Observou-se que a Paroxetina leva cerca de 200 horas para ser completamente eliminada do organismo.

Outra simulação feita no modelo foi para calcular a concentração de nicotina no sangue após o consumo de cigarros. Foram simuladas as condições do fumo de um único cigarro e de cigarros fumados em períodos de tempos menores. Pode-se verificar que o indivíduo que consome um cigarro a cada três horas já apresenta uma quantidade mínima de nicotina presente no sangue.

No caso do indivíduo que fuma um cigarro por hora, tem-se uma concentração média em torno de $0,22 \mathrm{ng} / \mathrm{ml}$.

Na comparação do consumo de cigarros a cada 20 minutos e a cada 40 minutos, foi observado que o fumo em menor intervalo de tempo ocasiona uma concentração mais estável, com menor amplitude entre a concentração mínima e máxima. Foi analisado também a situação em que o fumante fica um período de tempo grande sem fumar, sendo que sua concentração atinge praticamente valor nulo. Observou-se também que fumar cigarros de maior concentração em maiores intervalos de tempo ocasiona uma concentração menos estável do que o fumo de cigarros com menos nicotina em períodos menores.

O modelo foi utilizado também na simulação da terapia de medicamentos anti concepcionais. Observou-se que a utilização de infusão constante via transdermal é mais aconselhável, já que a quantidade de droga a ser infundida é menor do que na utilização de comprimidos. 
Foi verificado também que a interrupção no tratamento ocorre a queda rápida da concentração e levam cerca de 4 dias para que a concentração retorne ao valor médio.

Na condição de uma maior dosagem inicial, verificou-se que a concentração de regime permanente é atingida praticamente no mesmo período para os três casos. A diferença existe apenas no fato de que uma concentração maior é obtida mais rapidamente. Como não existem dados farmacodinâmicos referentes a este fato, não se pode concluir se isto é útil na terapia.

A simulação de sobre dosagem de analgésicos mostrou que a ingestão de uma dose duas vezes maior do que a permitida na bula ocasiona uma concentração acima da permitida que permanece durante um período de aproximadamente 5 horas.

\subsection{Trabalhos futuros}

O modelo desenvolvido neste trabalho foi um modelo matemático que utilizou dados experimentais presentes na literatura.

Para otimização do modelo podem ser feitos experimentos focados na obtenção das constantes farmacocinéticas de cada medicamento específico.

A abordagem mono e bicompartimental são úteis na verificação da concentração plasmática. No caso de um modelo mais complexo, que necessite de uma abordagem específica em determinados órgãos e tecidos, é necessária a geração de um modelo multicompartimental. Os modelos apresentados no trabalho utilizam concentrações, vazões de sangue e coeficientes de partição tecido plasma. No modelo desenvolvido neste trabalho utilizou-se a massa presente nos compartimentos. Assim, uma possível melhoria a ser feita neste modelo é aumentar o número de compartimentos gerando um modelo completo.

Os resultados do modelo foram apenas em termos de concentração. O modelo pode ser melhorado se forem considerados parâmetros farmacodinâmicos relacionando dose e efeito. Esta nova aplicação faria com que o modelo se tornasse uma ferramenta robusta na análise terapêutica. 


\section{REFERÊNCIAS}

ADOLPH, E. F. Quantitative relations in the physiological constitutions of mammals. Science, v. 109, n. 2841, p. 579-585, 1949.

ALBUQUERQUE-NETO, C.; YANAGIHARA, J. I.; TURRI, F. A. A carbon monoxide transport model of the human respiratory system applied to urban atmosphere exposure analysis. Journal of the Brazilian Society of Mechanical Sciences and Engineering, Scielo, v. 30, p. 253-260, 2008.

ARAUJO, B. V. Modelagem Farmacocinética-Farmacodinâmica do Antifúngico Voriconazol. Tese (Doutorado) — Universidade Federal do Rio Grande do Sul, Porto Alegre, 2008.

BARNNET, G. et al. Kinetic study of smoking marijuana. Science, v. 76, p. 204-212, 1982.

BAUER, L. A. Applied clinical pharmacokinetics. 2. ed. New York: McGraw-Hill, 2008.

BIRD, H. A. et al. Gastro-intestinal blood loss with high dose tilcotil (ro 12-0068) and aspirin: an open crossover clinical trial and pharmacokinetic assessment in normal volunteers. Current Medical Research and Opinion, v. 8, p. 412-416, 1983.

BISCHOFF, K. B. et al. Methotrexate pharmacokinetics. Journal of Pharmaceutical Sciences, v. 60, n. 8, p. 1128-1133, 1971.

BOXENBAUM, H.; D'SOUZA, R. W. Pharmacokinetic scale-up from animal to man. Montpellier: Sauramps Médical, 1988.

BULA DE MEDICAMENTOS. Disponível em <http://www.bulas.med.br >. Acesso em $03 / 03 / 2012$.

CHEN, C. N.; ANDRADE, J. D. Pharmacokinetic model for simultaneous determination of drug levels in organs and tissues. Journal of Pharmaceutical Sciences, Wiley Subscription Services, Inc., A Wiley Company, v. 65, n. 5, p. 717-724, 1976.

DALLEY, J.; GUPTA, P.; HUNG, C. A physiological pharmacokinetic model describing the disposition of lead in the absence and presence of l-ascorbic acid in rats. Toxicology Letters, v. 50, p. 337-348, 1990.

DEDRICK, R. L. Animal scale-up. Journal of Pharmacokinetics and Pharmacodynamics, Springer Netherlands, v. 1, p. 435-461, 1973.

DERSHWITZ, M. et al. Pharmacokinetics and pharmacodynamics of inhaled versus intravenous morphine in healthy volunteers. Anesthology, v. 1, p. 618-628, 2000.

DIXON, J. S.; LOWE, J. R. Rapid method for the determination of either piroxicam or tenoxicam in plasma using high performance liquid chromatography. Anesthology, v. 1, p. $455-459,1984$. 
DRUGS INFORMATION ONLINE. Disponível em $<$ http://www.drugs.com $>$. Acesso em 03/03/2012.

FARRIS, F. F.; DEDRICK, R. L.; KING, F. G. Cisplatin pharmacokinetics: applications of a physiological model. Toxology Letters, v. 43, p. 117-137, 1988.

FARRIS, F. F. et al. Physiological model for the pharmacokinetics of cisdichlorodiamineplatinum (ii) (ddp) in the tumoredrat. Journal of Pharmacokinerics Biopharmaceutics, v. 13, p. 13-39, 1985.

FERREIRA, M. S.; YANAGIHARA, J. I. A transient three-dimensional heat transfer model of the human body. International Communications in Heat and Mass Transfer, v. 36 , n. 7 , p. $718-724,2009$.

FOULDS, J. et al. Effect of smokeless tobacco (snus) on smoking and public health in sweden. Tobacco Control, v. 12, p. 349-359, 2003.

FUJIO, I. et al. Physiological pharmacokinetic model for pentazocine. i. tissue distribution and elimination in the rat. International Journal of Pharmaceutics, v. 15, n. 3 , p. $321-333,1983$.

Physiological pharmacokinetic model for distribution and elimination of pentazocine. ii. study in rabbits and scale-up to man. International Journal of Pharmaceutics, v. 19, p. 75-88, 1984.

GIBALDI, M.; PERRIER, D. Pharmacokinetics. New York: Marcel Dekker, 1982.

GORDON, R. G.; ROEMER, R. B.; HORVATH, S. M. A. A mathematical model of the human temperature regulatory system: transient cold exposure response. IEEE Transactions on Biomedical Engineering, v. 23, n. 6, p. 434-444, 1976.

GRANERO, L. et al. Physiological pharmacokinetic model for ceftazidime disposition in the rat and its application to prediction of plasma concentrations in humans. European Journal of Pharmaceutical Sciences, v. 1, n. 1, p. 3-11, 1993.

GRODINS, F. S. et al. Respiratory responses to co2 inhalation. a theoretical study of a nonlinear biological regulator. Journal of Applied Physiology, v. 7, n. 3, p. 283-308, 1954.

GUYTON, A. C. Textbook of Medical Physiology. Philadelphia: Saunders, 1981.

HAGGARD, H. W. The absorption, distribution, and elimination of ethyl ether. Journal of Biological Chemistry, v. 59, n. 3, p. 753-770, 1924a.

The absorption, distribution, and elimination of ethyl ether. Journal of Biological Chemistry, v. 59, n. 3, p. 771-781, 1924b.

HARRISON, L. I.; GIBALDI, M. Physiologically based pharmacokinetic model for digoxin disposition in dogs and its preliminary application to humans. Journal of Pharmaceutical Sciences, v. 66, n. 12, 1977.

HASSANI, K.; NAVIDBAKHSH, M.; ROSTAMI, M. Simulation of the cardiovascular system using equivalent electronic system. Biomedical papers of the Medical Faculty of the University Palacky, v. 150, p. 105-112, 2006.

HAYKIN, S.; VENN, B. V. Signals and Systems. [S.l.]: Wiley, 1999. 
HESSEL, P. A. et al. A nested case-control study of prostate cancer and antrazine exposure. Journal of Occupational and Enviromental Medicine, v. 46, p. 379-385, 2004.

HIMMELSTEIN, K. J.; LUTZ, R. J. A review of the applications of physiologically based pharmacokinetic modeling. Journal of Pharmacokinetics and Pharmacodynamics, Springer Netherlands, v. 7, p. 127-145, 1979.

HOSKIN, P. J. et al. The bioavailability and pharmacokinetics of morphine after intravenous, oral and buccal administration in healthy volunteers. British Journal of Clinical Pharmacology, v. 27, p. 499-505, 1989.

HUESTIS, M. A.; HENNINGFIELD, J. E.; CONE, E. J. Blood cannabinoids. i. absorption of the and formation of 11-oh-the and thccooh during and after smoking marijuana. Journal of Analitical Toxicology, v. 76, p. 204-212, 1992.

HUNAULT, C. C. et al. Disposition of smoked cannabis with high deltha9tetrahydrocannabinol content: A kinetic model. Toxicology and Applied Pharmacology, v. 246 , n. 3 , p. $148-153,2010$.

IGARI, Y. et al. Comparative physiologically based pharmacokinetics of hexobarbital, phenobarbital, and thiopental in the rat. Journal of Pharmacokinetics and Pharmacodynamics, Springer Netherlands, v. 10, p. 53-75, 1982.

JAMBHEKAR, S. S.; BRENN, P. J. Basic Pharmacokinetics. London: Pharmaceutical Press, 2009.

JOLY, R. Metabolism of tenoxicam in rats. Xenobiotica, v. 14, p. 727-739, 1984.

KIRCHHEINER, B. et al. A new long acting anti-inflammatory agent, tenoxicam (tilcotil): in osteoarthritis of the knee and the hip: a randomized comparison with indomethacin. Current Therapeutic Research, v. 32, p. 627-632, 1982.

KWON, K.; BOURNE, D. W. Physiological pharmacokinetic model for the distribution and elimination of tenoxicam. International Journal of Pharmaceutics, v. 37, n. 3, p. 219-226, 1987.

LAM, G.; CHEN, M.; CHIOU, W. L. Determination of tissue to blood partition coefficients in physiologically-based pharmacokinetic studies. Journal of Pharmaceutics Sciences, v. 71, p. 454-455, 1982.

LIMA, C. A. de M.; BAUMANN, P.; BIN, C. Concentrações plasmáticas de paroxetina em pacientes adultos e idosos com depressão. Revista de Psiquiatria do Rio Grande do Sul, v. 30, p. 13-18, 2008.

LIN, Z. et al. A physiologically based pharmacokinetic model for atrazine and its main metabolites in the adult male c57bl/6 mouse. Toxicology and Applied Pharmacology, v. 251 , p. $16-31,2011$.

LINDGREEN, J. E. et al. Clinical effects and plasma levels of delta 9tetrahydrocannabinol (delta 9-thc) in heavy and light users of cannabis. Psychopharmacology, v. 76, p. 204-212, 1981.

LITTER, M. Farmacologia experimental y clinica. Buenos Aires: El Ateneo, 1975. 
LUTZ, R. J.; DEDRICK, R. L.; ZAHARKO, D. S. Physiological pharmacokinetics: An in vivo approach to membrane transport. Pharmacology e Therapeutics, v. 11, p. 559-592, 1980.

MAKOID, M. C.; VUCHETICH, P. J.; BANAKAR, U. V. Basic Pharmacokinetics. Nebraska: The Virtual University Press, 1999.

MAPLESON, W. W. An electric analog for uptake and exchange of inert gases and other agents. Journal of Applied Physiology, v. 18, p. 197-204, 1963.

MIRZAE, M. R.; GHASEMALIZADEH; FIROOZABADI, B. Simulating of human cardiovascular system and blood vessel obstruction using lumped method. World Academy of Science, Engineeringand Technology, n. 41, p. 366-374, 2008.

NISE, N. S. Control Systems Engineering. 6. ed. Indianapolis: Willey, 2010.

OHLSSON, A. et al. Single dose kinetics of deuterium labeled delta 9tetrahydrocannabinol in heavy and light cannabis users. Biomedical Mass Spectrometry, v. 76 , p. $204-212,1982$.

PENNES, H. H. Analysis of tissue and arterial blood temperatures in the resting human forearm. Journal of Applied Physiology, 1948.

PERES-REYES, M. Comparison of effects of marihuana cigarettes of three different potencies. Clinical Pharmacology and Therapeutics, v. 76, p. 204-212, 1982.

PICKUP, M. E.; LOWE, J. R. Determination of ro 12-0068, a new anti-inflammatory and analgesic compound, in plasma by means of high-performance liquid chromatography. Journal of Chromatography, v. 225, p. 493-497, 1981.

PIERSON, R. N. et al. Extracellular water measurements: organ tracer kinetics of bromide and sucrose in rats and man. American Journal of Physiology, v. 253, p. 254-264, 1978.

PLOWCHALK, D. R.; ANDERSEN, M. E.; DEBETHIZY, J. D. A. Physiologically based pharmacokinetic model for nicotine disposition in the sprague-dawleyrat. Toxicology and Applied Pharmacology, v. 116, p. 117-188, 1992.

PROAKIS, J. G.; MANOLAKIS, D. G. Digital signal processing. 4. ed. New Jersey: Pearson Prentice Hall, 2007.

RAMSEY, J. C.; ANDERSEN, M. E. A physiologically based description of the inhalation pharmacokinetics of styrene in rats and humans. Toxicology and applied pharmacology, 1984.

RESCIGNO, A.; SEGRE, G. Drug and Tracer Kinetic. 1. ed. New York: Blaisdell Publishing, 1966.

RICHARDS, D. M.; BROGDEN, R. N. Ceftazidime: a review of its antibacterial activity, pharmacokinetic properties and therapeutic use. Drugs, 1985.

ROSENBAUM, S. Basic pharmacokinetics and pharmacodynamics: An integrated textbook and computer simulations. [S.l.]: John Wiley and Sons, 2011. 
SANTOS, V. J. Modelagem farmacocinética-farmacodinâmica da morfina administrada através de bomba controlada pelo paciente no pós-operatório de revascularização do miocárdio. Tese (Doutorado) — Universidade de São Paulo, Faculdade de Ciências Farmacêuticas, 2008.

SCHENTAG, J. J. Clinical significance of antibiotic tissue penetration. Clinical Pharmacokinetics, v. 16, p. 25-31, 1989.

TASSO, L. Modelagem farmacocinética-farmacodinâmica das fluorquinolonas levofloxacino e gatifloxacino. Tese (Doutorado) - Universidade Federal do Rio Grande do Sul, Porto Alegre, 2008.

TEORELL, T. Kinetics of distribution of substances administered to the body. i: The extravascular modes of administration. Archives of International Pharmacodynamics, v. 57 , p. 205-225, 1937a.

- Kinetics of distribution of substances administered to the body. ii: The extravascular modes of administration. Archives of International Pharmacodynamics, v. 57, p. 226-240, 1937b.

WEISS, M. Pharmacokinetics in organs and the intact body: model validation and reduction. European Journal of Pharmaceutical Sciences, v. 7, p. 119-127, 1998. 